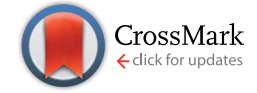

Cite this: J. Mater. Chem. A, 2015, 3 , 9353

Received 26th November 2014 Accepted 3rd March 2015

DOI: $10.1039 / c 4 t a 06467 d$

www.rsc.org/MaterialsA

\section{Recent developments in electrode materials for sodium-ion batteries}

\author{
Luyuan Paul Wang, ${ }^{\text {ab }}$ Linghui $\mathrm{Yu}^{\mathrm{a}}$ Xin Wang, ${ }^{\mathrm{c}}$ Madhavi Srinivasan ${ }^{\star a b}$ \\ and Zhichuan J. Xu*abd
}

The rapid consumption of non-renewable resources has resulted in an ever-increasing problem of $\mathrm{CO}_{2}$ emissions that has motivated people for investigating the harvesting of energy from renewable alternatives (e.g. solar and wind). Efficient electrochemical energy storage devices play a crucial role in storing harvested energies in our daily lives. For example, rechargeable batteries can store energy generated by solar cells during the daytime and release it during night-time. In particular, lithium-ion batteries (LIBs) have received considerable attention ever since their early commercialization in 1990s. However, with initiatives by several governments to build large-scale energy grids to store energy for cities, problems such as the high cost and limited availability of lithium starts to become major issues. Sodium, which also belongs to Group 1 of the periodic table, has comparable electrochemical properties to Lithium, and more importantly it is considerably more accessible than lithium. Nonetheless, research into sodium-ion batteries (NIBS) is currently still in its infancy compared to LIBs, although great leaps and bounds have been made recently in terms of research and development into this technology. Here in this review, we summarize the recent advancements made, also covering the prospective materials for both the battery cathode and anode. Additionally, opinions on possible solutions through correlating trends in recent papers will be suggested.

\section{Introduction}

Lithium-ion batteries (LIBs) have emerged as one of the most popular choice for energy storage in portable devices, since their early commercialization in the 1990s. The success of LIBs has been mainly attributed to their high energy density, long cycle life and affordable cost. Furthermore, the small ionic radius of lithium ions helps facilitate rapid diffusion within crystal structures. ${ }^{1-12}$ However, as the popularity of lithiumbased systems has continued to grow over the years, the demand for the raw materials has gradually outpaced the ability for its supply to recover. ${ }^{13,14}$ Controversial issues regarding the availability of battery grade raw materials have been debated. Most of the untapped lithium reserves have been found to be lying in isolated or geopolitically sensitive areas, in which the scaling up process would take large capital, involve a long lead time for processing of the raw material and which ultimately

${ }^{a}$ School of Materials Science and Engineering, Nanyang Technological University, 50 Nanyang Avenue, Singapore 639798, Singapore. E-mail: madhavi@ntu.edu.sg; xuzc@ntu.edu.sg

${ }^{b}$ Energy Research Institute@NTU, ERI@N, Interdisciplinary Graduate School, Nanyang Technological University, 50 Nanyang Avenue, Singapore 639798, Singapore ${ }^{c}$ School of Chemical and Biomedical Engineering, Nanyang Technological University, 50 Nanyang Avenue, Singapore 639798, Singapore

${ }^{d}$ Solar Fuels Lab, Nanyang Technological University, 50 Nanyang Avenue, Singapore 639798, Singapore would lead to much higher expenses and a more costly product. ${ }^{15}$ The lack of lithium availability has resulted in the price of its raw materials rising massively over the past few years (Fig. 1). ${ }^{16}$ Thus, there exists an immediate need to come up with alternatives to lithium, especially in view of government policies to develop large-scale energy storage grids and devices. ${ }^{17-20}$

Sodium, on the other hand, ranks as the world's $4^{\text {th }}$ most widely abundant element on earth. Investigations into sodiumion batteries (NIBs) began alongside LIBs in the 1970s, but were

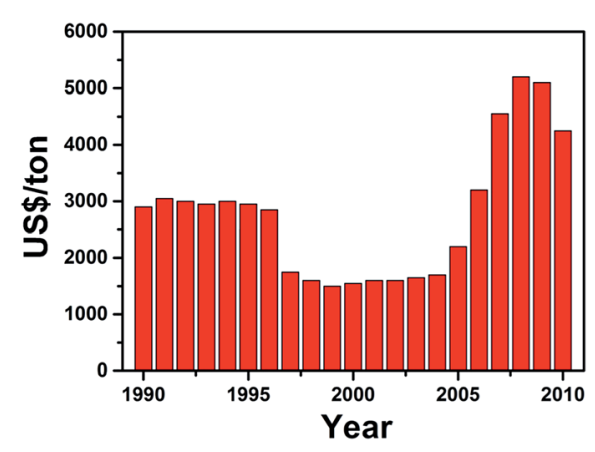

Fig. 1 Average price of lithium precursor $\left(\mathrm{Li}_{2} \mathrm{CO}_{3}\right)$ over the years. The sharp increase in price from 2004 was caused by the increasing demand for LIBs, while the decline in 2008 was due to the financial crisis affecting the demand for LIBs. The data is collected from ref. 16. 
almost completely overshadowed by LIBs following the successful commercialization of LIBs by Sony in $1990 .^{21,22}$ Despite the higher reducing potential that sodium $(E=-2.7 \mathrm{~V}$ vs. S.H.E.) has over lithium ( $E=-3.04 \mathrm{~V} v$ s. S.H.E. $)$, the cost per $\mathrm{kW} \mathrm{h}$ of energy that sodium is able to provide can offer a tremendous advantage when a huge amount of alkali metal is required for large-scale applications. A brief comparison between lithium and sodium can be seen in Table $1 .^{\mathbf{1 4 , 1 5}}$ The operating principles of the NIBs are identical to that of the "rocking-chair" mechanism in LIBs.

In the operation, a separator crucially separates the cathode and anode and the set-up is submerged in a Na-ion containing electrolyte. During the charge and discharge processes, alkali ions shuttle between the two electrodes. Although it has been frequently pointed out that NIBs will always fall behind their lithium counterparts in terms of theoretical energy density due to the heavier weight of sodium, recent computational studies by Cedar's group have demonstrated by using computational simulation that the output voltage of certain sodium-based materials could vie with that of their lithium counterparts. ${ }^{23}$ Hence, there lies a huge opportunity for the investigation of novel and cheaper sodium-based compounds as energy storage materials amidst all the lithium hype.

Important parameters, including specific capacity, operating voltage and cycling performance of the battery, are largely determined by the electrochemical properties of the alkali ion accommodating structure. Several lithium-based compounds that have shown excellent intercalation chemistry as LIB electrodes, have also proven to exhibit comparatively good electrochemical performance in their sodium analogues (e.g. $\left.\mathrm{Na}_{3} \mathrm{~V}_{2}\left(\mathrm{PO}_{4}\right)_{3}, \mathrm{Na}_{2} \mathrm{FePO}_{4} \mathrm{~F}\right) .^{24-30}$ For advances in the field of NIBs to occur, fundamental questions have to be first answered. These include questions about the mechanics in the diffusion of sodium ions through the SEI layer and into crystal structure, as well as the interaction of the electrolyte with the active particles. The kinetics and transport behaviours also need to be investigated to explain how sodium and lithium could be so similar but yet so electrochemically different.

In recent years, there has been a surge in the number of excellent reviews on room temperature NIBs. ${ }^{14,15,19,31-39}$ For instance, Ellis ${ }^{19}$ and Palomares ${ }^{35}$ compared the different types of sodium systems (e.g. aqueous/non-aqueous NIB, Na-S cell, Na-air cell and etc.) available. Kim, ${ }^{13} \operatorname{Pan}^{39}$ and Yabuuchi ${ }^{37}$ covered in detail the different electrode materials that have been reported. Ponrouch et al. provided a detailed analysis on the various non-aqueous NIB electrolytes. ${ }^{36}$ Several other

Table 1 Comparison between sodium and lithium ${ }^{14,15}$

\begin{tabular}{lll}
\hline & Sodium & Lithium \\
\hline Potential (V vs. S.H.E.) & -2.70 & -3.04 \\
Cation radii (̊) & 0.97 & 0.68 \\
Price (US\$ per ton) & $250-300$ & 5800 \\
Atomic weight (g) & 23 & 6.9 \\
Capacity (mA h $\left.{ }^{-1}\right)$ & 1160 & 3860
\end{tabular}

reviews focusing on either the anode $\mathrm{e}^{\mathbf{3 4 , 3 8}}$ or cathode $\mathrm{c}^{32,33,40}$ have also been reported. However, we believe that the NIB family is constantly growing and frequent reviews are indeed necessary to assist progress towards commercialization of the technology. We aim to cover the advancements in electrode materials for NIBs that have been recently reported. For the cathodic component, we will focus on sodium intercalation alkali compounds. Here, a wide group of materials, including layered oxides, polyanionic phosphates, pyrophosphates, will be extensively reviewed. As for the negative electrodes, since the successful utilization of graphitic carbon in LIB could not be mimicked in NIBs, alternative materials, including hard carbons, alloying and conversion materials, will be covered in detail. Recently, organic compounds have also made a significant impact as alternative environmentally sustainable electrode materials and so will also be covered here. Finally, we will conclude with some perspectives on possible solutions and suggestions that could be of significant interest for progress in this field.

\section{Positive electrode materials}

Cathode materials in Na-ion batteries are able to reversibly insert $\mathrm{Na}$ ions within the crystal structure at a high redox potential, usually $>2 \mathrm{~V} v s$. $\mathrm{Na}^{+} / \mathrm{Na}$. Ideal candidates for cathode materials should exhibit low volume expansion upon intercalating/deintercalating of the $\mathrm{Na}$ ion, in order to provide superior cycling performance for the cell. Research on $\mathrm{Na}$ intercalating compounds is not new and has already been thoroughly researched alongside LIB research over several decades.

\subsection{Oxides}

A widely studied structure for the cathode material for LIBS would be layered oxides with the empirical formula $\mathrm{LiMO}_{2}$ (where $\mathbf{M}=$ one or more $3 \mathrm{~d}$ ions with multiple oxidation states), because of their high intercalating potentials ( $v s . \mathrm{Li}^{+} / \mathrm{Li}$ ) and, hence, high energy density. The layered structure is made up of layers of edge-shared transition metal centered oxygen octahedra $\left(\mathrm{MO}_{6}\right)$, in which the alkali ions are able to intercalate into either the trigonal prismatic $(\mathrm{P})$ or octahedral $(\mathrm{O})$ vacancy spot. Similar to their lithium analogues, such layered oxides also have the ability to accommodate $\mathrm{Na}$ ions too. Layered oxides are classified according to the stacking arrangement of the alkali ions between each interlayer. ${ }^{\mathbf{4 1 , 4 2}}$ The different polytypes are each unique in terms of how the oxygen layers are being stacked. The general consensus follows where $\mathrm{O}$ and $\mathrm{P}$ refer to the octahedral and trigonal coordination of the alkali ion by oxygen within the interstitial layer of the crystal structure, respectively, while the number 2 or 3 represents the repeated transition metal layers within a unit cell; for example, ABCABC in O3, ABBA in P2 and ABBCCA in P3 as shown in Fig. 2. The difference in stacking order in each structure results in distinctive insertion sites for the alkali ions. However, unlike $\mathrm{Li}$ ions, Na ions are only able to occupy the trigonal prismatic sites in the P2 structure, due to the larger ionic size of the $\mathrm{Na}$ ion. ${ }^{43}$ 

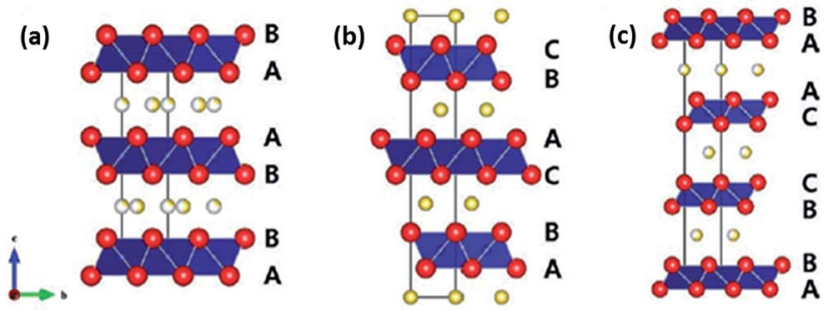

Fig. 2 Crystal structure of various layered metal oxides. (a) P2$\mathrm{Na}_{x} \mathrm{MO}_{2}$, (b) O3-Nax $\mathrm{MO}_{2}$, (c) P3- $\mathrm{Na}_{x} \mathrm{MO}_{2}$ (ref. 13). Copyright 2012 Wiley-VCH Verlag GmbH \& Co. KGaA, Weinheim.

Phase transition occurs during sodiation/desodiation in both $\mathrm{O}$ and $\mathrm{PAMO}_{2}$ phases, whereby gliding of the oxygen layers results in structural distortion and rearrangement. The phase structure is dependent on the number of $\mathrm{Na}$ ions that are intercalated in the structure. ${ }^{44,45}$

$\mathrm{LiCoO}_{2}$ is one example from the $\mathrm{AMO}_{2}$ family that has seen tremendous success as a cathodic material in LIBs following its commercialization by Sony in $1990 .^{46,47}$ Hence, it is not surprising that its $\mathrm{Na}$ counterpart, $\mathrm{Na}_{x} \mathrm{CoO}_{2}$, has attracted much interest as an alternative. In 1981, Delmas et al. compared the electrochemical properties of $\mathrm{P} 2$ and $\mathrm{O} 3 \mathrm{Na}_{x} \mathrm{CoO}_{2}$. During the electrochemical desodiation, it was observed that the $\mathrm{O} 3$ $\mathrm{Na}_{x} \mathrm{CoO}_{2}$ transformed into monoclinic distorted $\mathrm{O}^{\prime} 3 \mathrm{Na}_{x} \mathrm{CoO}_{2}$ and finally to $\mathrm{P} 3 \mathrm{Na}_{x} \mathrm{CoO}_{2}$ within a Na content of $0.5 \leq x \leq 1 .^{48}$ On the other hand, the $\mathrm{P} 2 \mathrm{Na}_{x} \mathrm{CoO}_{2}$ was found to be able to maintain its structure throughout electrochemical sodiation and desodiation. It was reported that for phase transition to take place from P2- to O-type structured $\mathrm{Na}_{x} \mathrm{CoO}_{2}$, energy is required for rotation of the $\mathrm{CoO}_{6}$ octaherdra and for cleavage of the $\mathrm{Co}-\mathrm{O}$ bond. Hence, $\mathrm{P} 2 \mathrm{Na}_{x} \mathrm{CoO}_{2}$ generally retains its structure at room temperature during electrochemical cycling reactions. ${ }^{49}$

Shibata $e t$ al. reported the diffusion coefficient of $\mathrm{Na}$ ions into $\mathrm{Na}_{x} \mathrm{CoO}_{2}$ at $303 \mathrm{~K}$ with values of $(0.7-1.9) \times 10^{-11} \mathrm{~cm}^{2} \mathrm{~s}^{-1}$ $(0.54<x<0.85)$, which are comparable to that of the diffusion coefficient $\left(10^{-12}\right.$ to $\left.10^{-11}\right)$ of $\mathrm{Li}$ in $\mathrm{LiCoO}_{2} \cdot{ }^{50,51}$ Analogues of P2$\mathrm{Na}_{x} \mathrm{CoO}_{2}$ were also investigated. The electrochemical discharge profiles of $\mathrm{P} 2-\mathrm{Na}_{x} \mathrm{CoO}_{2}$ vs. $\mathrm{P} 2-\mathrm{Na}_{2 / 3} \mathrm{Co}_{2 / 3} \mathrm{Mn}_{1 / 3} \mathrm{O}_{2}$ are compared in Fig. 3a. P2- $\mathrm{Na}_{x} \mathrm{CoO}_{2}$ recorded a total of 9 phase transformations when cycled between $0.5 \leq x \leq 0.9$. In contrast, $\mathrm{Mn}$ doped $\mathrm{P} 2-\mathrm{Na}_{2 / 3} \mathrm{Co}_{2 / 3} \mathrm{Mn}_{1 / 3} \mathrm{O}_{2}$ exhibited a typical solid-solution like curve, with a single phase transformation at $x=0.67 .{ }^{23} \mathrm{Na}$ MAS (Magic Angle Spinning) NMR (Nuclear Magnetic Resonance) was also carried out, with the results indicating the disordered arrangement of both $\mathrm{Co}^{3+}$ and $\mathrm{Mn}^{4+}$, which prevents structural transformation. However, a subsequent in situ X-ray Absorption Spectroscopy (XAS) carried out during the discharge process showed both Co and Mn K-edges shifted to a lower energy level when the Na content $>0.67$ (Fig. 3b), indicating a concurrent reduction in both $\mathrm{Co}^{3+} / \mathrm{Co}^{2+}$ and $\mathrm{Mn}^{4+} / \mathrm{Mn}^{3+}$ during the structural change. ${ }^{52,53}$

O3- $\mathrm{NaFeO}_{2}$ similarly belongs to the group of layered oxides that has potential electrochemical storage capabilities.
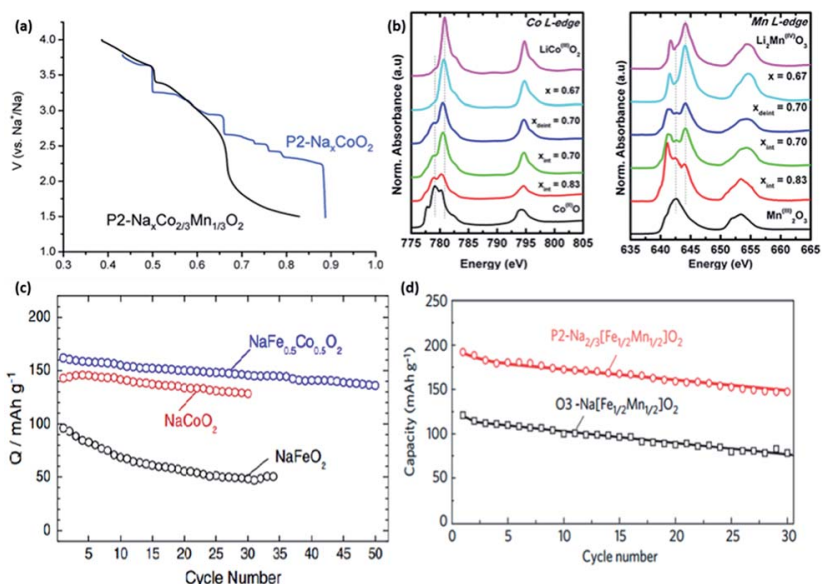

Fig. 3 (a) $2^{\text {nd }}$ discharge curve comparison of $\mathrm{P} 2-\mathrm{Na}_{x} \mathrm{CoO}_{2}$ and P2$\mathrm{Na}_{x} \mathrm{CO}_{2 / 3} \mathrm{Mn}_{1 / 3} \mathrm{O}_{2}$ (ref. 53) (b) normalized in situ X-ray Absorption Spectroscopy (XAS) of $\mathrm{P} 2-\mathrm{Na}_{x} \mathrm{CO}_{2 / 3} \mathrm{Mn}_{1 / 3} \mathrm{O}_{2}$ with respect to the reference materials, revealing shifts in the peaks during the discharge process, indicating the simultaneous redox reaction occurring in $\mathrm{Co}^{3+} / \mathrm{Co}^{2+}$ and $\mathrm{Mn}^{4+} / \mathrm{Mn}^{3+}$ (ref. 52) (c) comparison of cycling capability between different oxides. ${ }^{54}$ (d) Comparison of cycling discharge capacity between $\mathrm{P} 2$ and $\mathrm{O} 3-\mathrm{Na}_{x}\left[\mathrm{Fe}_{1 / 2} \mathrm{Mn}_{1 / 2}\right] \mathrm{O}_{2}$ (ref. 55) (a) reproduced from ref. 53 with permission from The Royal Society of Chemistry (b) reprinted with permission from ref. 52. Copyright 2014 American Chemical Society (c) reprinted with permission from ref. 54. Copyright 2013 Elsevier (d) reprinted with permission from Macmillan Publishers Ltd.: (Nat. Mater.) (ref. 55), Copyright 2012.

Yabuuchi et al. synthesized $\mathrm{NaFeO}_{2}$ via a simple solid-state method and with varying different cut-off voltages to evaluate its cycling performance. The optimum performance was observed when the cut-off voltage was limited to $3.5 \mathrm{~V}$. Despite the low initial specific capacity of $80 \mathrm{~mA} \mathrm{~h} \mathrm{~g}^{-1}$, its cycling performance demonstrated a reversible retention of $75 \%$ after 30 cycles. $E x$ situ XRD revealed the presence of an irreversible structure change when the cut-off voltage was increased to $4.0 \mathrm{~V}$ and over vs. $\mathrm{Na}^{+} / \mathrm{Na}\left(x \geq 0.4\right.$ in $\left.\mathrm{Na}_{1-x} \mathrm{FeO}_{2}\right)$, which explained the severe capacity fading. ${ }^{56}$ Moving on, the partial substitution of Fe with Co in $\mathrm{NaFeO}_{2}$ has been effectively shown to suppress the iron migration that was previously observed in the first principle calculations. ${ }^{57}$ The cycling performance of O3-type $\mathrm{NaFe}_{1 / 2} \mathrm{Co}_{1 / 2} \mathrm{O}_{2}$ compared to $\mathrm{NaFeO}_{2}$ and $\mathrm{NaCoO}_{2}$, is shown in Fig. 3c. $\mathrm{NaFe}_{1 / 2} \mathrm{Co}_{1 / 2} \mathrm{O}_{2}$ was able to deliver a reversible capacity of $160 \mathrm{~mA} \mathrm{~h} \mathrm{~g}{ }^{-1}(C / 20)$ within $1.5-4.0 \mathrm{~V} v$ s. $\mathrm{Na}^{+} / \mathrm{Na}$ with an energy density of $510 \mathrm{~W} \mathrm{~h} \mathrm{~kg}^{-1} .{ }^{54}$

Komaba's group also recently compared the electrochemical performance of P2-and O3-type $\mathrm{Na}_{x}\left[\mathrm{Fe}_{1 / 2} \mathrm{Mn}_{1 / 2}\right] \mathrm{O}_{2}$ in a sodium cell set-up. The rationale for the synthesis of $\mathrm{Na}_{x}\left[\mathrm{Fe}_{1 / 2} \mathrm{Mn}_{1 / 2}\right] \mathrm{O}_{2}$ stems from the fact that the $\mathrm{Fe}^{4+}$ cation in $\mathrm{P} 2-\mathrm{Na}_{x} \mathrm{FeO}_{2}$ cannot be stabilized in its oxide structure under ambient conditions, along with the partial reversibility problem in $\mathrm{NaFeO}_{2}$, as previously mentioned. The $\mathrm{P} 2$-type $\mathrm{Na}_{2 / 3}\left[\mathrm{Fe}_{1 / 2} \mathrm{Mn}_{1 / 2}\right] \mathrm{O}_{2}$ was able to deliver a reversible capacity of up to $190 \mathrm{~mA} \mathrm{~h} \mathrm{~g}{ }^{-1}$, compared to $124 \mathrm{~mA} \mathrm{~h} \mathrm{~g}^{-1}$ in $\mathrm{O} 3-\mathrm{Na}\left[\mathrm{Fe}_{1 / 2} \mathrm{Mn}_{1 / 2}\right] \mathrm{O}_{2}$, as shown in Fig. 3d. The capacity delivered by $\mathrm{P} 2-\mathrm{Na}_{2 / 3}\left[\mathrm{Fe}_{1 / 2} \mathrm{Mn}_{1 / 2}\right] \mathrm{O}_{2}$ is approximately $72 \%$ of its theoretical capacity, assuming a single electron transfer of a $\mathrm{M}^{3+} / \mathrm{M}^{4+}\left(\mathrm{M}=\mathrm{Fe}_{1 / 2}, \mathrm{Mn}_{1 / 2}\right)$ couple. 
In addition, the energy density is estimated to be about $520 \mathrm{~W} \mathrm{~h} \mathrm{~kg}^{-1}$, which is comparable to $530 \mathrm{~W} \mathrm{~h} \mathrm{~kg}^{-1}$ demonstrated in $\mathrm{LiFePO}_{4}$. However, the electrode stability of the P2type $\mathrm{Na}_{2 / 3}\left[\mathrm{Fe}_{1 / 2} \mathrm{Mn}_{1 / 2}\right] \mathrm{O}_{2}$ is rather poor, as shown by a capacity retention of approximately $77 \%$ at the end of 30 cycles. $\mathrm{Na}_{2 / 3} \mathrm{Ni}_{1 / 3} \mathrm{Mn}_{1 / 2} \mathrm{Ti}_{1 / 6} \mathrm{O}_{2}$ was able to deliver a reversible capacity of $127 \mathrm{~mA} \mathrm{~h} \mathrm{~g}^{-1}$ at an average voltage plateau of $3.7 \mathrm{Vvs.} \mathrm{Na}^{+} / \mathrm{Na}$. The energy density is estimated to be $470 \mathrm{~W} \mathrm{~h} \mathrm{~kg}^{-1}$ in a half-cell configuration. Furthermore, it was found that the presence of $\mathrm{Ti}$ helps to suppress the volume change during charge discharge, hence leading to excellent cyclability performance compared to P2-type $\mathrm{Na}_{2 / 3}\left[\mathrm{Fe}_{1 / 2} \mathrm{Mn}_{1 / 2}\right] \mathrm{O}_{2} .^{58}$

Another prospective cathode material for NIB is the monoclinic $\mathrm{O}^{\prime} 3 \mathrm{NaNiO}_{2}$. The electrochemical profile of $\mathrm{NaNiO}_{2}$ is similar to that of $\mathrm{P} 2-\mathrm{Na}_{x} \mathrm{CoO}_{2}$, with multiple well-defined phase transformations during charge/discharge processes. In situ XRD during the discharge process revealed several phase transformations of $\mathrm{O}^{\prime} 3, \mathrm{P}^{\prime} 3, \mathrm{P}^{\prime \prime} 3, \mathrm{O}^{\prime \prime} 3$ and $\mathrm{O}^{\prime \prime \prime} 3$ layered structures when cycled in a voltage range of $1.5-4.0 \mathrm{~V}$ at a rate of $C / 10$. The $\mathrm{NaNiO}_{2}$ recorded a $1^{\text {st }}$ charge capacity of $160 \mathrm{~mA} \mathrm{~h} \mathrm{~g}^{-1}$; however, only $114.6 \mathrm{~mA} \mathrm{~h} \mathrm{~g}^{-1}$ is obtained during the $1^{\text {st }}$ discharge process. ${ }^{59}$ Cedar et al. described, through XRD and galvanostatic discharge results, how the excess capacity was attributed to the removal of the higher $\mathrm{Na}$ content of $\sim 0.91$ in the $1^{\text {st }}$ cycle, compared to a much lower Na content $\sim 0.52$ during subsequent cycles. ${ }^{60}$ Hasa et al. also demonstrated the synthesis of P2 layered $\mathrm{Na}_{0.5}\left[\mathrm{Ni}_{0.23} \mathrm{Fe}_{0.13} \mathrm{Mn}_{0.63}\right] \mathrm{O}_{2}$ via a simple co-precipitation/ rinsing method. Fig. 4a shows the electrochemical response within a voltage window of $1.5-4.6 \mathrm{~V}\left(v s . \mathrm{Na}^{+} / \mathrm{Na}\right)$ at increasing current densities $(C / 10$ to $5 C$ ). At a rate of $C / 10$, the capacity achieved was $180 \mathrm{~mA} \mathrm{~h} \mathrm{~g}^{-1}$, which decreased with an increasing rate to $60 \mathrm{~mA} \mathrm{~h} \mathrm{~g}^{-1}$ at $5 C$. Moreover, a near complete capacity
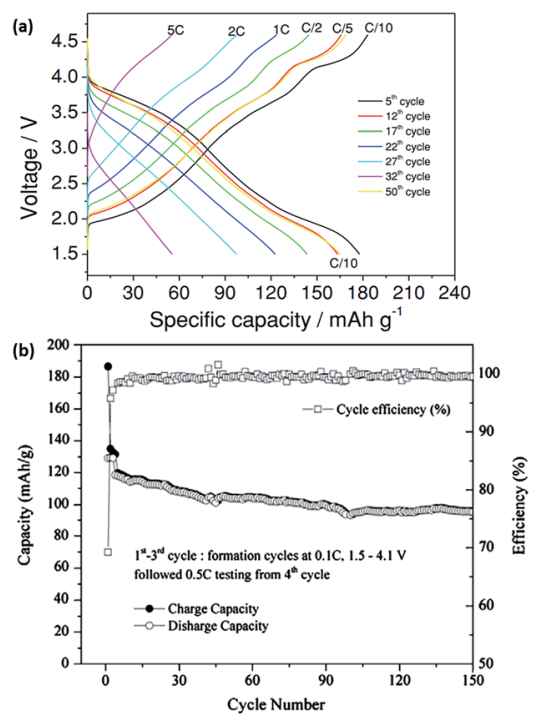

Fig. 4 (a) Rate capability of $\mathrm{Na}_{0.5}\left[\mathrm{Ni}_{0.23} \mathrm{Fe}_{0.13} \mathrm{Mn}_{0.63}\right] \mathrm{O}_{2}$ at different cycles. ${ }^{61}$ (b) Cycling capability and coulombic efficiency of $\mathrm{Na}_{y} \mathrm{C} /$ $\mathrm{Na}_{1-y}\left(\mathrm{Ni}_{1 / 3} \mathrm{Fe}_{1 / 3} \mathrm{Mn}_{1 / 3}\right) \mathrm{O}_{2}$ cell.62 (a) Copyright 2014 Wiley-VCH Verlag $\mathrm{GmbH} \& \mathrm{Co}$. KGaA, Weinheim (b) reprinted with permission from ref. 62. Copyright 2012 Elsevier. was observed when the current reverted back to $C / 10$, which indicated rapid kinetics during sodiation/desodiation, as well as exceptional electrode stability. ${ }^{61} \mathrm{Kim}$ et al. fabricated layered $\mathrm{Na}\left[\mathrm{Ni}_{1 / 3} \mathrm{Fe}_{1 / 3} \mathrm{Mn}_{1 / 3}\right] \mathrm{O}_{2}$ via a solid-state synthesis and tested this in both half ( $v s$. sodium metal) and full ( $v s$. hard carbon) cell configuration. The half-cell exhibited gradual sloping electrochemical profiles with a reversible capacity of $100 \mathrm{~mA} \mathrm{~h} \mathrm{~g}$ $(0.5 C)$ for up to 150 cycles when tested between 1.5 and $4.0 \mathrm{~V}$. Furthermore, ex situ XRD showed excellent crystal structure integrity even after 123 cycles. The $1^{\text {st }}$ cycle charge discharge curve of the $\mathrm{Na}_{y} \mathrm{C} / \mathrm{Na}_{1-y}\left[\mathrm{Ni}_{1 / 3} \mathrm{Fe}_{1 / 3} \mathrm{Mn}_{1 / 3}\right] \mathrm{O}_{2}$ full cell showed an initial irreversible capacity of approximately $28 \%$, which could be attributed to the formation of SEI. The cycling performance of the full cell (Fig. 4b) demonstrated a capacity retention of approximately $70 \%$ after 150 cycles, while the coulombic efficiency increased and was stable at $99 \%$ after the initial SEI formation cycles. ${ }^{62}$ A quaternary layered oxide (O3-Na $\left(\mathrm{Mn}_{0.25^{-}}\right.$ $\left.\mathrm{Fe}_{0.25} \mathrm{Co}_{0.25} \mathrm{Ni}_{0.25}\right) \mathrm{O}_{2}$ ) was also reported recently by Cedar's group. X-ray Absorption Near Edge Structure (XANES) was carried out and the valence states of $\mathrm{Mn}, \mathrm{Fe}, \mathrm{Co}, \mathrm{Ni}$ in the quaternary structure were determined to be $4+, 3+, 2+$ and $1+$, respectively. Additionally, in situ XRD was carried out to determine the structure evolution of the quaternary structure, revealing a transition of $\mathrm{O} 3-\mathrm{P} 3-\mathrm{O}^{\prime}-\mathrm{O}^{\prime \prime}$ during $\mathrm{Na}$ deinsertion. Comparably to other $\mathrm{O} 3$ group materials, the quaternary oxide was able to deliver a much higher capacity of $180 \mathrm{~mA} \mathrm{~h} \mathrm{~g}^{-1}$ when cycled between 1.9 and $4.3 \mathrm{~V}$, producing an energy density of $578 \mathrm{~W} \mathrm{~h} \mathrm{~kg}^{-1}$. The electrochemical performance of the quaternary oxide was compared to $\mathrm{O} 3-\mathrm{Na}\left(\mathrm{Fe}_{0.5} \mathrm{Co}_{0.5}\right) \mathrm{O}_{2}$ and O3$\mathrm{Na}\left(\mathrm{Ni}_{0.5} \mathrm{Mn}_{0.5}\right) \mathrm{O}_{2}$, as shown in Fig. 5a. The synergistic effect of the multiple transition metals in $\mathrm{O} 3-\mathrm{Na}\left(\mathrm{Mn}_{0.25} \mathrm{Fe}_{0.25} \mathrm{Co}_{0.25} \mathrm{Ni}_{0.25}\right)$ $\mathrm{O}_{2}$ allows it to be much more stable at higher cut-off voltages during cycling (Fig. 5b), in which high cut-off voltage is an issue present in $\mathrm{Na}\left(\mathrm{Fe}_{0.5} \mathrm{Co}_{0.5}\right) \mathrm{O}_{2}$, as well as in $\mathrm{Na}\left(\mathrm{Ni}_{0.5} \mathrm{Mn}_{0.5}\right) \mathrm{O}_{2}{ }^{63}$ Similarly, copper-based layered electrode materials ( $\mathrm{P} 2-\mathrm{Na}_{0.68^{-}}$ $\mathrm{Cu}_{0.34} \mathrm{Mn}_{0.66} \mathrm{O}_{2}, \quad \mathrm{P} 2-\mathrm{Na}_{0.68} \mathrm{Cu}_{0.34} \mathrm{Mn}_{0.55} \mathrm{Ti}_{0.16} \mathrm{O}_{2}, \quad \mathrm{O}^{\prime} 3-\mathrm{NaCu}_{0.67^{-}}$ $\mathrm{Sb}_{0.33} \mathrm{O}_{2}$ and $\mathrm{O} 3-\mathrm{Na}_{0.9} \mathrm{Cu}_{1 / 4} \mathrm{Fe}_{1 / 4} \mathrm{Mn}_{1 / 4} \mathrm{Ti}_{1 / 4} \mathrm{O}_{2}$ ) were studied as prospective cathode materials in NIBs. ${ }^{64,65}$ The materials demonstrated the use of $\mathrm{Cu}^{2+} / \mathrm{Cu}^{3+}$ redox pairs for energy storage. Whilst their specific capacity was lower compared to $\mathrm{NaCuO}_{2},{ }^{66}$ the average voltage plateaus and cyclability of the doped compounds were significantly enhanced.
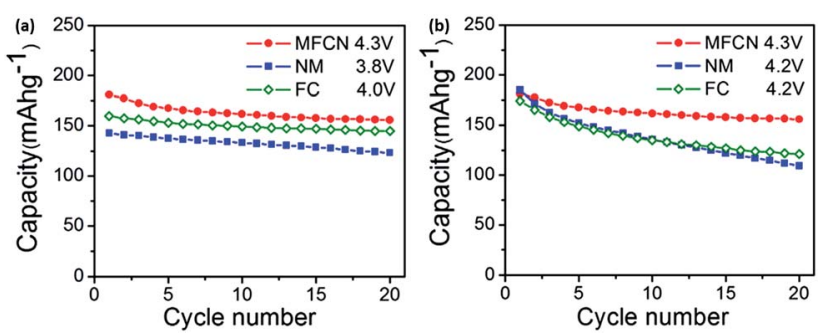

Fig. 5 Cycling capability of quaternary oxide $\mathrm{O} 3-\mathrm{Na}\left(\mathrm{Mn}_{0.25} \mathrm{Fe}_{0.25^{-}}\right.$ $\mathrm{CO}_{0.25} \mathrm{Ni}_{0.25} \mathrm{OO}_{2}$ at (a) different cut-off voltage (b) similar cut-off voltage $^{63}$ reprinted with permission from ref. 63. Copyright 2014 Elsevier. 
Other oxides, including $\mathrm{NaCrO}_{2},{ }^{67,68}$ have been of recent particular interest in light of the fact that the lithium counterpart, $\mathrm{LiCrO}_{2}$, demonstrates a poor reversible capacity of only 10 $\mathrm{mA} \mathrm{h} \mathrm{g}{ }^{-1}$, while a reversible capacity of $120 \mathrm{~mA} \mathrm{~h} \mathrm{~g}{ }^{-1}$ can be achieved in $\mathrm{NaCrO}_{2}$ (Fig. 6). ${ }^{69}$ The authors believed that the bonding distance affects the reactivity of the two different compounds. In the case of $\mathrm{LiCrO}_{2}, \mathrm{Cr}^{4+}$ in the tetrahedral sites tends to disproportionately convert into $\mathrm{Cr}^{6+}$ during charging, which easily gets trapped within the tetrahedral sites. However, this does not occur in $\mathrm{NaCrO}_{2}$, as XANES elucidated that $\mathrm{Cr}^{4+}$ is the more stable redox state during charging. ${ }^{70}$ The larger size of the $\mathrm{Cr}^{4+}$ (compared to $\mathrm{Cr}^{6+}$ ) restricts the irreversible migration, ensuring $\mathrm{Cr}^{4+}$ stays within the interslab layers, thus allowing for reversible sodiation/desodiation. This example opens up several opportunities to look into the sodium counterpart of lithiumbased materials that have previously been considered electrochemically inactive in LIBs.

Manganese-based oxides are known to crystallize in different polymorphs depending on the synthesis method. Several polymorphs exist because of the different ways $\mathrm{MnO}_{6}$ octahedra are interlinked. Hollandite $\alpha-\mathrm{MnO}_{2}$, which has corner and edge sharing octaherdra forming large $2 \times 2$ tunnels for facile ion diffusion along the $c$-axis, have been considered as potential alkali-ion battery material. Additionally, the computational results have exhibited interesting results, indicating that the migration barriers for the diffusion of both $\mathrm{Li}$ and $\mathrm{Na}$ ions within the structure are comparable. ${ }^{71} \mathrm{Su}$ et al. synthesized $\alpha-\mathrm{MnO}_{2}$ and $\beta-\mathrm{MnO}_{2}$ nanorods via a facile hydrothermal synthesis, and recorded initial discharge capacities of 278 and $298 \mathrm{~mA} \mathrm{~h} \mathrm{~g}^{-1}$, respectively (Fig. 7a), which subsequently
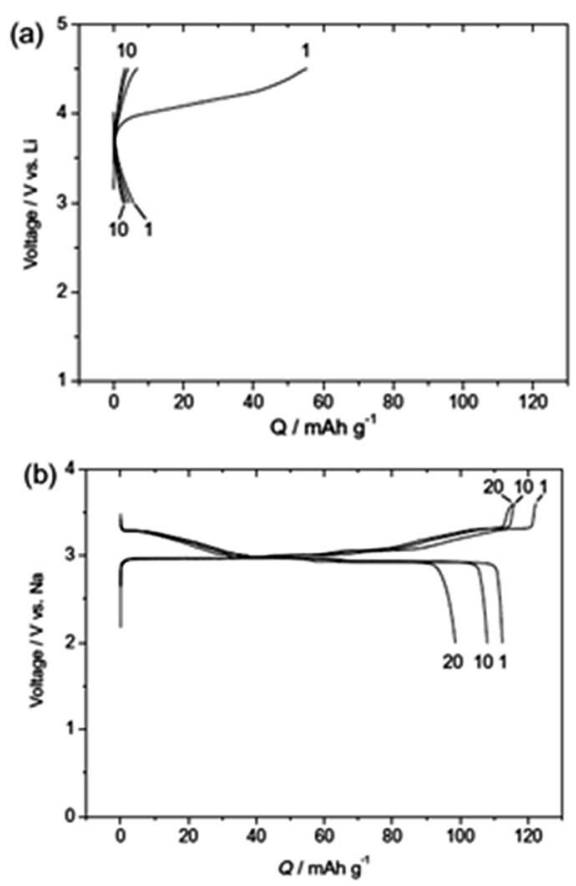

Fig. 6 Comparison of charge-discharge profiles for (a) $\mathrm{LiCrO}_{2}$ and (b) $\mathrm{NaCrO}_{2}$ tested at a current density of $20 \mathrm{~mA} \mathrm{~g}^{-1}$ (ref. 67) reprinted with permission from ref. 67. Copyright 2010 Elsevier.
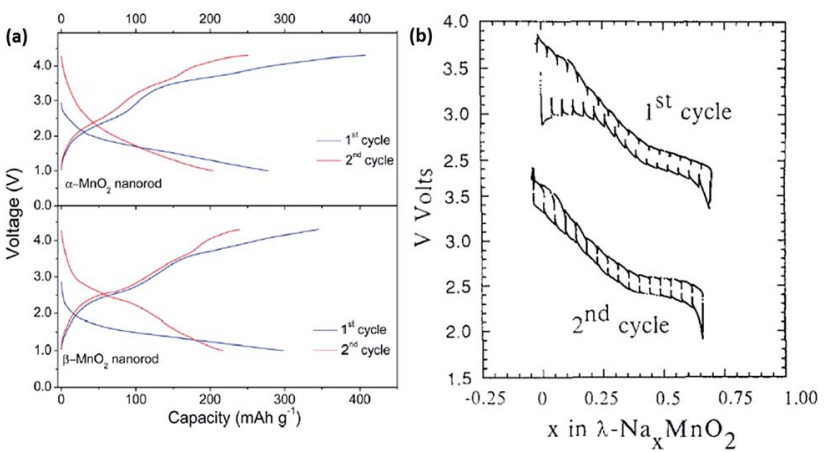

Fig. 7 (a) Galvanostatic charge-discharge curves during the $1^{\text {st }}$ and $2^{\text {nd }}$ cycle of $\alpha-\mathrm{MnO}_{2}$ and $\beta-\mathrm{MnO}_{2}$ tested at a current density of $20 \mathrm{~mA}$ $\mathrm{g}^{-1}$, respectively ${ }^{72}$ (b) galvanostatic charge-discharge curve of $\lambda$ $\mathrm{MnO}_{2}$ cycled between the voltage window of 2.0-4.0 V. Top curve shows the $1^{\text {st }}$ cycle, while the bottom curve shows the $2^{\text {nd }}$ cycle. ${ }^{73}$ (a) Reproduced from ref. 72 with permission from The Royal Society of Chemistry (b) reprinted with permission from ref. 73. Copyright 1992 Elsevier.

dropped to 204 and $250 \mathrm{~mA} \mathrm{~h} \mathrm{~g}^{-1}$ in the second cycle, respectively. ${ }^{72}$ However, they did not explain why the initial capacity was recorded to be much higher than the theoretical capacity of $244 \mathrm{~mA} \mathrm{~h} \mathrm{~g}^{-1}$ assuming single electron transfer. Tarascon et al. demonstrated $\mathrm{Na}$ insertion into $\lambda-\mathrm{MnO}_{2}$, in which the spinelbased structure irreversibly transformed into a layered structure after the $1^{\text {st }}$ discharge cycle (Fig. 7b). Following the irreversible phase transformation, only $0.6 \mathrm{~mol}$ of $\mathrm{Na}$ ions could be reversibly extracted out. ${ }^{73}$

Pre-sodiated manganese oxide, $\mathrm{Na}_{0.44} \mathrm{MnO}_{2}$ (also known as $\mathrm{Na}_{4} \mathrm{Mn}_{9} \mathrm{O}_{18}$ ), has also been thoroughly investigated over the years, particularly because of its attractive large-sized tunnels for sodium insertion. ${ }^{74-76}$ Sauvage et al. studied pure $\mathrm{Na}_{0.44} \mathrm{MnO}_{2}$ samples synthesized via a solid-state method and recorded a specific capacity of $\sim 80 \mathrm{~mA} \mathrm{~h} \mathrm{~g}^{-1}$ when cycled at a rate of $C / 10$ over a voltage range between 2.0 and $3.8 \mathrm{~V} v s . \mathrm{Na}^{+} /$ Na. A potentiostatic intermittent titration technic (PITT) was also carried out at an extremely slow rate of $C / 200$, as shown in Fig. 8a. The peak shifts during sodiation indicated an expansion of the lattice parameters with respect to the accommodation of the sodium ions. No new phases were detected, as could be backed up by the biphasic transition in the electrochemical profiles, indicating similar crystal structures of the sodiated and desodiated phases. ${ }^{74}$ However, an $a b$ initio study coupled with experiments found that seven intermediate phases were present during the electrochemical charge/discharge. The results are shown in Fig. 8b, and reveal that the calculated voltage profile along the minimum energy path of formation is in coherence with that of the first experimental galvanostatic cycle. ${ }^{75}$ It is well documented that the nanosizing of materials could lead to improved properties, including a higher electrode-electrolyte interface for improved ion diffusion. ${ }^{2}$ Cao et al. synthesized uniform $\mathrm{Na}_{0.44} \mathrm{MnO}_{2}$ nanowires (diameter $\approx 50 \mathrm{~nm}$ ) through a polymer-pyrolysis method. The galvanostatic charge-discharge curves exhibited a capacity of $130 \mathrm{~mA} \mathrm{~h} \mathrm{~g}^{-1}$ at a rate of $0.1 C$. A full cell coupled with a hard carbon anode demonstrated an 

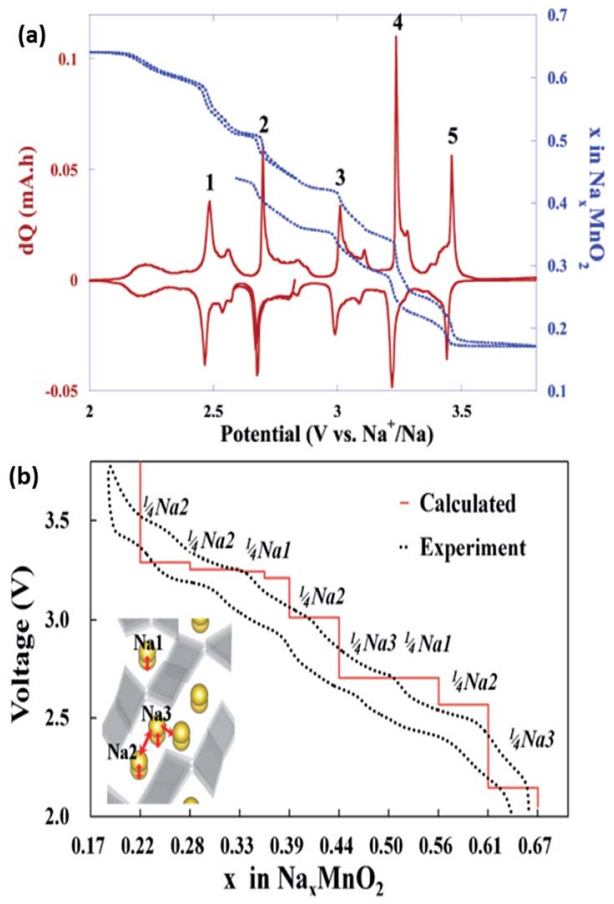

Fig. 8 (a) PITT (blue dotted line) curve, starting with the reduction reaction (at $\mathrm{C} / 200$ with a $5 \mathrm{mV}$ step) of the $\mathrm{Na}_{0.44} \mathrm{MnO}_{2} / \mathrm{C}$ composite. ${ }^{74}$ (b) Calculated voltage profile of $\mathrm{Na}_{0.44} \mathrm{MnO}_{2}$ along the minimum energy path of the formation energies, which agrees well with that of the experimental values ${ }^{75}$ (a) Reprinted with permission from ref. 74. Copyright 2007 American Chemical Society (b) reprinted with permission from ref. 75. Copyright 2012 American Chemical Society.

initial capacity of about $109 \mathrm{~mA} \mathrm{~h} \mathrm{~g}{ }^{-1}$ over a voltage window of $2.5 \mathrm{~V}$. However, capacity fading was severe, with only $73 \%$ capacity retained after 100 cycles. $^{76}$

Vanadium-based oxides have also been studied for application as cathode materials in NIBs. Su et al. first studied the diffusion coefficient of $\mathrm{Na}$ in $\mathrm{V}_{2} \mathrm{O}_{5}{ }^{77}$ Subsequently, Tang et al. looked into the reversible intercalation of $\mathrm{Na}^{+}$into a $\mathrm{V}_{2} \mathrm{O}_{5}$ aerosol. ${ }^{78}$ Initially, it was shown that the electrochemical performance of bilayered $\mathrm{V}_{2} \mathrm{O}_{5}$ outperforms that of orthorhombic $\mathrm{V}_{2} \mathrm{O}_{5}$. This is explained to be due to the compact orthorhombic structure. ${ }^{79}$ Tepavcevic was first to demonstrate the nanostructure tailoring of $\mathrm{V}_{2} \mathrm{O}_{5}$ to form bilayered $\mathrm{V}_{2} \mathrm{O}_{5}$ via an electrochemical deposition method. A capacity of $250 \mathrm{~mA} \mathrm{~h}$ $\mathrm{g}^{-1}$ could be observed (Fig. 9a), with a relatively decent cyclability ( $\sim 200 \mathrm{~mA} \mathrm{~h} \mathrm{~g}^{-1}$ after 320 cycles). Extremely high energy and power densities of $700 \mathrm{~W} \mathrm{~h} \mathrm{~kg}^{-1}$ and $1200 \mathrm{~W} \mathrm{~kg}^{-1}$ were recorded in the half-cell configuration. ${ }^{80}$ Single crystalline bilayered $\mathrm{V}_{2} \mathrm{O}_{5}$ nanobelts were found to be a promising cathode material, with the capability of providing a capacity of up to 231 $\mathrm{mA} \mathrm{h} \mathrm{g}{ }^{-1}$ when tested at a current density of $80 \mathrm{~mA} \mathrm{~g}^{-1}$, corresponding to the formation of $\mathrm{Na}_{2} \mathrm{~V}_{2} \mathrm{O}_{5}$. In addition, characterization techniques revealed a large $d$-spacing (11.53 $\AA$ ) between the (001) planes, thus allowing for the intercalation of sodium ions. ${ }^{81}$ Recently, works regarding orthorhombic $\mathrm{V}_{2} \mathrm{O}_{5}$ have started to surface in the literature. Hierarchical $\mathrm{V}_{2} \mathrm{O}_{5}$
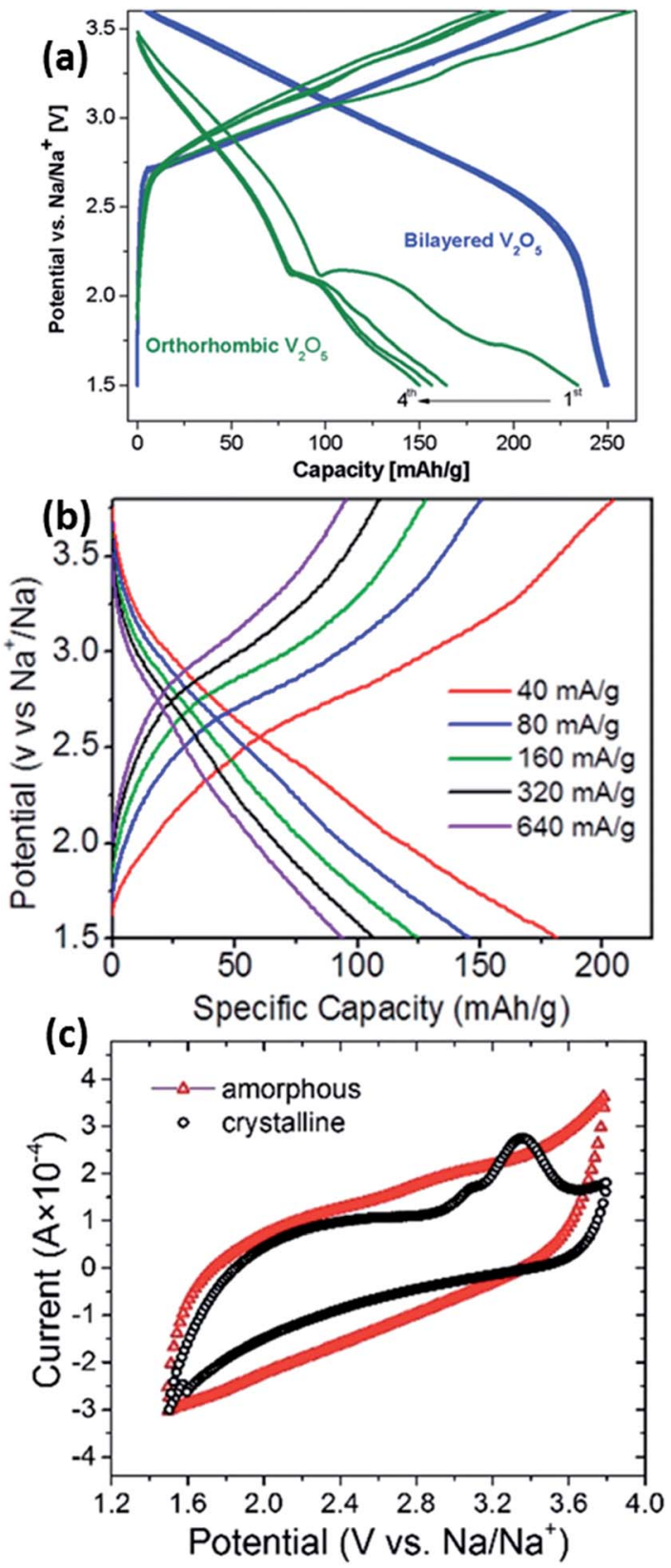

Fig. 9 (a) Electrochemical charge-discharge profiles of orthorhombic vs. bilayered $\mathrm{V}_{2} \mathrm{O}_{5}$ at a current rate of $20 \mathrm{~mA} \mathrm{~g}^{-1}$ (ref. 80) (b) galvanostatic charge-discharge profiles of orthorhombic $\mathrm{V}_{2} \mathrm{O}_{5}$ at different current rates $^{83}$ (c) $\mathrm{CV}$ curves of amorphous vs. crystalline $\mathrm{V}_{2} \mathrm{O}_{5}$ at 1.0 $\mathrm{mV} \mathrm{s}^{-1}$ (ref. 84) (a) reprinted with permission from ref. 80. Copyright 2012 American Chemical Society (b) reprinted with permission from ref. 83. Copyright 2013 American Chemical Society (c) reproduced from ref. 84 with permission from The Royal Society of Chemistry.

hollow nanospheres with exposed 110 crystal planes were able to provide channels for facile $\mathrm{Na}^{+}$insertion/extraction and were tested as cathode materials in NIBs. A high discharge capacity of $\sim 150 \mathrm{~mA} \mathrm{~h} \mathrm{~g}^{-1}$ was obtained, corresponding to the formation of $\mathrm{NaV}_{2} \mathrm{O}_{5}$, which was confirmed by ex situ XRD analysis. The enhanced electrochemical performance is a beneficiary of the unique hollow nanosphere architecture having voids between 
the nanocrystals, which are able to accommodate volume expansion during cycling processes. ${ }^{82}$ Raju et al. demonstrated a carbon-encapsulated orthorhombic $\mathrm{V}_{2} \mathrm{O}_{5}$, in which the overall composite demonstrates a discharge capacity of $170 \mathrm{~mA} \mathrm{~h} \mathrm{~g}{ }^{-1}$. However, the electrochemical profile of the $\mathrm{V}_{2} \mathrm{O}_{5} / \mathrm{C}$ composite showed a general sloping behaviour at all current rates (Fig. 9b), which was coherent with further analysis that the dominant charge storage mechanism by $\mathrm{V}_{2} \mathrm{O}_{5}$ was mainly pseudocapacitive. ${ }^{83}$ Amorphous $\mathrm{V}_{2} \mathrm{O}_{5}$ was also recently prepared via a sol-gel and subsequent electrochemical deposition method. A high initial specific capacity of $241 \mathrm{~mA} \mathrm{~h} \mathrm{~g}^{-1}$ was obtained in the amorphous $\mathrm{V}_{2} \mathrm{O}_{5}$, compared to only $120 \mathrm{~mA} \mathrm{~h} \mathrm{~g}{ }^{-1}$ in nanocrystalline $\mathrm{V}_{2} \mathrm{O}_{5}\left(1.5-3.8 \mathrm{~V}\right.$ vs. $\left.\mathrm{Na}^{+} / \mathrm{Na}\right)$. Additionally, the C.E. of the amorphous phase was much higher and stable compared to the nanocrystalline counterpart. However, as illustrated in Fig. 9c, the $\mathrm{CV}$ of amorphous $\mathrm{V}_{2} \mathrm{O}_{5}$ shows a rectangular-shaped profile, which is a typical characteristic of pseudocapacitive behaviour as opposed to an intercalation nature. ${ }^{84} \mathrm{P}^{\prime} 3-\mathrm{Na}_{0.6} \mathrm{VO}_{2}$ was prepared by a chemical deintercalation of $\mathrm{Na}$ from $\mathrm{NaVO}_{2}$ with iodine, followed by thermal treatment at $200{ }^{\circ} \mathrm{C}$ under hydrogen flow. It should be noted that $\mathrm{NaVO}_{2}$ is very reducing and should be stored under an oxygen-free atmosphere. Despite the low working potential $(1.5-2.5 \mathrm{~V} v$ s. Na $/ \mathrm{Na}), \mathrm{P}^{\prime} 3-\mathrm{Na}_{0.6} \mathrm{VO}_{2}$ shows cathodic characteristics, whereby reversible charge storage occurs via electrochemical reactions by charging and discharging to form $\mathrm{Na}_{0.5} \mathrm{VO}_{2}$ and $\mathrm{NaVO}_{2}$, respectively. When the upper voltage limit is increased, the reversibility of the material decreases drastically. It was explained that the reduced reversibility is mainly due to the migration of vanadium ions into the sodium intercalation sites, which was similar to that observed in $\mathrm{Na}_{x} \mathrm{TiO}_{2}{ }^{85,86} \mathrm{Na}_{x} \mathrm{VO}_{2}$ compounds where $x=1.0$ and 0.7 , corresponding to $\mathrm{O} 3-\mathrm{NaVO}_{2}$ and $\mathrm{P} 2-\mathrm{Na}_{0.7} \mathrm{VO}_{2}$, were also studied. They were able to accommodate up to $0.5 \mathrm{Na}$ per formula unit, corresponding to a capacity of approximately 120 $\mathrm{mA} \mathrm{h} \mathrm{g}^{-1}$ when cycled within a voltage window between 1.2 and $2.5 \mathrm{~V}$ vs. $\mathrm{Na}^{+} / \mathrm{Na}$. In situ XRD showed that the Na storage sites were preserved during sodiation/desodiation. ${ }^{87}$ In situ XRD was performed on the $\mathrm{P} 2-\mathrm{Na}_{x} \mathrm{VO}_{2}$ to obtain a room temperature phase diagram of the material. Four main single domains were observed, with the structure demonstrating a unique sodium/ vacancy ordering between the $\mathrm{VO}_{2}$ slabs within the sodiation range of $0.5<x<0.9$. The structure of $\mathrm{P} 2-\mathrm{Na}_{1 / 2} \mathrm{VO}_{2}$ showed pseudo-trimers with very short $\mathrm{V}-\mathrm{V}$ distances, leading to the possibility of the overlapping of $t_{2 \mathrm{~g}}$ orbitals through the common edge of the $\mathrm{VO}_{6}$ octehedra and resulting in unusual magnetic properties. However, the pseudo-trimers disappear above $322 \mathrm{~K}$ with a first order-structural transition, resulting in a twofold increase in electrical conductivity. ${ }^{88}$

$\mathrm{NaV}_{3} \mathrm{O}_{8}$ is one other oxide that has been widely studied as a potential LIB and NIB cathode material. ${ }^{89-91} \mathrm{NaV}_{3} \mathrm{O}_{8} \cdot x \mathrm{H}_{2} \mathrm{O}$ nanowires recorded an initial specific discharge capacity of $169.6 \mathrm{~mA} \mathrm{~h} \mathrm{~g}{ }^{-1}$, with a capacity retention of $91.1 \%$ after 50 cycles. ${ }^{90} \mathrm{NaV}_{6} \mathrm{O}_{15}\left(\mathrm{Na}_{0.33} \mathrm{~V}_{2} \mathrm{O}_{5}\right)$ also showed promising performance as a cathode material in NIBs. Liu et al. reported the electrochemical performance of $\mathrm{NaV}_{6} \mathrm{O}_{15}$ nanorods synthesized via a hydrothermal method. The nanorods were able to deliver a capacity of $142 \mathrm{~mA} \mathrm{~h} \mathrm{~g}^{-1}$ at a current density of $20 \mathrm{~mA} \mathrm{~g}^{-1}$.
However, the cycling performance at the same rate showed almost a $45 \%$ capacity decay after 30 cycles. ${ }^{92} \mathrm{NaV}_{6} \mathrm{O}_{15}$ nanoflakes synthesized by $\mathrm{He}$ et al. showed a promising performance by exhibiting an initial capacity of $147.7 \mathrm{~mA} \mathrm{~h} \mathrm{~g}^{-1}$ at $15 \mathrm{~mA} \mathrm{~g}^{-1}$, with a capacity retention of $92.2 \%$ after 30 cycles. $^{93}$

\subsection{Polyanions and pyrophosphates}

Following the successful introduction of $\mathrm{LiFePO}_{4}$ as a cathode material by Goodenough et al., several other chemical groups have also been explored in LIBs. The main reason for the success in $\mathrm{LiFePO}_{4}$ is largely attributed to the strong inductive effect coming from the $\mathrm{PO}_{4}{ }^{3-}$ anion, resulting in a high operating voltage..$^{94-96}$ Hence, the ability for the operating voltage to be tailored in polyanion compounds has led to much interest in its sodium counterpart in recent years. The crystal structures of several Na-based polyanions are shown in Fig. 10. The thermodynamically stable form of $\mathrm{NaFePO}_{4}$ (Fig. 10b) exists as the maricite structure, but this is, however, electrochemically inactive due to the lack of a $\mathrm{Na}$ diffusion channel compared to the olivine counterpart. ${ }^{97}$ Metastable olivine $\mathrm{NaFePO}_{4}$ has been reported to have been obtained through a delithiation of $\mathrm{LiFePO}_{4}$ into heterosite structured $\mathrm{FePO}_{4}$, before electrochemical sodiation to yield $\mathrm{NaFePO}_{4} \cdot{ }^{\mathbf{9 8}}$ The reversible intercalation for olivine $\mathrm{NaFePO}_{4}$ differs from that of its olivine $\mathrm{LiFePO}_{4}$ counterpart. During the charging process, two plateaus are observed instead of one, compared to the discharge process, indicating that the sodiation process might go through different electrochemical pathways (Fig. 11a). An intermediate phase of $\mathrm{Na}_{0.7} \mathrm{FePO}_{4}$ was observed through XRD analysis. The formation of $\mathrm{Na}_{0.7} \mathrm{FePO}_{4}$ as an intermediate helps cushion the large stress induced during the ion insertion/extraction. The difference in mechanism is attributed to the difference in volumetric mismatch between $\mathrm{NaFePO}_{4}$ and $\mathrm{Na}_{0.7} \mathrm{FePO}_{4}$ (3.62\% volume mismatch), compared to $\mathrm{Na}_{0.7} \mathrm{FePO}_{4}$ and $\mathrm{FePO}_{4} \quad(13.48 \%$ volume mismatch). Hence, during charging, $\mathrm{FePO}_{4}$ will not start
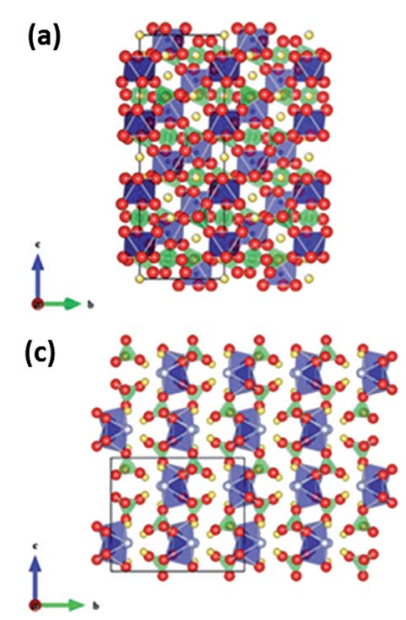

(b)

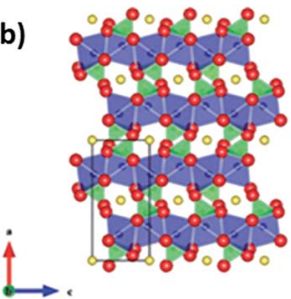

(d)

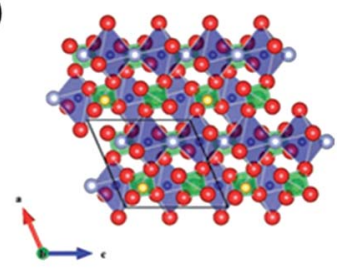

Fig. 10 Crystal structure of several polyanionic compounds (Yellow: $\mathrm{Na}$, Blue: V/Fe, Red: O, Grey: F), (a) NASICON Na $\mathrm{V}_{2}\left(\mathrm{PO}_{4}\right)_{3}$, (b) olivine $\mathrm{NaFePO}_{4}$, (c) $\mathrm{Na}_{2} \mathrm{FePO}_{4} \mathrm{~F}$, (d) $\mathrm{Na}_{2} \mathrm{FeSO}_{4} \mathrm{~F}$ (ref. 13). Copyright 2012 Wiley-VCH Verlag GmbH \& Co. KGaA, Weinheim. 

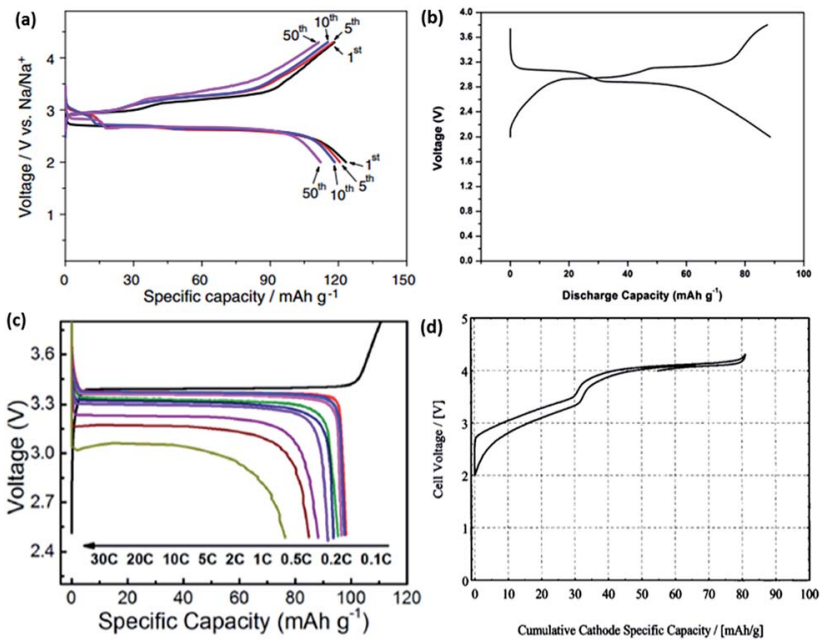

Fig. 11 (a) Cycling of an electrochemical $\mathrm{Li}-\mathrm{Na}$ exchange prepared $\mathrm{NaFePO}_{4}$ at a rate of $\mathrm{C} / 20 .{ }^{100}$ (b) Galvanostatic charge discharge curve of carbon-coated hollow $\mathrm{Na}_{2} \mathrm{FePO}_{4} \mathrm{~F}$ spheres tested at $0.1 \mathrm{C} .{ }^{103}$ (c) Initial charge/discharge curves of $\mathrm{Na}_{3} \mathrm{~V}_{2}\left(\mathrm{PO}_{4}\right)_{3}$ tested between 2.5 and $3.8 \mathrm{~V}$ at various $\mathrm{C}$-rates. ${ }^{107}$ (d) Electrochemical profile of a Na-based full cell, comprising hard carbon $/ \mathrm{NaVPO}_{4} \mathrm{~F}$, with a reversible capacity of $80 \mathrm{~mA} \mathrm{~h} \mathrm{~g}^{-1}$ when cycled between 2.0 and $4.3 \mathrm{~V} .^{104}$ (a) Reprinted with permission from ref. 100. Copyright 2012 Elsevier (b) reprinted with permission from ref. 103. Copyright 2013 Elsevier (c) reprinted with permission from ref. 107. Copyright 2014 Elsevier (d) reprinted with permission from ref. 104. Copyright 2003 The Electrochemical Society.

to form until all the $\mathrm{NaFePO}_{4}$ have been converted into $\mathrm{Na}_{0.7^{-}}$ $\mathrm{FePO}_{4}$, thus this is a two-step reaction. However, during discharge, the lattice mismatch between $\mathrm{FePO} 4$ and $\mathrm{Na}_{0.7} \mathrm{FePO}_{4}$ is already large to begin with, hence the reaction from $\mathrm{FePO}_{4}$ to $\mathrm{Na}_{0.7} \mathrm{FePO}_{4}$ and $\mathrm{Na}_{0.7} \mathrm{FePO}_{4}$ to $\mathrm{NaFePO}_{4}$ can occur concurrently. ${ }^{99} \mathrm{Oh}$ et al. then tested such a $\mathrm{Li}-\mathrm{Na}$ electrochemical exchanged $\mathrm{NaFePO}_{4}$, which exhibited a two-step discharge plateau, resulting in an initial capacity of $125 \mathrm{~mA} \mathrm{~h} \mathrm{~g}^{-1}$. Cycling of the $\mathrm{Na} / \mathrm{NaFePO}_{4}$ cell showed an excellent capacity retention, with $\sim 110 \mathrm{~mA} \mathrm{~h} \mathrm{~g}^{-1}$ being retained after 50 cycles. ${ }^{\mathbf{1 0 0}}$

Fluorophosphates have also been studied in both LIBs and NIBs. Iron-based fluorophosphates were first reported by Ellis et al. for LIB applications in $2007 .{ }^{101}$ Recham et al. compared the performance of different Na-based fluorophosphates compounds synthesized using ionic liquids as templates at low temperatures. In this method, both the morphology and narrow particle size could be accurately controlled. Despite having the same synthesis method for both $\mathrm{Na}_{2} \mathrm{FePO}_{4} \mathrm{~F}$ and $\mathrm{Na}_{2} \mathrm{MnPO}_{4} \mathrm{~F}$, their structures differ largely from one another. $\mathrm{Na}_{2} \mathrm{FePO}_{4} \mathrm{~F}$ exists in a layered structure where $\mathrm{Na}^{+}$occupies the space between the layers of the $\mathrm{FeO}_{4} \mathrm{~F}_{2}$ octahedra and $\mathrm{PO}_{4}$ tetrahedra (Fig. 10c). Comparatively, $\mathrm{Na}_{2} \mathrm{MnPO}_{4} \mathrm{~F}$ forms a tunnel structure with $\mathrm{Mn}_{2} \mathrm{~F}_{2} \mathrm{O}_{8}$ chains linked by tetrahedra $\mathrm{PO}_{4}$. While the nanosized $\mathrm{Na}_{2} \mathrm{FePO}_{4} \mathrm{~F}$ showed a considerable reversible intercalation of $0.8 \mathrm{~mol}$ of $\mathrm{Na}$ when cycled between 1.5 and $4.3 \mathrm{~V} v s$. $\mathrm{Na}^{+} / \mathrm{Na}, \mathrm{Na}_{2} \mathrm{MnPO}_{4} \mathrm{~F}$ showed no reversible capacity, even when cycled within the same voltage range. ${ }^{\mathbf{1 0 2}}$ Langrock et al. also synthesized carbon-coated hollow $\mathrm{Na}_{2} \mathrm{FePO}_{4} \mathrm{~F}$ spheres via a spray pyrolysis. The electrochemical process exhibited two plateau profiles at $3.1 \mathrm{~V}$ and $2.9 \mathrm{~V}$, and recorded a discharge capacity of $89 \mathrm{~mA} \mathrm{~h} \mathrm{~g}^{-1}$ at a current density of $C / 10$ (Fig. 11b). In addition, the hollow $\mathrm{Na}_{2} \mathrm{FePO}_{4} \mathrm{~F}$ spheres demonstrated excellent cyclability, with a capacity retention of $80 \%\left(60 \mathrm{~mA} \mathrm{~h} \mathrm{~g}{ }^{-1}\right)$ after 750 cycles. The excellent performance could be attributed to the design of the material that allows for rapid ion diffusion, as well as good structure integrity during cycling. ${ }^{103} \mathrm{NaVPO}_{4} \mathrm{~F}$ prepared by a solid-state synthesis was first introduced by Barker et al. in 2003. A reversible alkali intercalation results in the formation of $\mathrm{VPO}_{4} \mathrm{~F}$ derived with the $\mathrm{V}^{3+} / \mathrm{V}^{4+}$ redox couple, as shown in Fig. 11d. A full cell was assembled using hard carbon as the anode and $\mathrm{NaVPO}_{4} \mathrm{~F}$ as the cathode, which delivered a reversible capacity of $80 \mathrm{~mA} \mathrm{~h} \mathrm{~g}^{-1}$, with an average discharge potential of $3.7 \mathrm{~V} \cdot{ }^{\mathbf{1 0 4}}$ Park et al. recently reported novel $\mathrm{Na}_{1.5} \mathrm{VPO}_{4.8} \mathrm{~F}_{0.7}$ with a high redox potential $\left(3.8 \mathrm{~V} v s . \mathrm{Na}^{+} / \mathrm{Na}\right)$ and a high theoretical energy density $\left(600 \mathrm{~W} \mathrm{~h} \mathrm{~kg}^{-1}\right)$, as a result of tailoring the polyanionic group. ${ }^{105}$ In addition, ex situ XRD was employed to understand the volume change during the phase transformations, of which a value of $2.9 \%$ was obtained, which is close to the first principal calculation of $3.1 \%$. The extremely small volume change during the phase transformations results in the material being extremely stable during the charge-discharge processes. ${ }^{106}$

NASICON $\left(\mathrm{Na}^{+}\right.$superionic conductor)-type materials have been extensively studied as solid electrolytes in $\mathrm{Na}-\mathrm{S}$ batteries. Delmas et al. first reported reversible $\mathrm{Na}^{+}$intercalation with a NASICON-type $\mathrm{NaTi}_{2}\left(\mathrm{PO}_{4}\right)_{3}$ in $1987 .{ }^{108}$ Since then, the insertion of host materials with the general formula $\mathrm{A}_{x} \mathrm{M}_{2}\left(\mathrm{XO}_{4}\right)_{3}$ (where $\mathrm{A}=\mathrm{Li}, \mathrm{Na} ; \mathrm{M}=\mathrm{V}, \mathrm{Fe}, \mathrm{Mn}, \mathrm{Co}$, and $\mathrm{X}=\mathrm{P}, \mathrm{S}, \mathrm{W}$ ) have been extensively studied for both LIB and NIB applications. $\mathrm{Na}_{3} \mathrm{~V}_{2}\left(\mathrm{PO}_{4}\right)_{3}$ has been investigated as a prospective cathodic material for NIBs. It comprises a $3 \mathrm{D}$ framework of $\mathrm{PO}_{4}$ tetrahedra and $\mathrm{VO}_{6}$ octahedra, as shown in Fig. 10a. However, the electrochemical performance of pure $\mathrm{Na}_{3} \mathrm{~V}_{2}\left(\mathrm{PO}_{4}\right)_{3}$ is relatively poor because of the poor intrinsic electronic conductivity. Jian et al. were first to implement a thin conductive carbon coating $(6 \mathrm{~nm})$ on $\mathrm{Na}_{3} \mathrm{~V}_{2}\left(\mathrm{PO}_{4}\right)_{3}$ with ball-milling and by subsequent Arthermal treatments. The $\mathrm{CV}$ profile indicated two significant electrochemical reactions at $3.4 \mathrm{~V}$ and $1.63 \mathrm{~V} v s$. $\mathrm{Na}^{+} / \mathrm{Na}$. The composite exhibited reversible capacities of $90.9 \mathrm{~mA} \mathrm{~h} \mathrm{~g}^{-1}$ after 10 cycles when cycled between 2.7 and $3.8 \mathrm{~V}$; while, $60 \mathrm{~mA} \mathrm{~h} \mathrm{~g}{ }^{-1}$ was recorded after 50 cycles within a voltage window between 1.0 and $3.0 \mathrm{~V} .{ }^{109} \mathrm{Na}_{3} \mathrm{~V}_{2}\left(\mathrm{PO}_{4}\right)_{3} / \mathrm{C}$ composite prepared from a solid-state glucose-assisted reduction method displayed a voltage plateau at $3.4 \mathrm{~V}$ vs. $\mathrm{Na}^{+} / \mathrm{Na}$, with a recorded initial capacity of $98 \mathrm{~mA} \mathrm{~h} \mathrm{~g}^{-1}$ when cycled between 2.5 and $3.8 \mathrm{~V}$ (Fig. 11c). ${ }^{107}$ Nonetheless, the low C.E. remains a problem with the $\mathrm{Na}_{3} \mathrm{~V}_{2}\left(\mathrm{PO}_{4}\right)_{3} / \mathrm{C}$ composite in $\mathrm{NaClO}_{4} / \mathrm{PC}$ electrolyte. Several other electrolytes have been explored as alternatives, and it was found that the sodium bis(fluorosulfonyl) imides (NaFSI) salt demonstrated the best performance. In contrast, it was also found that $\mathrm{Na}_{3} \mathrm{~V}_{2}\left(\mathrm{PO}_{4}\right)_{3} / \mathrm{C}$ with a lower carbon content performs much better in NaFSI electrolyte. NaFSI/PC demonstrated the best performance with an initial coulombic efficiency of $98.7 \%$ and $99.8 \%$ in subsequent cycles. This is much higher compared to $\mathrm{NaClO}_{4} / \mathrm{PC}$ (82\% initial/91\% subsequent), $\mathrm{NaBF}_{4} / \mathrm{PC}(94.4 \%$ 
initial/98\% subsequent), $\mathrm{NaPF}_{6} / \mathrm{EC}+\mathrm{DEC}$ (96.3\% initial/99\% subsequent) and NaFSI/EC + DEC (98\% initial/98.2\% subsequent) electrolytes. ${ }^{\mathbf{1 1 0}}$ Characterization techniques, including Annular bright field (ABF), scanning transmission electron microscopy (STEM) and solid-state NMR, were employed to elucidate the charge/discharge mechanism of $\mathrm{Na}_{3} \mathrm{~V}_{2}\left(\mathrm{PO}_{4}\right)_{3}$. It was observed that two coordination environments (6b, M1 and 18e, M2) exist in $\mathrm{Na}_{3} \mathrm{~V}_{2}\left(\mathrm{PO}_{4}\right)_{3}$, while only a single Na site (6b, M1) exists in $\mathrm{NaV}_{2}\left(\mathrm{PO}_{4}\right)_{3}$, which correlates to a direct $\mathrm{M} 2-\mathrm{M} 2$ ion conduction pathway present during the charge process; whereby up to two $\mathrm{Na}^{+}$can be extracted from the M2 site, while the $\mathrm{Na}$ ions in the $\mathrm{M} 1$ site remain intact in $\mathrm{Na}_{3} \mathrm{~V}_{2}\left(\mathrm{PO}_{4}\right)_{3}{ }^{111}$

A mixed polyanionic and pyrophosphate cathode material was studied by Kang's group via both a first principle calculation and experimentally. $\mathrm{Na}_{4} \mathrm{Fe}_{3}\left(\mathrm{PO}_{4}\right)_{2}\left(\mathrm{P}_{2} \mathrm{O}_{7}\right)$ was synthesized through a conventional solid-state method, and delivered an energy density of $380 \mathrm{~W} \mathrm{~h} \mathrm{~kg}{ }^{-1}$. Mössbauer spectroscopy (Fig. 12a) revealed the deinsertion of up to three Na ions from $\mathrm{Na}_{4} \mathrm{Fe}_{3}\left(\mathrm{PO}_{4}\right)_{2}\left(\mathrm{P}_{2} \mathrm{O}_{7}\right)$ to $\mathrm{NaFe}_{3}\left(\mathrm{PO}_{4}\right)_{2}\left(\mathrm{P}_{2} \mathrm{O}_{7}\right)$ during charging, with the $\mathrm{Fe}^{2+} / \mathrm{Fe}^{3+}$ redox couple being active (Fig. 12b). ${ }^{29,112}$ Further analyses via in situ and ex situ XRD, neutron diffraction and $\mathrm{X}$-ray absorption spectroscopy demonstrated that the electrochemical reaction in $\mathrm{Na}_{4} \mathrm{Fe}_{3}\left(\mathrm{PO}_{4}\right)_{2}\left(\mathrm{P}_{2} \mathrm{O}_{7}\right)$ results in only a small volume change of $4 \%$. The PITT results showed a single plateau during the discharge process (Fig. 12c), indicating a single phase topotactic reaction. Additionally the strong framework, comprising of polyanion and pyrophosphate anions, makes the structure both physically and thermally stable. ${ }^{112}$

Recently, sodium-based pyrophosphates $\left(\mathrm{Na}_{2} \mathrm{MeP}_{2} \mathrm{O}_{7}\right.$ where $\mathrm{Me}=\mathrm{Fe}, \mathrm{Mn}$ or $\mathrm{Co}$ ) have been reported to be a group of
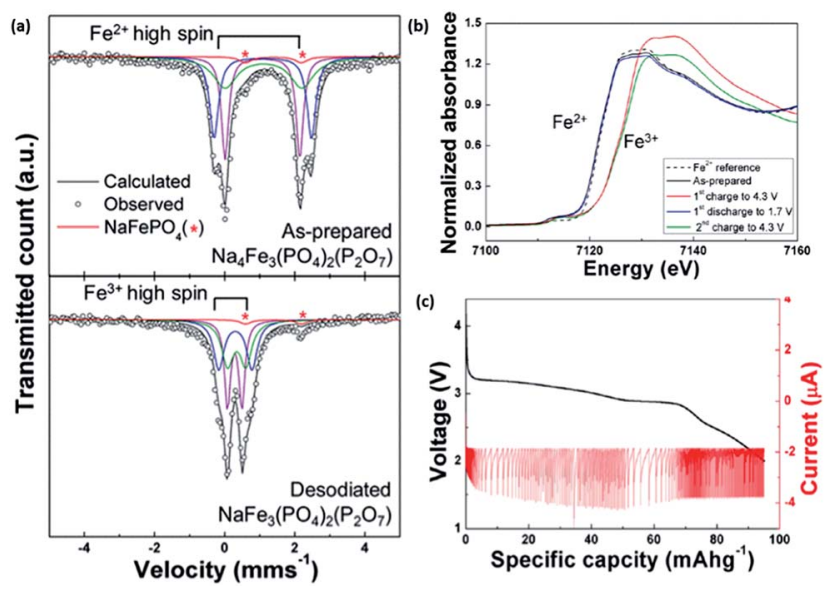

Fig. 12 (a) Mössbauer spectra of $\mathrm{Na}_{x} \mathrm{Fe}_{3}\left(\mathrm{PO}_{4}\right)_{2}\left(\mathrm{P}_{2} \mathrm{O}_{7}\right)(x=1,4)$. The observed and calculated patterns are present as black circles and lines, respectively, in the Mössbauer spectrum. The blue, green and purple lines represent the three distinct iron sites. The red line shows the $\mathrm{Fe}^{2+}$ component in the $\mathrm{NaFePO}_{4}$ impurity; this peak does not change during the desodiation process ${ }^{29}$ (b) XANES spectra of the initial and end states of $\mathrm{Na}_{x} \mathrm{Fe}_{3}\left(\mathrm{PO}_{4}\right)_{2}\left(\mathrm{P}_{2} \mathrm{O}_{7}\right)(x=1$, 4). (c) PITT measurement of $\mathrm{Na}_{4} \mathrm{Fe}_{3}\left(\mathrm{PO}_{4}\right)_{2}\left(\mathrm{P}_{2} \mathrm{O}_{7}\right)$ during discharge at a cut-off current corresponding to the $C / 50$ rate $^{112}$ (a) reprinted with permission from ref. 29. Copyright 2012 American Chemical Society (b and c) reprinted with permission from ref. 112. Copyright 2013 American Chemical Society. prospective cathodic materials for NIBs. ${ }^{\mathbf{1 1 3 - 1 1 6}}$ Barpanda et al. was the first to study $\mathrm{Na}_{2} \mathrm{FeP}_{2} \mathrm{O}_{7}$ pyrophosphate synthesized via a simple solid-state synthesis method. Electrochemical cycling at a rate of $C / 20$ exhibited a reversible capacity of $82 \mathrm{~mA} \mathrm{~h} \mathrm{~g}^{-1}$ within a potential window of 2.0-4.0 V vs. $\mathrm{Na}^{+} / \mathrm{Na}$. Mössbauer spectroscopy of $\mathrm{Na}_{2} \mathrm{FeP}_{2} \mathrm{O}_{7}$ indicated that $\mathrm{Fe}^{2+}$ ions reside in two distinct sites within the crystal structure, and which oxidize to $\mathrm{Fe}^{3+}$ during charging. ${ }^{117}$ A novel polymorph, $\beta-\mathrm{Na}_{2} \mathrm{MnP}_{2} \mathrm{O}_{7}$, was synthesized first by a solid-state method and followed by carbon coating. The assembled half-cells exhibited a reversible discharge capacity of about $80 \mathrm{~mA} \mathrm{~h} \mathrm{~g}{ }^{-1}$ at a rate of $C / 20$. However, the rate capability of $\mathrm{Na}_{2} \mathrm{MnP}_{2} \mathrm{O}_{7}$ has yet to be determined. ${ }^{118}$ Likewise, $\mathrm{Na}_{2} \mathrm{CoP}_{2} \mathrm{O}_{7}$ was also synthesized via a solidstate synthesis and carbon coating by Barpanda et al. Electrochemical cycling yielded a similar capacity of $80 \mathrm{~mA} \mathrm{~h} \mathrm{~g}$ within a voltage window of $3 \mathrm{~V}^{119}$ Despite the novelty of such sodium-based pyrophosphate materials, the low capacity, cyclability and stability remain as major obstacles to be overcome.

\subsection{Organic materials}

Novel multifunctional organic compounds have also been studied as prospective electrode materials in NIBs. Sakaushi et al. successfully demonstrated a bipolar porous organic electrode (BPOE) comprising benzene rings and triazine rings in a two-dimensional (2D) structure. The porous organic electrode was able to deliver energy and a power density of up to $500 \mathrm{~W} \mathrm{~h}$ $\mathrm{kg}^{-1}$ and $10 \mathrm{~kW} \mathrm{~kg}{ }^{-1}$, respectively. Such performance is comparable to that of the oxides and polyanion cathode materials. ${ }^{55,120}$ In addition, BPOE is a unique bipolar material with a p-dopable region $\left(\left[\mathrm{C}_{3} \mathrm{~N}_{3}{ }^{x+}\left(\mathrm{ClO}_{4}{ }^{-}\right)_{x}\right]+x \mathrm{Na}^{+}+x \mathrm{e}^{-} \rightarrow\left(\mathrm{C}_{3} \mathrm{~N}_{3}\right)+\right.$ $\left.x \mathrm{Na}^{+} \mathrm{ClO}_{4}{ }^{-}\right)$at above OCV $(2.8 \mathrm{~V})$ and an n-dopable $\left(\left(\mathrm{C}_{3} \mathrm{~N}_{3}\right)+\right.$ $\left.y \mathrm{Na}^{+}+y \mathrm{e}^{-} \rightarrow\left[\mathrm{C}_{3} \mathrm{~N}_{3}{ }^{y-}\left(\mathrm{Na}^{+}\right)_{y}\right]\right)$ region at below the OCV, thus giving rise to a wide potential and energy density (Fig. 13). Moreover, cyclability of the half-cell remained at $80 \%$ for over 7000 cycles. ${ }^{121}$ An all-organic symmetric NIB was demonstrated with the use of a novel tetrasodium salt of 2,5-dihydroxyterephthalic acid $\left(\mathrm{Na}_{4} \mathrm{DHTPA}\left(\mathrm{Na}_{4} \mathrm{C}_{8} \mathrm{H}_{2} \mathrm{O}_{6}\right)\right)$ as both a cathode and

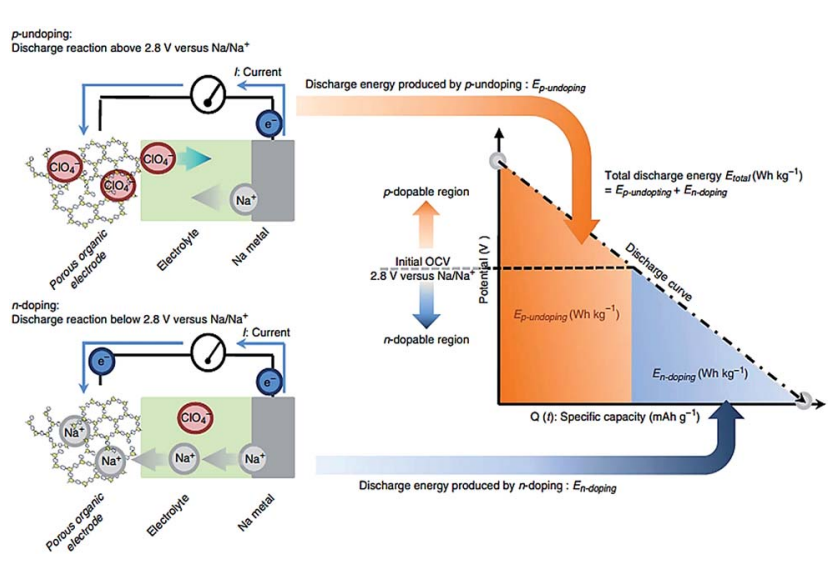

Fig. 13 Energy storage mechanism ( $p$-undoping and $n$-doping) of organic BPOE in a discharge process ${ }^{121}$ reprinted with permission from Macmillan Publishers Ltd.: (Nat. Commun.) (ref. 121), Copyright 2013. 
(a)
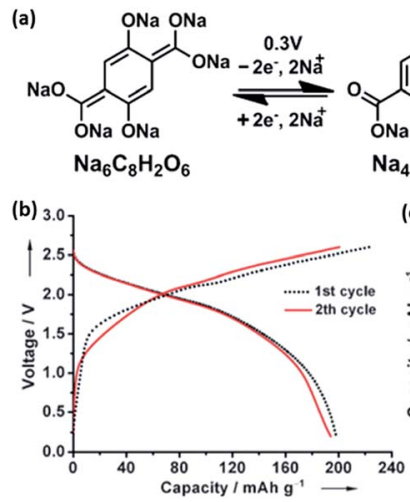
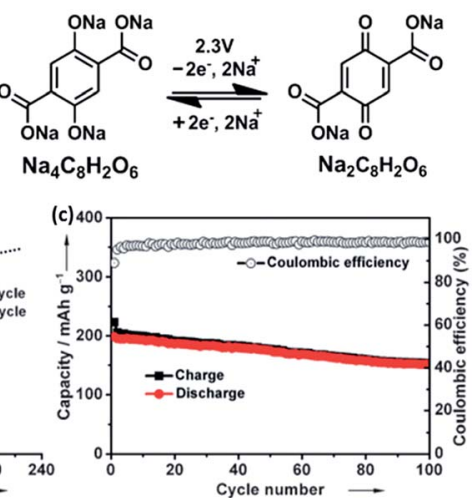

Fig. 14 (a) Schematic of redox reactions between $\mathrm{Na}_{6} \mathrm{C}_{8} \mathrm{H}_{2} \mathrm{O}_{6} /$ $\mathrm{Na}_{4} \mathrm{C}_{8} \mathrm{H}_{2} \mathrm{O}_{6}$ and $\mathrm{Na}_{4} \mathrm{C}_{8} \mathrm{H}_{2} \mathrm{O}_{6} / \mathrm{Na}_{2} \mathrm{C}_{8} \mathrm{H}_{2} \mathrm{O}_{6}$ (b) galvanostatic charge/ discharge profiles of full cells assembled with $\mathrm{Na}_{4} \mathrm{C}_{8} \mathrm{H}_{2} \mathrm{O}_{6}$ as both the cathode and anode. (c) Cycling and coulombic efficiency under a current density of $19 \mathrm{~mA} \mathrm{~g}^{-1}$ (ref. 122). Copyright 2014 Wiley-VCH Verlag GmbH \& Co. KGaA, Weinheim.

anode material. Charge storage for the cathode occurs via a 2electron redox process (Fig. 14a) in the enolate and quinonoid carbonyl group. $\mathrm{Na}_{4} \mathrm{DHTPA}$ was able to provide a capacity of 180 $\mathrm{mA} \mathrm{h} \mathrm{g}^{-1}$ when cycled between a voltage range of 1.6 and $2.8 \mathrm{~V}$ vs. $\mathrm{Na}^{+} / \mathrm{Na}$ in $1 \mathrm{M} \mathrm{NaClO}_{4}$ (EC : DMC $1: 1$ ) electrolyte. A full cell was assembled with $\mathrm{Na}_{4}$ DHTPA as both the cathode and anode. The galvanostatic charge-discharge curves are shown in Fig. 14b. The full cell was able to deliver an estimated energy density of $65 \mathrm{~W} \mathrm{~h} \mathrm{~kg}{ }^{-1}$ (taking into consideration the cell components), with an average discharge voltage of $1.8 \mathrm{~V}$. The cyclability over 100 cycles showed a capacity retention of $76 \%$ at a $0.1 \mathrm{C}$ rate, and the coulombic efficiency remained stable at 99\% after the initial cycles (Fig. 14c). ${ }^{\mathbf{1 2 2}}$

Several dianhydride-based polyimides (PI) were also investigated by Wang et al. as organic cathodes for NIBs. A simple one-pot synthesis comprising polycondensation followed by imidization was employed for various dianhydride (pyrometallic dianhydride (PMDA), 1,4,5,8-naphthalenetetracarboxylic dianhydrides (NTCDA), perylene 3,4,9,10-tetracarboxylic dianhydride (PTCDA)) and diamines (with varying alkyl chains from $\mathrm{C} 2$ to $\mathrm{C} 4$ ). A correlation could be drawn from tuning the individual dianhydride and diamine groups. When the aromatic group varied from PMDA, NTCDA and PTCDA, the average discharge voltage varied from 1.73 to 1.89 and $1.94 \mathrm{~V}$, respectively. This is attributed to the difference in the lowest unoccupied molecular orbital (LUMO) energy level in the presence of different electron withdrawing aromatic groups. Likewise, heavier alkyl chain groups in the polyimide resulted in a lower overall gravimetric energy density. Amongst the different permutations, PTCDA-PI2 had the most stable performance, with exceptional cycling stability and a capacity retention of $87.5 \%$, even after 5000 cycles, owing to its unique polymer structure composed of interconnecting alkyl chains and PTCDA that prohibits unwanted dissolution into the electrolyte. Furthermore, the maximum energy and power density achievable in PTCDA-PI2 were $285 \mathrm{~W} \mathrm{~h} \mathrm{~kg}^{-1}$ and $20.99 \mathrm{~kW} \mathrm{~kg}^{-1}$, respectively. ${ }^{\mathbf{1 2 2}}$

\subsection{Prussian blue analogues}

Several Prussian blue analogues have been studied for application as a cathode material in NIBs. ${ }^{\text {123-128 }}$ Prussian blue comprises an open framework capable of accommodating the insertion of alkali ions.

Its analogues $\left(\mathrm{Na}_{x} \mathrm{MFe}(\mathrm{CN})_{6}\right.$, where $\mathrm{M}=\mathrm{Fe}, \mathrm{Co}, \mathrm{Ni}$ and other transition metals) have been widely explored as potential $\mathrm{Na}$ storage cathode materials, owing to their high capacity following two electron redox reactions. ${ }^{\mathbf{1 2 6}}$ A schematic of their crystal structure is shown in Fig. 15a. The crystal structure of such Prussian blue analogues follows the general formula of $\mathrm{A}_{x} \mathrm{M}\left[\mathrm{D}(\mathrm{CN})_{6}\right] \cdot n \mathrm{H}_{2} \mathrm{O}$, where $\mathrm{A}=$ alkali metal ion, $\mathrm{M}=\mathrm{N}$-coordinated transition metal cation, and $\mathrm{D}=\mathrm{C}$-coordinated transition metal cation. While the activation energy for alkali insertion/ desinsertion in oxoperovskites is considered to be too high, replacement of the $\mathrm{O}^{2-}$ anions with $\mathrm{CN}^{-}$ions helps weaken the bonding with $\mathrm{Na}^{+}$, thus reducing the overall activation energy. ${ }^{127}$ The number of $\mathrm{Na}^{+}$intercalated could vary from 0 to 2 , where the overall charge neutrality would be maintained by the reduction of transition metals. ${ }^{\mathbf{1 2 4}}$

Goodenough et al. were first to demonstrate the use of hexacyanides in organic system NIBs. Various $\mathrm{KMFe}(\mathrm{CN})_{6}$ (where $\mathrm{M}$ $=\mathrm{Mn}, \mathrm{Fe}, \mathrm{Co}$, Ni and Zn) compounds were synthesized, with their electrochemical performance studied. Among the different compositions, $\mathrm{KFeFe}(\mathrm{CN})_{6}$ had the highest capacity of $70 \mathrm{~mA} \mathrm{~h} \mathrm{~g}{ }^{-1}$ with a redox potential of approximately $3.7 \mathrm{~V} v s$. $\mathrm{Na}^{+} / \mathrm{Na}$. This was attributed to the enhancement of the crystal field splitting, which stabilizes the low-spin state $\mathrm{Fe}(\mathrm{III}): 3 \mathrm{~d}^{5}$ configuration to the octahedral site of the $\mathrm{C}$ atom, while the $\mathrm{Fe}(\mathrm{II}): 3 \mathrm{~d}^{6}$ configuration is coordinated to $\mathrm{N}$ atoms in its highspin state. ${ }^{129}$ Subsequently, rhombohedral $\mathrm{Na}_{1.72} \mathrm{MnFe}(\mathrm{CN})_{6}$ and cubic $\mathrm{Na}_{1.4} \mathrm{MnFe}(\mathrm{CN})_{6}$ were synthesized at room temperature. In both cases, $\mathrm{Mn}$ is coordinated by $\mathrm{N}$ and is in the high-

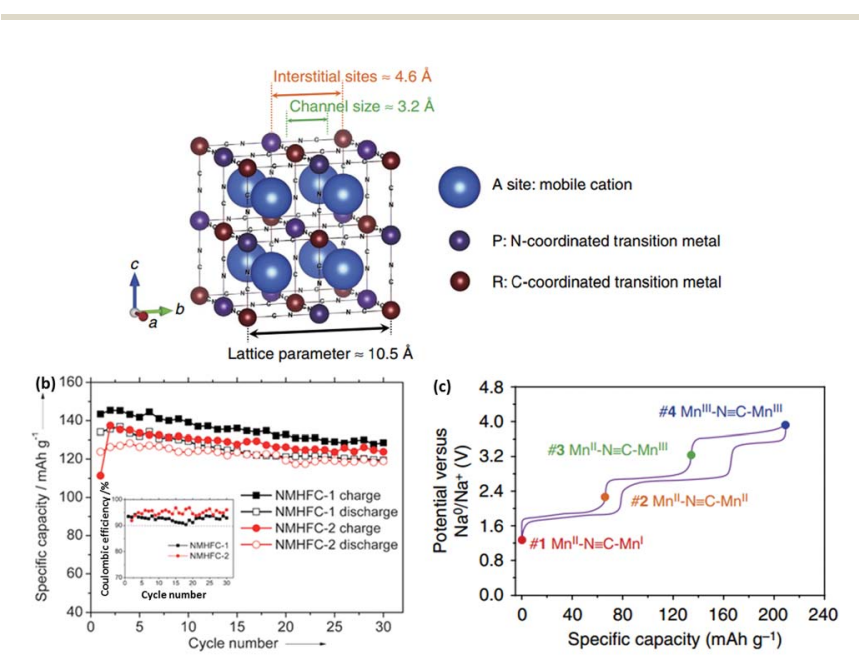

Fig. 15 (a) Schematic illustration of open framework cubic Prussian blue analogues ${ }^{126}$ (b) cycling performance and coulombic efficiency of $\mathrm{Na}_{1.72} \mathrm{MnFe}(\mathrm{CN})_{6}$ and $\mathrm{Na}_{1.40} \mathrm{MnFe}(\mathrm{CN})_{6}$ (ref. 127) (c) galvanostatic charge and discharge curves of sodium manganese hexacyanomanganate $\mathrm{a} / 5 .{ }^{126}$ ( $\mathrm{a}$ and $\mathrm{c}$ ) Reprinted with permission from Macmillan Publishers Ltd.: (Nat. Commun.) (ref. 126), Copyright 2014. (b) Copyright 2013 Wiley-VCH Verlag GmbH \& Co. KGaA, Weinheim. 
spin state, while Fe is coordinated by $\mathrm{C}$ and is in a low-spin state. The electrochemical profiles also showed no influence of structural differences on the reaction potentials. At $0.1 C$, a discharge capacity of $134 \mathrm{~mA} \mathrm{~h} \mathrm{~g}{ }^{-1}$ was obtained when cycled between 2.0 and $4.2 \mathrm{~V} v$ s. $\mathrm{Na}^{+} / \mathrm{Na}$. Excellent cyclability was also observed, with a capacity retention of about $90 \%$ after 30 cycles (Fig. 15b). ${ }^{127}$

Wu et al. studied single crystal $\mathrm{FeFe}(\mathrm{CN})_{6}$ nanoparticles capable of achieving up to $120 \mathrm{~mA} \mathrm{~h} \mathrm{~g}{ }^{-1}$, with an amazing capacity retention of $87 \%$, even after 500 cycles. ${ }^{123}$ A modified $\mathrm{NaZnFe}(\mathrm{CN})_{6}$ capable of accommodating up to two $\mathrm{Na}^{+}$ions was investigated for its cathodic properties. However, a reversible capacity of only 56.4 $\mathrm{mA} \mathrm{h} \mathrm{g}{ }^{-1}$ was obtained. Additionally, it was observed that the electrochemical performance varied largely with the choice of electrolyte, with $1 \mathrm{M} \mathrm{NaPF}_{6}$ in EC: DMC $(1: 1 \mathrm{v} / \mathrm{v})$ exhibiting a capacity retention of $94.6 \%$ compared to $85.2 \%$ in $1 \mathrm{M} \mathrm{NaClO}_{4}$ in PC. ${ }^{125}$ Nanocrystalline $\mathrm{NaFe}\left[\mathrm{Fe}(\mathrm{CN})_{6}\right]$ was synthesized from a simple but slow technique with a low water content. The electrochemical performance was much better compared to low crystalline $\mathrm{NaFe}\left[\mathrm{Fe}(\mathrm{CN})_{6}\right]$. Ex situ $\mathrm{XRD}$ was used to understand the structure evolution throughout the sodiation process. The two electron reaction was observed with structure changes from cubic $\mathrm{Fe}^{\mathrm{III}}\left[\mathrm{Fe}^{\mathrm{III}}(\mathrm{CN})_{6}\right]$ to cubic $\mathrm{NaFe}^{\mathrm{III}}\left[\mathrm{Fe}^{\mathrm{II}}(\mathrm{CN})_{6}\right]$, and subsequently to rhombohedral $\mathrm{Na}_{2} \mathrm{Fe}^{\mathrm{II}}\left[\mathrm{Fe}^{\mathrm{II}}(\mathrm{CN})_{6}\right] .^{128}$

Very recently, Cui et al. introduced sodium manganese hexacyanomanganate $\left(\mathrm{Na}_{2} \mathrm{Mn}^{\mathrm{II}}\left[\mathrm{Mn}^{\mathrm{II}}(\mathrm{CN})_{6}\right]\right.$, which was capable of delivering a capacity of up to $209 \mathrm{~mA} \mathrm{~h} \mathrm{~g}^{-1}$ (Fig. 15c). Additionally, the rate capability was excellent, with a discharge capacity of 157 $\mathrm{mA} \mathrm{h} \mathrm{g}^{-1}$ at $5 C$. Synchrotron XRD was carried out to elucidate the redox mechanism and how the high capacity was achievable. It was found that sodiation of the material causes a change in the crystal structure gradually from cubic to a distorted monoclinic structure, which eventually allows the accommodation of up to three sodium ions. It should be noted that the electrochemical measurements were carried out in a flooded three-electrode cell, with a $\mathrm{Ag} / \mathrm{AgCl}$ mesh pseudo-reference electrode coupled to a ferrocene $\left(\mathrm{Fc}^{+} / \mathrm{Fc}\right)$ redox couple. ${ }^{126}$

\subsection{Other potential cathode materials}

Phosphate-based polyanion cathode materials have been well investigated over the past years. As such, modification of the polyanion groups (e.g. replacing phosphate $\left(\mathrm{PO}_{4}{ }^{3-}\right)$ with sulphate $\left.\left(\mathrm{SO}_{4}{ }^{2-}\right)\right)$ results in a varying inductive influence within the framework. Compared to $\mathrm{NaFePO}_{4}\left(2.7 \mathrm{~V}\right.$ vs. $\left.\mathrm{Na}^{+} / \mathrm{Na}\right)$, the novel $\mathrm{Na}_{2} \mathrm{Fe}_{2}\left(\mathrm{SO}_{4}\right)_{3}$ had a much higher $\mathrm{Fe}^{2+} / \mathrm{Fe}^{3+}$ redox couple of $3.8 \mathrm{~V}$ vs. $\mathrm{Na}^{+} / \mathrm{Na}$. The electrochemical profile of $\mathrm{Na}_{2} \mathrm{Fe}_{2}\left(\mathrm{SO}_{4}\right)_{3}$ cycled between 2.0 and $4.5 \mathrm{~V}\left(v s . \mathrm{Na}^{+} / \mathrm{Na}\right)$ recorded a specific capacity of about $100 \mathrm{~mA} \mathrm{~h} \mathrm{~g}^{-1}$. Even at a high rate of $20 C$, a reversible capacity of approximately $50 \mathrm{~mA} \mathrm{~h} \mathrm{~g}{ }^{-1}$ has been recorded. As shown in Fig. 16, $\mathrm{Na}_{2} \mathrm{Fe}_{2}\left(\mathrm{SO}_{4}\right)_{3}$ records the highest working potential amongst Fe-based cathodes for NIBs. This in turn would result in a high energy density (theoretical value of $540 \mathrm{~W} \mathrm{~h} \mathrm{~kg}{ }^{-1}$ ), which would be a key factor for overcoming mileage problems in EVs. Moreover, the precursors, $\mathrm{Na}, \mathrm{Fe}$ and $S$ are among the most abundant materials on earth, which makes commercialization more feasible. ${ }^{\mathbf{1 3 0}}$

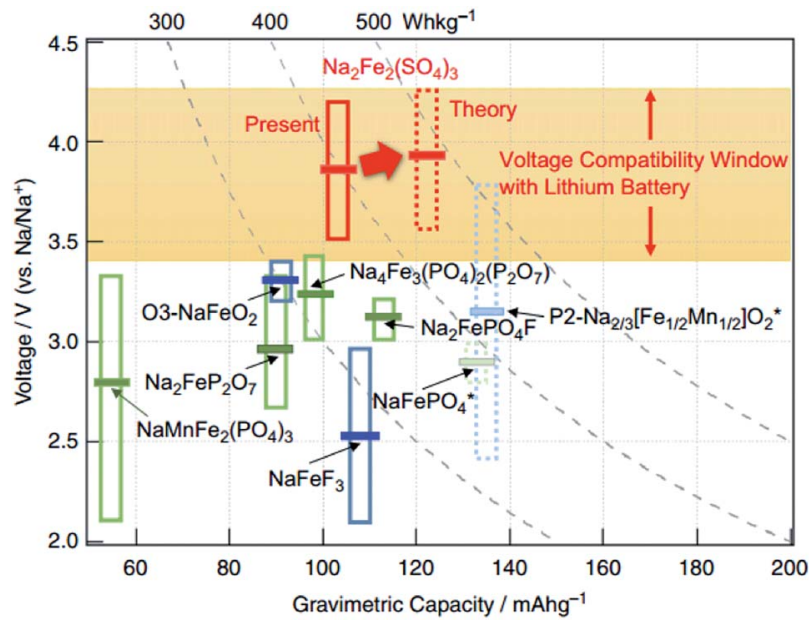

Fig. 16 An overall comparison of Fe-based cathode materials in NIBs. ${ }^{130}$ Reprinted with permission from Macmillan Publishers Ltd:: (Nat. Commun.) (ref. 130), Copyright 2014.

$\mathrm{TiS}_{2}$ was studied early on in the 1970 s and 80 s as an intercalation host for both LIBs and NIBs. Nagelberg and Worrell studied the thermodynamics of $\mathrm{TiS}_{2}$ via the intercalation of sodium ions into the layered structure. It was found that the lithium-intercalated $\mathrm{TiS}_{2}$ possesses a more negative standard free energy of intercalation compared to sodium-intercalated $\mathrm{TiS}_{2}$. Additionally, the compositional variation of the sodium chemical potential in $\mathrm{Na}_{x} \mathrm{TiS}_{2}$ exhibits two plateaus, which indicates the presence of twophase regions. ${ }^{131}$ Newman and Klemann studied the intercalation of $\mathrm{Na}$ ions into $\mathrm{TiS}_{2}$ in a dioxolane solution of sodium triethyl ( $\mathrm{N}$ pyrrolyl) borate at room temperature. Complete discharge at a current density of $2.5 \mathrm{~mA} \mathrm{~cm} \mathrm{~cm}^{-2}$ resulted in the formation of $\mathrm{Na}_{0.8} \mathrm{TiS}_{2}$. Two discharge plateaus could be observed during the formation of $\mathrm{Na}_{x} \mathrm{TiS}_{2}$, particularly at $\sim 1.9 \mathrm{~V}(0 \leq x \leq 0.4)$ and at $\sim 1.5 \mathrm{~V}(0.4 \leq x \leq 0.8)$, which is in agreement with Nagelberg's results. However, the cycling performance of the cathode was rather poor and the theoretical energy density was only $144 \mathrm{~W} \mathrm{~h}$ $\mathrm{kg}^{-1}$, compared to $480 \mathrm{~W} \mathrm{~h} \mathrm{~kg}^{-1}$ in $\mathrm{Li}^{-\mathrm{TiS}_{2}}$ systems. ${ }^{132}$ In the $1970-$ $80 \mathrm{~s}$, several reviews on electrode materials for SIB had already reported. Whittingham reviewed different types of intercalation cations in several transition metal dichalcogenides, ${ }^{\mathbf{1 3 3}}$ while Abraham summarized the electrochemical performance of transition metal dichalcogenides in rechargeable sodium systems. ${ }^{\mathbf{1 3 4}}$ Readers are advised to refer to the reviews for a more detailed overview.

Popular choices of commercially available LIB cathode materials, such as $\mathrm{LiCoO}_{2}$ and $\mathrm{LiFePO}_{4}$, are generally made up of oxygen containing compounds. A major disadvantage as such in $\mathrm{LiCoO}_{2}$ (charged-state) is the decomposition at elevated temperature to release oxygen, which then exothermally reacts with organic electrolytes and can thus raise safety issues. ${ }^{\mathbf{1 3 5 , 1 3 6}}$ Metal fluorides have been considered as an alternative, albeit with poor electronic conductivity, owing to the large bandgap induced by the high ionic characteristic of the metal-halogen bond. However, their large ionic nature should theoretically help in providing a higher voltage output when used as electrode materials. ${ }^{137}$ 
Gocheva et al. reported the electrochemical performance of several sodium metal fluorides $\left(\mathrm{NaMF}_{3}\right.$ where $\left.\mathrm{M}=\mathrm{Ni}, \mathrm{Mn}, \mathrm{Fe}\right)$ prepared via mechanochemical synthesis. When tested in a half-cell configuration, $\mathrm{NaFeF}_{3}$ was able to exhibit a capacity of $128 \mathrm{~mA} \mathrm{~h} \mathrm{~g}{ }^{-1}$ when cycled between 1.5 and 4.0 vs. $\mathrm{Na}^{+} / \mathrm{Na}$. However, the electrolyte decomposition cut-off voltage limited the electrochemical performances of NaMnF3 and NaNiF3. ${ }^{\mathbf{1 3 8}}$ Liquid phase synthesis using an organic solvent produced highly dispersed uniform $\mathrm{NaFeF}_{3}$ nanoparticles. The particle sized could be controlled by using different oleic acid/oleyamine ratios. It can be observed from Fig. 17a that smaller-sized particles delivered a higher capacity, especially at high current densities. When tested at $0.01 C$, discharge capacities within a range of $170-181 \mathrm{~mA} \mathrm{~h} \mathrm{~g}^{-1}$ could be obtained. ${ }^{139}$ DFT calculations showed that $\mathrm{Na}_{0.5} \mathrm{FeF}_{3}$ is the only energetically stable phase, resulting in two voltage plateaus at $2.63 \mathrm{~V}$ when $1 \geq x \geq$ 0.5 and 2.82 V during $0.5 \geq x \geq 0 .{ }^{140}$
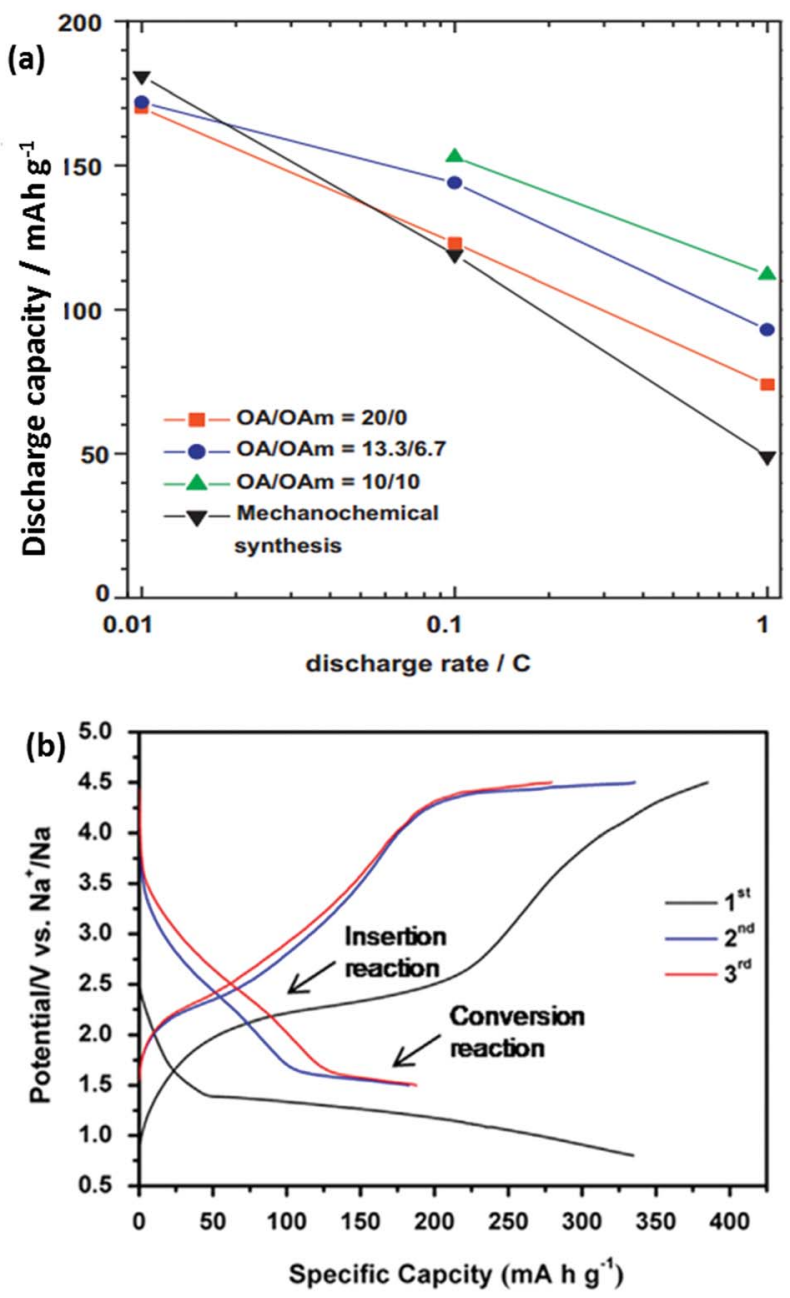

Fig. 17 (a) Variation of the discharge capacity and current rates of different $\mathrm{NaFeF}_{3}$ particles synthesized from a liquid phase synthesis. ${ }^{139}$ (b) In situ electrochemical activation of the $\mathrm{FeF}_{2}-\mathrm{rGO}$ composite to form $\mathrm{FeF}_{3}-\mathrm{Fe}-\mathrm{rGO}$ during the first cycle, followed by its subsequent charge-discharge curves ${ }^{142}$ (a) reprinted with permission from ref. 139. Copyright 2011 Elsevier (b) reprinted with permission from ref. 142. Copyright 2014 Elsevier.
The perovskite-type metal trifluoride $\mathrm{FeF}_{3}$ was also explored as a potential cathode material for NIB. Nishijima reported ball-milled $\mathrm{FeF}_{3}$ with $25 \%$ acetylene black for both $\mathrm{Li}$ and $\mathrm{Na}$ systems. When tested in NIB, a reversible capacity of $\sim 100 \mathrm{~mA} \mathrm{~h} \mathrm{~g}^{-1}$ could be obtained, with an average discharge voltage of $2.2 \mathrm{~V}$. Other metal fluorides, including $\mathrm{TiF}_{3}, \mathrm{MnF}_{3}, \mathrm{CoF}_{3}$, were prepared using the same methodology, and were tested. ${ }^{\mathbf{1 4 1}}$ By homogeneously distributing $\mathrm{FeF}_{3}$ within a matrix of metallic $\mathrm{Fe}$ and reduced graphene oxide (rGO) through an in situ method, the $\mathrm{FeF}_{3}-\mathrm{Fe}-\mathrm{rGO}$ composite was able to deliver a high capacity of $\sim 180 \mathrm{~mA} \mathrm{~h} \mathrm{~g}^{-1}$ when cycled at $20 \mathrm{~mA} \mathrm{~g}^{-1}$ (Fig. 17b). By allowing poorly conductive $\mathrm{FeF}_{3}$ to be in intimate contact with highly conductive Fe and rGO, a good rate capability and long cyclability could be achieved in the overall compound. ${ }^{\mathbf{1 4 2}}$ Nanocellular carbon foams have also been recently studied as a cathode material in NIBs. Their energy storage mechanism is attributed to the surface reactions between $\mathrm{Na}^{+}$and oxygen-containing functional groups on the surface of the carbon foams (i.e. $-\mathrm{C}=\mathrm{O}+\mathrm{Na}^{+}+\mathrm{e}^{-} \leftrightarrow-\mathrm{C}-\mathrm{O}-\mathrm{Na}$ ). The relationship between the peak current and scanning rates shows a linear profile, indicating that the redox reaction is limited to the surface and is not diffusion limited. The carbon foam was able to deliver a reversible specific capacity of $152 \mathrm{~mA} \mathrm{~h} \mathrm{~g}^{-1}$ when tested at $100 \mathrm{~mA}$ $\mathrm{g}^{-1}$, along with a capacity retention of $90 \%$ over 1600 cycles. Despite the excellent electrochemical performance, the volumetric energy density still remains a problem in such carbon-based compounds. In addition, for commercialization to be possible, an anode prepared in the charged state is necessary. ${ }^{143}$

\section{Negative electrode materials}

In current commercialized LIBs, both electrodes employ insertion host materials. Despite the fact that lithium metal has the lowest reduction potential $(-3.04$ vs. S.H.E.) and is able to provide a theoretical capacity of up to $3840 \mathrm{~mA} \mathrm{~h} \mathrm{~g} \mathrm{~g}^{-1}$, it is avoided, mainly due to safety issues resulting from the growth of dendrites that could potentially lead to a short circuit of the cell. ${ }^{17,144}$ Compared with lithium, these issues are even more problematic with sodium, due to its much higher reactivity with organic solvents; while additionally, sodium has a low melting point $\left(97.7^{\circ} \mathrm{C}\right)$ which is also a drawback related to safety issues when used in anodes for room-temperature batteries. ${ }^{\mathbf{1 4}}$ Hence, it is necessary and critical to find a suitable sodium host material with a low redox potential as the anode for NIBs. So far, various materials have been exploited for this purpose, including carbonaceous materials, sodium alloys, metal oxides/ sulfides, phosphorus and phosphides.

\subsection{Carbonaceous materials}

Graphite has been the most widely used anode material in commercial LIBs. It has a relatively high capacity $(\sim 350 \mathrm{~mA} \mathrm{~h}$ $\left.\mathrm{g}^{-1}\right)$, low potential plateau $\left(\sim 0.1 v s\right.$. $\left.\mathrm{Li}^{+} / \mathrm{Li}\right)$ and high stability. A LIB composed of a graphite anode and an appropriate cathode, such as $\mathrm{LiCoO}_{2}$, could offer high energy density, high energy efficiency and long cycle life. However, it has been proven that a very small amount of sodium can insert into graphite, probably because the process is not thermodynamically favorable. ${ }^{\mathbf{3 1}, \mathbf{1 4 5 , 1 4 6}}$ 
To find an alternative anode for NIBs, amorphous carbons have been investigated thoroughly. Early work has demonstrated the sodium storage behaviour in varying textured amorphous carbons pyrolyzed from different precursors and at different temperatures. ${ }^{\mathbf{1 4 7 - 1 4 9}}$ Among these, several hard carbons have exhibited a high reversible capacity of close to $300 \mathrm{~mA} \mathrm{~h}$ $\mathrm{g}^{-1} \cdot{ }^{149-153}$ Hard carbon is known to be a type of non-graphitizable amorphous carbon with inherent nanoporosity due to the random stacking of graphene sheets and pores on the order of size of the graphene sheets. ${ }^{\mathbf{1 5 4 , 1 5 5}}$ The discharge/charge voltage profiles of hard carbon for sodium storage are similar to lithium systems, with an inclined region at a relatively high potential window and a plateau at low potential close to that of sodium metal (Fig. 18a and b). Thus, lithium insertion mechanisms in hard carbon have been similarly proposed for sodium insertion, i.e. the sloping region was attributed to sodium insertion into parallel layers of graphene sheets; and the low-potential plateau was attributed to the pore-filling of sodium. ${ }^{151}$ Such mechanisms were further confirmed by an NMR study on electrochemically sodiated hard carbon. ${ }^{156}$ Although early reports on hard carbon have shown poor cyclability and an insufficient initial coulombic efficiency (usually lower than 80\%), the initial reversible capacity of $\sim 300 \mathrm{~mA} \mathrm{~h} \mathrm{~g}{ }^{-1}$ is significant and close to the lithium intercalation in graphite, thus rendering it a promising anode for sodium-ion batteries.

One of the main challenges to the poor cyclability is probably associated with the high reactivity of sodiated hard carbon with electrolytes. When carbonaceous materials are used in LIBs with the electrolyte $\mathrm{LiPF}_{6}$ in ethylene carbonate (EC):diethyl carbonate (DEC), or, $\mathrm{LiPF}_{6}$ in EC : dimethyl carbonate (DMC), a stable solid electrolyte interface (SEI) layer between the materials and electrolyte, which contains several inorganic salts, such as $\mathrm{LiF}$ and $\mathrm{Li}_{2} \mathrm{CO}_{3}$, is formed because of decomposition of the $\mathrm{LiPF}_{6}$ and electrolyte solvents during the initial discharge. ${ }^{157,158}$ Such a stable SEI layer serves as one of the main contributions to the stable cycling behaviour. However, in the case of $\mathrm{NaPF}_{6}$, there may be a lack of formation of a stable SEI layer even when using the same solvents and this thus results in its poor cyclability. ${ }^{31,159,160}$ Optimization of the electrolytes has been carried out by several groups and it was reported that when electrolytes such as $\mathrm{NaClO}_{4}$ in PC and $\mathrm{NaPF}_{6}$ in EC : PC were used, a long cycling performance of up to more than a hundred of cycles could be achieved (Fig. 19a and b). ${ }^{\mathbf{1 6 1 , 1 6 2}}$ Moreover, it

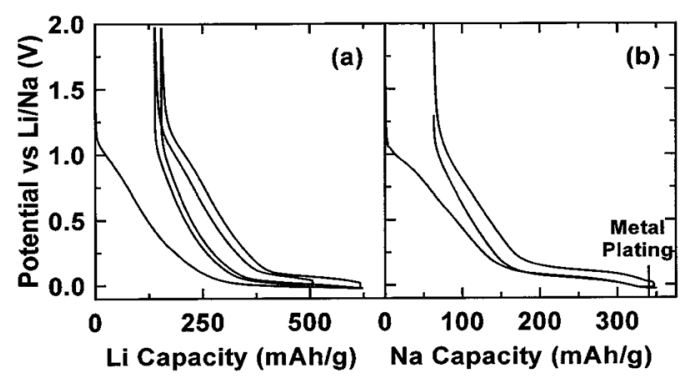

Fig. 18 Voltage profiles of lithium (a) and sodium (b) storage in hard carbon $^{149}$ reprinted with permission from ref. 149. Copyright 2001 The Electrochemical Society.
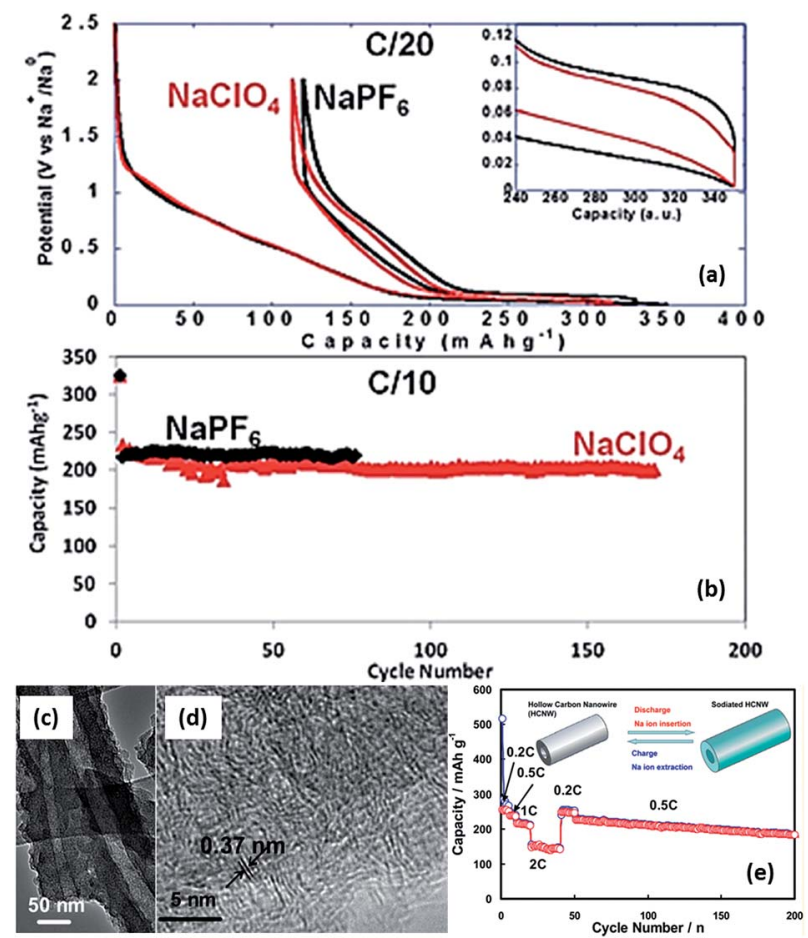

Fig. 19 (a) First cycle voltage versus capacity profiles for hard carbon electrodes cycled in EC : PC based electrolytes with $1 \mathrm{M}$ of $\mathrm{NaClO}_{4}$ or NaPF6 (recorded at C/20) and (b) discharge capacity versus cycle number for similar cells cycled at C/10 (ref. 162) (c and d) high-resolution TEM images of hollow carbon nanowires, and (e) their rate and cycling properties. ${ }^{166}$ ( $a$ and $b$ ) Reproduced from ref. 162 with permission from The Royal Society of Chemistry (c-e) reprinted with permission from ref. 166. Copyright 2012 American Chemical Society.

has been reported that additives such as fluoroethylene carbonate (FEC) that can form more stable SEI layers can also enhance the stability of carbon electrodes. ${ }^{\mathbf{1 6 3}}$ Recently, various nanostructured carbonaceous materials were examined as anodes for sodium-ion batteries, and it was found that the sodium storage properties, including the cyclability and rate capability, largely depended on the carbon structures/architecture. The first carbon materials with high rate capabilities were prepared by a templating method by Wenzel et al. The materials owned a hierarchical porous structure which allowed easy accessibility to the electrolyte over the interconnected pores and a short sodium ion diffusion distance in the bulk. As a result, a high rate capability, with a capacity of $\sim 100 \mathrm{~mA} \mathrm{~h} \mathrm{~g}^{-1}$ at a rate of $5 C\left(1860 \mathrm{~mA} \mathrm{~g}^{-1}\right)$ could be achieved. ${ }^{164}$ Tang et al. reported that hollow carbon nanospheres with mesoporous carbon shells of thicknesses of $\sim 12 \mathrm{~nm}$ could also have a high rate capability, and that even at a current density of $10 \mathrm{~A} \mathrm{~g}^{-1}$, a capacity of $\sim 50$ $\mathrm{mA} \mathrm{h} \mathrm{g}^{-1}$ could still be obtained. Furthermore, these nanospheres also showed a long cycling performance, with insignificant fading after more than 100 cycles. ${ }^{165}$ Cao et al. obtained a high-rate carbonaceous material that also had a long cycling performance based on hollow carbon nanowires with thin carbon walls, as shown in Fig. 19c-e. ${ }^{166}$ A similar concept of porosity and short ion diffusion distance was reported in 
subsequent publications. ${ }^{167,168}$ These materials, while on the one hand, exhibited enhanced electrochemical performance, especially in terms of rate capability; on the other hand, they usually had a rather low initial coulombic efficiency - in some cases, even lower than $50 \%$. For example, an efficiency of $42 \%$ was recorded for Tang's hollow spheres, and $51 \%$ for Cao's hollow nanowires. This is because of the irreversible formation of SEI layers on materials with large surface areas, resulting from their porosity and nanostructures. Such a low coulombic efficiency would usually be a drawback preventing them from practical applications. For enhanced sodium storage properties, many authors also emphasized the feature of enlarged graphene interlayer spacing and claimed that this benefited sodium insertion, because sodium ion have a relatively larger radius $(1.02 \AA)$ compared to lithium ions $(0.79 \AA) .{ }^{165-170}$ Very recently; a remarkable improvement was achieved by $\mathrm{Hu}$ et al. based on a hydrothermally carbonized sucrose method, which was further pyrolyzed at high temperature, where the surface was coated with soft (graphitizable) carbon. The graphitized carbon coating could improve the $1^{\text {st }}$ cycle coulombic efficiency from $53 \%$ to $83 \%$. Using a pyrolysis temperature of $1600{ }^{\circ} \mathrm{C}$, a long plateau capacity of $220 \mathrm{~mA} \mathrm{~h} \mathrm{~g}^{-1}$ could be obtained. The full cell capability was demonstrated using $1600{ }^{\circ} \mathrm{C}$ pyrolysed carbon as anode and $\mathrm{P} 2-\mathrm{Na}_{2 / 3} \mathrm{Ni}_{1 / 3} \mathrm{Mn}_{2 / 3} \mathrm{O}_{2}$ as the cathode. The theoretical capacity of this system was estimated to be $200 \mathrm{~W} \mathrm{~h}$ $\mathrm{kg}^{-1}$. This performance is believed to be closest to the requirements for practical devices. ${ }^{171}$

Nitrogen-doped porous carbons were also reported for use as anodes for sodium-ion batteries. ${ }^{172-174}$ They were able to achieve capacities of $\sim 300 \mathrm{~mA} \mathrm{~h} \mathrm{~g}{ }^{-1}$ and long cycling performances. However, they also exhibited a low initial coulombic efficiency (29-53\%). Functionalized N-doped carbon nanofibers are also reported to exhibit excellent electrochemical performance as an anode material in NIBs. A capacity of $134.2 \mathrm{~mA} \mathrm{~h} \mathrm{~g}^{-1}$ was maintained after 200 cycles when tested at a relatively high current density of $200 \mathrm{~mA} \mathrm{~g}^{-1}$, corresponding to a capacity retention of $88.7 \%$. However, a low initial coulombic efficiency of $41.8 \%$ was also observed in the work. ${ }^{175}$ For these materials, a high proportion of the capacity might be due to interfacial storage related to nitrogen doping. Moreover, graphene also remains a promising anode material for sodium-ion batteries. Although the reversible capacity reported so far, based on reduced graphene oxides, is also $\sim 300 \mathrm{~mA} \mathrm{~h} \mathrm{~g}^{-1}$, and with a low coulombic efficiency (20-50\%), a study based on first principle calculations has suggested a maximum capacity of higher than $1000 \mathrm{~mA} \mathrm{~h} \mathrm{~g}^{-1}$ for defective graphene. ${ }^{176-178}$

\subsection{Sodium alloys}

Similar to the alloying reactions in LIBs, several metals, such as tin (Sn) and antimony (Sb), are able to undergo electrochemical alloying reactions with sodium, and thus can provide high capacities in NIBs. A simulation based on Density Functional Theory (DFT) by Chevrier et al. predicted that the electrochemical sodiation of tin involves several phase transitions, including $\mathrm{NaSn}_{5}, \mathrm{NaSn}$, and $\mathrm{Na}_{9} \mathrm{Sn}_{4}$ phases, that eventually lead to the final formation of $\mathrm{Na}_{15} \mathrm{Sn}_{4}$ with a theoretical capacity of
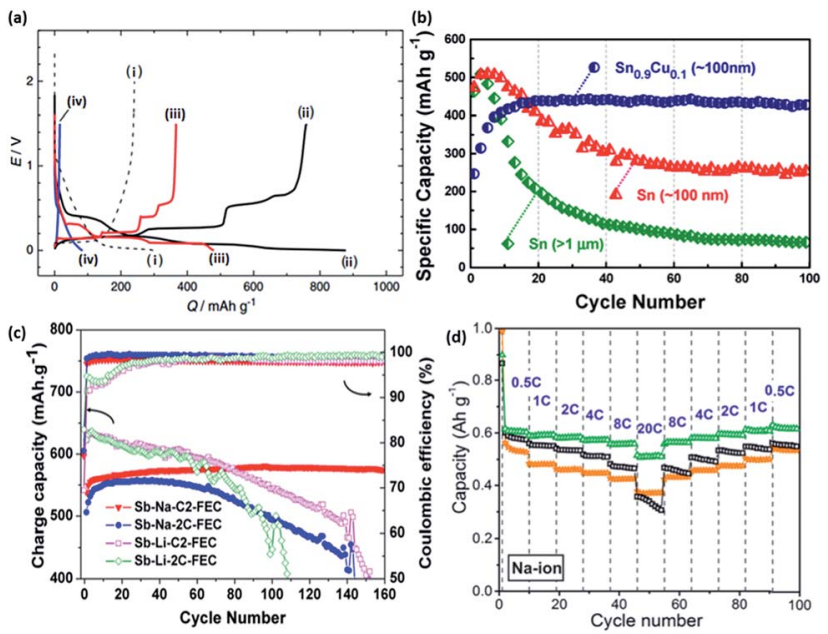

Fig. 20 (a) Initial galvanostatic reduction and oxidation curves of (i) hard-carbon with PVdF binder, (ii) $\mathrm{Sn}-\mathrm{PAA}$, (iii) Pb-PAA, (iv) Si-PAA, and (v) Sn-PVdF. The hard-carbon electrodes were examined in beaker-type $\mathrm{Na}$ cells at $25 \mathrm{~mA} \mathrm{~g}^{-1}$, and the other electrodes were tested in coin-type $\mathrm{Na}$ cells at $50 \mathrm{~mA} \mathrm{~g}^{-1}$ (ref. 180) (b) reversible discharge capacities of electrodes made of $\mathrm{Sn}_{0.9} \mathrm{Cu}_{0.1}$ nanoparticles, Sn nanoparticles, and Sn microparticles. All the electrodes were cycled at $0.2 \mathrm{C}$ rate $\left(169 \mathrm{~mA} \mathrm{~g}^{-1}\right) .{ }^{192}$ (c) Cycling performance of micrometric antimony in Li and Na systems with 5 wt\% FEC. ${ }^{193}$ (d) Cycling and rate performance of antimony with different sizes. ${ }^{194}$ (a) Reprinted with permission from ref. 180. Copyright 2012 Elsevier (b) reprinted with permission from ref. 192. Copyright 2013 American Chemical Society (c) reprinted with permission from ref. 193. Copyright 2012 American Chemical Society (d) reprinted with permission from ref. 194. Copyright 2014 American Chemical Society.

$847 \mathrm{~mA} \mathrm{~h} \mathrm{~g}^{-1}$ (Fig. 20a). ${ }^{179}$ The first investigation of such sodium-tin alloying reactions in a sodium cell was reported recently by Komaba et al. ${ }^{180} \mathrm{~A}$ large capacity of 878 and $758 \mathrm{~mA} \mathrm{~h}$ $\mathrm{g}^{-1}$ was obtained for the initial discharge and charge processes, respectively, corresponding to a coulombic efficiency of $86 \%$. In addition, similar electrochemical profiles between the theoretical and experimental results were observed. ${ }^{181-183}$ However, it was also suggested that the first sodiation process of tin occurs via a two-step reaction. This involved a two phase reaction that first forms a Na-poor, amorphous $\mathrm{Na}_{x} \mathrm{Sn}$ alloy $(x=\sim 0.5)$, followed by further sodiation into Na-rich amorphous phases, which are then followed by a one phase mechanism to finally form crystalline $\mathrm{Na}_{15} \mathrm{Sn}_{4} \cdot{ }^{1.4}$

One drawback from using tin for sodium storage is the large volume expansion ( $420 \%$ volume change) during the formation of $\mathrm{Na}_{15} \mathrm{Sn}_{4},{ }^{179}$ which appears to be even larger than the expansion during the insertion of lithium $(260 \%){ }^{185}$ This large volume change during the sodiation/desodiation causes an instability of the electrodes, and results in the capacity fast fading. This issue of large volume expansion is also present for lithium storage application. In order to improve the stability of Sn, many strategies used in the lithium case have been applied to the sodium case, which includes nanosizing and the preparation of composites materials, such as a tin/carbon composite, ${ }^{186-188}$ tin-based active/inactive intermetallics $\left(\mathrm{CoSn}_{2}\right.$ and $\left.\left(\mathrm{Cu}_{6} \mathrm{Sn}_{5}\right)_{1-x} \mathrm{C}_{x}\right){ }^{189-191}$ and other composites. ${ }^{181}$ Carbon and 
the inactive components within the composites usually serve as a buffering matrix for the volume expansion during the electrochemical reaction. Via an active/inactive strategy, Lin et al. prepared a $\mathrm{Sn}_{0.9} \mathrm{Cu}_{0.1}$ composite made of $\mathrm{Sn}$ and $\mathrm{Cu}_{6} \mathrm{Sn}_{5},{ }^{192}$ which was able to retain $\sim 400 \mathrm{~mA} \mathrm{~h} \mathrm{~g}^{-1}$ after 100 cycles, as shown in Fig. 20b.

Antimony is another promising element that can undergo an alloying reaction with sodium. It has a theoretical capacity of $660 \mathrm{~mA} \mathrm{~h} \mathrm{~g}{ }^{-1}$ with the formation of $\mathrm{Na}_{3} \mathrm{Sb}$. Darwiche et al. reported that the intermediate phases during the sodiation/ desodiation of antimony were mostly amorphous, in which a competition takes place between the formation of the hexagonal (main) and the cubic polymorphs of $\mathrm{Na}_{3} \mathrm{Sb}$ at the end of the discharge of the $\mathrm{Sb} / \mathrm{Na}$ cell. ${ }^{193}$ Considering the molar volume of $\mathrm{Sb}$ (rhombohedral, $18.17 \mathrm{~cm}^{3} \mathrm{~mol}^{-1}$ ) and $\mathrm{Na}_{3} \mathrm{Sb}$ (hexagonal, $71.43 \mathrm{~cm}^{3} \mathrm{~mol}^{-1}$ ), the volume expansion of this material after sodiation is $\sim 290 \%$. However, this material seems to be able to exhibit a good cycling performance, with a capacity close to 600

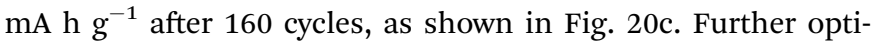
mization using similar strategies as used for tin might lead to an even better performance. ${ }^{195-200}$ For example, He et al. reported antimony synthesized with a size of $\sim 20 \mathrm{~nm}$ that possessed both a long cycling performance (larger than $600 \mathrm{~mA} \mathrm{~h} \mathrm{~g}^{-1}$ after 100 cycles $)$ and high rate capability $\left(\sim 500 \mathrm{~mA} \mathrm{~h} \mathrm{~g}^{-1}\right.$ at a current density of $13.2 \mathrm{~A} \mathrm{~g}^{-1}$ ), as shown in Fig. 20d. ${ }^{194}$

The SnSb intermetallic is also an attractive alternative for sodium storage. Xiao et al. reported a $\mathrm{SnSb} / \mathrm{C}$ composite with an initial capacity of $544 \mathrm{~mA} \mathrm{~h} \mathrm{~g}^{-1}$ and a capacity retention of $80 \%$ after 50 cycles. The cyclic voltammetry (CV) results suggested that the alloying and dealloying reactions occur in a sequential manner based on the Sn-rich and Sb-rich phases, similar to that of the $\mathrm{SnSb}$ alloy reacting with $\mathrm{Li}$. It was assumed that the sodiation of $\mathrm{SnSb}$ proceeds to first form $\mathrm{Na}_{3} \mathrm{Sb}$ and $\mathrm{Sn}$, followed by the sodiation of $\mathrm{Sn}$ into $\mathrm{Na}_{15} \mathrm{Sn}_{4}$. By a combination study of XRD and ${ }^{119} \mathrm{Sn}$ and ${ }^{121} \mathrm{Sb}$ Mössbauer spectroscopies, Baggetto et al. reported that the sodiation of $\mathrm{SnSb}$ yields hexagonal $\mathrm{Na}_{3} \mathrm{Sb}$ at a full discharge at higher temperatures (65 and $95{ }^{\circ} \mathrm{C}$ ), while the room temperature reaction yielded amorphous compounds. ${ }^{201} \mathrm{Ji}$ et al. reported a porous carbon nanofibersupported SnSb with a relatively lower capacity of $\sim 400 \mathrm{~mA} \mathrm{~h}$ $\mathrm{g}^{-1}$, but with no visible fading, even after more than 200 cycles. $^{202}$

Other elements, such as lead $(\mathrm{Pb})$ and germanium (Ge), have also been reported to be able to electrochemically alloy with sodium, and to have a significant capacity. ${ }^{203-205}$ The theoretical capacity predicted from DFT calculations for lead and germanium are 485 and $369 \mathrm{~mA} \mathrm{~h} \mathrm{~g}{ }^{-1}$, respectively. ${ }^{179}$ Silicon, which alloys with lithium and provides a high capacity of larger than $4000 \mathrm{~mA} \mathrm{~h} \mathrm{~g}^{-1}$, only showed a capacity of less than $100 \mathrm{~mA} \mathrm{~h} \mathrm{~g}^{-1}$ during sodium storage, although the DFT calculation predicted it should have a sodium capacity of approximately $954 \mathrm{~mA} \mathrm{~h} \mathrm{~g}^{-1}$.

In addition to the optimization of alloying materials from a materials point of view, many reports have shown that the optimization of electrolytes could lead to a better battery cycling performance. For instance, the presence of FEC in electrolytes is widely reported to be able to form more stable SEI layers, which is beneficial for the cycling performance $;^{\mathbf{2 0 6}, 207}$ although, there are also other reports that have shown no significant improvement by adding FEC. $^{208}$ Moreover, using more stable or conductive binders, such as sodium carboxymethyl cellulose (CMC), poly(acrylic acid) (PAA), or poly(9,9-dioctylfluorene-cofluorenone-co-methylbenzoic ester) (PFM), in the electrode, instead of the most widely used poly(vinylidene fluoride) (PVDF) binder could improve the stability of electrodes..$^{34,180}$

\subsection{Oxides}

One other emerging class of anode material for NIBs belongs to the titanium-based compounds, including $\mathrm{TiO}_{2}$, spinel type $\mathrm{Li}_{4} \mathrm{Ti}_{5} \mathrm{O}_{12}$, and layered $\mathrm{Na}_{2} \mathrm{Ti}_{3} \mathrm{O}_{7}$ and $\mathrm{Na}_{0.66}\left[\mathrm{Li}_{0.22} \mathrm{Ti}_{0.78}\right] \mathrm{O}_{2}$.

$\mathrm{TiO}_{2}$ is well known to be a versatile material that exists in several polymorphs, depending on the respective synthesis technique. The polymorphs exist depending on how the octahedral $\mathrm{TiO}_{6}$ are linked within the structure. Significant advantages which have captured researchers' attention include cheap cost, availability, and that it possesses a low intercalation potential $\left(\sim 1.5 \mathrm{~V}\right.$ vs. $\left.\mathrm{Li}^{+} / \mathrm{Li}\right)$. Various sodium storage mechanisms, such as pseudo-capacitance and sodium insertion, have been proposed for this material. Recently, $\mathrm{Wu}$ et al. reported that anatase $\mathrm{TiO}_{2}$ could be partially reduced into metallic titanium when discharged to $0.1 \mathrm{~V} v s$. $\mathrm{Na}^{+} / \mathrm{Na}$, and is accompanied by the formation of sodium oxide and amorphous sodium titanate. The formation of the metallic titanium was first confirmed by X-ray photoelectron spectroscopy (XPS) analysis, and it was further proposed that the following cycles were based on the insertion/deinsertion of sodium in the newly formed amorphous sodium titanate. ${ }^{209} \mathrm{Xu}$ et al. recently reported the electrochemical performance of anatase $\mathrm{TiO}_{2}$ as an anode in NIBs. Anatase $\mathrm{TiO}_{2}$ comprises a $3 \mathrm{D}$ structure with an interconnecting network of zigzag channels of $1 \mathrm{D} \mathrm{TiO}_{6}$ octahedra. The mesoporous $\mathrm{TiO}_{2}$ was fabricated using cellulose as the sacrificial template, along with hydrolysis and an annealing treatment. A reversible capacity, as shown in Fig. 21a, of about $150 \mathrm{~mA} \mathrm{~h} \mathrm{~g}^{-1}$ could be obtained when cycled between 0.01 and $2.5 \mathrm{~V}$ (vs. $\left.\mathrm{Na}^{+} / \mathrm{Na}\right) .{ }^{210}$ However, comparative to the intercalation of $\mathrm{Li}$ into anatase $\mathrm{TiO}_{2}$, the absence of a well-defined voltage plateau was observed in its $\mathrm{Na}$ counterpart. Bronze $\mathrm{TiO}_{2}$ synthesized via a hydrothermal method was also investigated as a potential anode material for NIBs; however, a capacity retention of only $37.8 \%$ was recorded after 90 cycles (Fig. 21b). ${ }^{211}$ Binder-free amorphous $\mathrm{TiO}_{2}$ nanotubes (interior diameter $>80$ $\mathrm{nm}$ ) deposited directly via electrochemical anodization have also been studied as an anode material in NIBs. It was noted that the diameter of the nanotubes play an important role in $\mathrm{Na}$ intercalations. For $\mathrm{TiO}_{2}$ nanotubes with an internal diameter of $45 \mathrm{~nm}$, the electrochemical profile remained inactive, compared to nanotubes with an internal diameter of $80 \mathrm{~nm}$, where $150 \mathrm{~mA}$ $\mathrm{h} \mathrm{g}^{-1}$ of capacity could be achieved after 15 cycles (Fig. 21c). ${ }^{212}$ Hollandite $\mathrm{TiO}_{2}$ prepared via an oxidation-ion extraction process from $\mathrm{K}_{0.21} \mathrm{TiO}_{2}$ was also employed for NIB use. The wide $(2 \times 2)$ channels along the [001] direction were thought to help facilitate ion diffusion, as well as to provide a "zero-strain" intercalation behaviour, as per its lithium predecessors. 

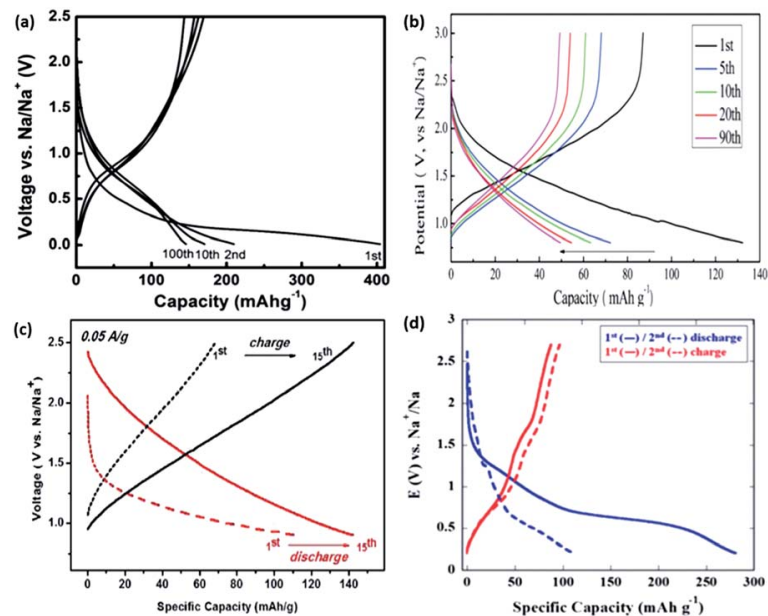

Fig. 21 Galvanostatic charge-discharge curve of (a) mesoporous anatase $\mathrm{TiO}_{2}$ cycled between 0.01-2.5 $\mathrm{V}^{210}$ (b) Hydrothermally synthesized bronze $\mathrm{TiO}_{2}$ cycled between 0.8-3.0 V. ${ }^{211}$ (c) Amorphous $\mathrm{TiO}_{2}$ cycled between $0.8-2.5 \mathrm{~V} .{ }^{212}$ (d) Hollandite-type $\mathrm{TiO}_{2}$ during the $1^{\text {st }}$ and $2^{\text {nd }}$ cycle ${ }^{213}$ (a) reproduced from ref. 210 with permission from The Royal Society of Chemistry (b) reproduced from ref. 211 with permission from The Royal Society of Chemistry (c) reprinted with permission from ref. 212. Copyright 2011 American Chemical Society (d) reproduced from ref. 213 with permission from The Royal Society of Chemistry.

Similarly, a sloping profile resulting in an initial capacity of 280 $\mathrm{mA} \mathrm{h} \mathrm{g}^{-1}$ was obtained during discharge, but subsequently only $0.25 \mathrm{~mol}$ of Na could be extracted (Fig. 21d). ${ }^{213}$ As observed from all the galvanostatic charge/discharge curves of the $\mathrm{TiO}_{2}$ polymorphs in Fig. 21, the electrochemical profiles lack a flat potential plateau during $\mathrm{Na}$ insertion, compared to Li insertion, during reversible reactions. This could suggest a different mechanism present during the reaction.

Spinel $\mathrm{Li}_{4} \mathrm{Ti}_{5} \mathrm{O}_{12}$ has been investigated intensively as a "zerostrain" anode for LIBs. Recently, Sun et al. also demonstrated its promising sodium storage behaviour, showing a reversible capacity of $\sim 150 \mathrm{~mA} \mathrm{~h} \mathrm{~g}^{-1}$, with an average plateau at $\sim 0.9 \mathrm{~V} v s$. $\mathrm{Na}^{+} / \mathrm{Na}$, and a first coulombic efficiency of up to $81 \%$. An interesting three-phase reaction $\left(2 \mathrm{Li}_{4} \mathrm{Ti}_{5} \mathrm{O}_{12}+6 \mathrm{Na} \leftrightarrow \mathrm{Li}_{7} \mathrm{Ti}_{5} \mathrm{O}_{12}\right.$ $+\mathrm{Na}_{6} \mathrm{LiTi}_{5} \mathrm{O}_{12}$ ) has been proposed for sodium storage of the material, instead of the two-phase mechanism $\left(\mathrm{Li}_{4} \mathrm{Ti}_{5} \mathrm{O}_{12}+3 \mathrm{Li}\right.$ $\left.\leftrightarrow \mathrm{Li}_{7} \mathrm{Ti}_{5} \mathrm{O}_{12}\right)$ for lithium storage. ${ }^{2 \mathbf{1 4 - 2 1 7}}$ Such a mechanism has been supported by DFT calculations and a variety of advanced characterization techniques, such as spherical aberration-corrected scanning transmission electron microscope. The sodium storage behaviour was reported to be highly size dependent, due to the slow diffusion kinetics with an apparent sodium diffusion coefficient of $2.7 \times 10^{-16} \mathrm{~cm}^{2} \mathrm{~s}^{-1}$, i.e. five order of magnitudes smaller than that of lithium. ${ }^{217}$ Thus nanosizing is necessary to achieve high performance.

Senguttuvan et al. first reported layered $\mathrm{Na}_{2} \mathrm{Ti}_{3} \mathrm{O}_{7}$ as a sodium insertion host for an efficient low voltage anode in 2011. In situ XRD revealed the phase transformation from $\mathrm{Na}_{4} \mathrm{Ti}_{3} \mathrm{O}_{7}$ to $\mathrm{Na}_{2} \mathrm{Ti}_{3} \mathrm{O}_{7}$ during discharge of the anode (Fig. 22a-f). A voltage plateau at $0.3 \mathrm{~V} v s$. $\mathrm{Na}^{+} / \mathrm{Na}$, resulting in a discharge capacity of

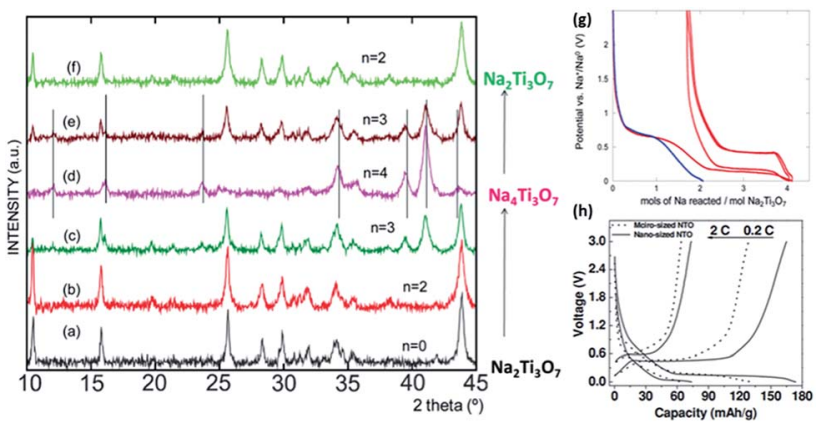

Fig. 22 (a-f) In situ X-ray diffraction of a $\mathrm{Na} / \mathrm{Na}_{2} \mathrm{Ti}_{3} \mathrm{O}_{7}$ cell cycled between 0.01 and $2.5 \mathrm{~V}$ at a C/50 rate. (g) Electrochemical profile of a (blue) blank electrode consisting of only carbon black (red) $\mathrm{Na}_{2} \mathrm{Ti}_{3} \mathrm{O}_{7}$ and $30 \mathrm{wt} \%$ carbon black ${ }^{218}$ (h) galvanostatic charge-discharge curves elucidating the size effect of micro- and nanosized $\mathrm{Na}_{2} \mathrm{Ti}_{3} \mathrm{O}_{7}$ tested at varying current densities of 0.2 and $2 C$, respectively. ${ }^{216}(a-f)$ Reprinted with permission from ref. 218. Copyright 2011 American Chemical Society. (h) Copyright 2013 Wiley-VCH Verlag GmbH \& Co. KGaA, Weinheim.

approximately $200 \mathrm{~mA} \mathrm{~h} \mathrm{~g}^{-1}$, was observed when cycled between 0.01 and $2.5 \mathrm{~V}$ (Fig. 22g). ${ }^{218}$ Pan et al. also studied $\mathrm{Na}_{2} \mathrm{Ti}_{3} \mathrm{O}_{7}$ prepared via a solid-state synthesis. The microsized $\mathrm{Na}_{2} \mathrm{Ti}_{3} \mathrm{O}_{7}$ was able to deliver a discharge capacity of $188 \mathrm{~mA} \mathrm{~h} \mathrm{~g}^{-1}$ in $1 \mathrm{M}$ NaFSI in PC when tested at $C / 10$ within a voltage window of 0.01-3.0 V vs. $\mathrm{Na}^{+} / \mathrm{Na}$. The experimental results were in good agreement with the first-principles prediction of $0.35 \mathrm{~V}$ (Fig. 22h). The size variation also showed that nanoparticles provided a higher discharge capacity compared to micron-sized $\mathrm{Na}_{2} \mathrm{Ti}_{3} \mathrm{O}_{7}$; however, with the problem of poor cycleability. ${ }^{216}$

A low strain $\mathrm{P} 2-\mathrm{Na}_{0.66}\left[\mathrm{Li}_{0.22} \mathrm{Ti}_{0.78}\right] \mathrm{O}_{2}$ anode material was also proposed by Wang et al. Similar ionic-sized $\mathrm{Li}^{+}$was used as a doping element for $\mathrm{Ti}$, so as to increase the valence state of $\mathrm{Ti}^{3+}$ to $\mathrm{Ti}^{4+}$, thus stabilizing the $\mathrm{TiO}_{6}$ octahedra in the previously reported low-voltage layered $\mathrm{Na}_{2 / 3} \mathrm{TiO}_{2}{ }^{85} \mathrm{P} 2-\mathrm{Na}_{0.66}\left[\mathrm{Li}_{0.22} \mathrm{Ti}_{0.78}\right]-$ $\mathrm{O}_{2}$ possesses a $\mathrm{P} 2$-layered structure, isostructural to that of $\mathrm{P} 2$ $\mathrm{Na}_{2 / 3} \mathrm{CoO}_{2}$. The AA-type oxygen stacking provides a large interlayer (5.5636 $\AA$ ) along the (002) plane. The galvanostatic profile (Fig. 23a) shows a quasi-solid-solution like reaction, giving rise to a reversible capacity of $116 \mathrm{~mA} \mathrm{~h} \mathrm{~g}^{-1}$ when cycled between 0.4 and $2.5 \mathrm{~V} v s$. $\mathrm{Na}^{+} / \mathrm{Na}$. An incredible cyclability was observed after 1200 cycles, with a small capacity decay of only $0.02 \%$ over each cycle (Fig. 23b). The coulombic attraction between $\mathrm{Na}$ ions and the interlayers reduces the interplanar distance during intercalation, while the reduction of the transition metal gives rise to an increase in transition metal-oxygen bonding. Li deinsertion was explained to be not possible due to the presence of a narrow $\mathrm{Li}^{+}$migration path, while the migration of $\mathrm{Li}$ to $\mathrm{Na}$ sites was also found to be difficult when using density functional theory (DFT) calculations (Fig. 23c and d). ${ }^{219}$

A large number of metal oxides and sulfides have been reported to be capable of delivering high capacity during lithium insertion via the conversion reaction: $\mathrm{M}_{\mathrm{a}} \mathrm{O}_{\mathrm{b}}+2 b \mathrm{Li} \leftrightarrow$ $a \mathrm{M}+b \mathrm{Li}_{2} \mathrm{O}$, (where, $\mathrm{M}=$ transition metal). ${ }^{8}$ Similar conversion mechanisms to form the elemental metal have also been proposed for many other oxides that electrochemically react 

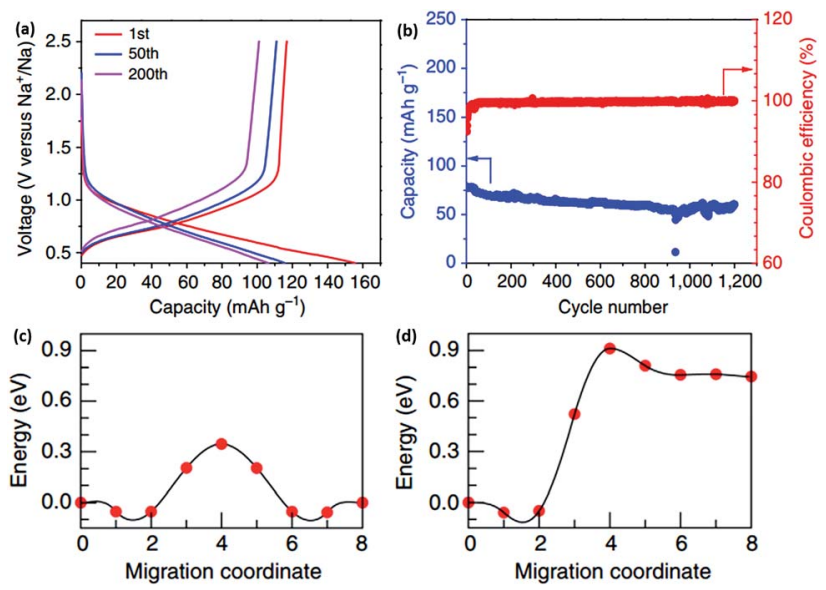

Fig. 23 (a) The $1^{\text {st }}, 50^{\text {th }}$, and $200^{\text {th }}$ galvanostatic charge-discharge profiles of $\mathrm{P} 2-\mathrm{Na}_{0.66}\left[\mathrm{Li}_{0.22} \mathrm{Ti}_{0.78}\right] \mathrm{O}_{2}$ within a voltage range (b) cycling performance over 1200 cycles at 2C rate. DFT calculations for the migration energy barrier of a single vacancy assisted (c) $\mathrm{Na}^{+}$diffusion in the $\mathrm{Na}$ layer, and (d) $\mathrm{Li}^{+}$diffusion from the transition metal layer to the $\mathrm{Na}$ layer in $\mathrm{P} 2 \mathrm{Na}_{0.66}\left[\mathrm{Li}_{0.22} \mathrm{Ti}_{0.78} \mathrm{O}_{2}\right.$ (ref. 219) reprinted with permission from Macmillan Publishers Ltd.: (Nat. Commun.) (ref. 219), copyright 2013.

with sodium. The first metal oxide reported as a conversion-type anode for NIBs was $\mathrm{NiCo}_{2} \mathrm{O}_{4}$ by Alcántara et al., as shown in Fig. 24a. ${ }^{220}$ Through a conversion reaction of $\mathrm{NiCo}_{2} \mathrm{O}_{4}$ to form $\mathrm{Ni}$, Co and $\mathrm{Na}_{2} \mathrm{O}$, although not completely confirmed in the report, a theoretical capacity of $890 \mathrm{~mA} \mathrm{~h} \mathrm{~g}{ }^{-1}$ should be expected. However, the experimental results recorded a capacity of only $\sim 618 / \sim 200 \mathrm{~mA} \mathrm{~h} \mathrm{~g}^{-1}$ for the initial discharge/charge process. Iron-based oxides, such as $\mathrm{Fe}_{2} \mathrm{O}_{3}$ (ref. 221-224) and $\mathrm{Fe}_{3} \mathrm{O}_{4},{ }^{225}$ have also been reported to deliver significant sodium storage capacity via conversion reactions. Hariharan et al. reported an initial discharge/charge capacity of 643/366 mA h $\mathrm{g}^{-1}$ for $\mathrm{Fe}_{3} \mathrm{O}_{4} \cdot{ }^{226}$ Selected area electron diffraction (SAED) patterns confirmed the formation of $\mathrm{Fe}$ and $\mathrm{Na}_{2} \mathrm{O}$ after discharge to $0.04 \mathrm{~V}$ vs. $\mathrm{Na}^{+} / \mathrm{Na}$. Upon a further charge to $3.0 \mathrm{~V}$, $\mathrm{Fe}_{3} \mathrm{O}_{4}$ was found on the SAED patterns, along with $\mathrm{Fe}$ and $\mathrm{Na}_{2} \mathrm{O}$, suggesting poor reversibility in the conversion mechanism. The same group also reported $\alpha-\mathrm{MoO}_{3}$ to have an initial discharge/ charge capacity of 771 and $410 \mathrm{~mA} \mathrm{~h} \mathrm{~g}{ }^{-1}$ via a conversion reaction. ${ }^{227}$ Yuan et al. reported that $\mathrm{CuO}$ had a high initial discharge/charge capacity of $\sim 935 / 640 \mathrm{~mA} \mathrm{~h} \mathrm{~g}^{-1}$ (Fig. 24b). The $\mathrm{CuO}$ nanorod arrays were prepared by engraving copper foils, which ensured good contact between the active material and the current collector. However, a much lower capacity of $<400 \mathrm{~mA} \mathrm{~h} \mathrm{~g}^{-1}$ was recorded for $\mathrm{CuO}$ electrodes prepared via a normal technique using PVDF as a binder, suggesting the importance of the electrode preparation in the utilization of active materials. ${ }^{228}$ When the metal element in an oxide is able to electrochemically alloy with sodium, an alloying reaction will further occur after the formation of the elemental metal via a conversion reaction, and this thus offers a very large capacity. These materials include $\mathrm{Sb}_{2} \mathrm{O}_{4}{ }^{229} \mathrm{SnO},{ }^{230,231}$ and $\mathrm{SnO}_{2} \cdot{ }^{232-235} \mathrm{Sb}_{2} \mathrm{O}_{4}$ has been reported to exhibit a very high capacity of $\sim 1000 \mathrm{~mA} \mathrm{~h} \mathrm{~g}{ }^{-1}$. Other metal oxides reported to have a conversion reaction with
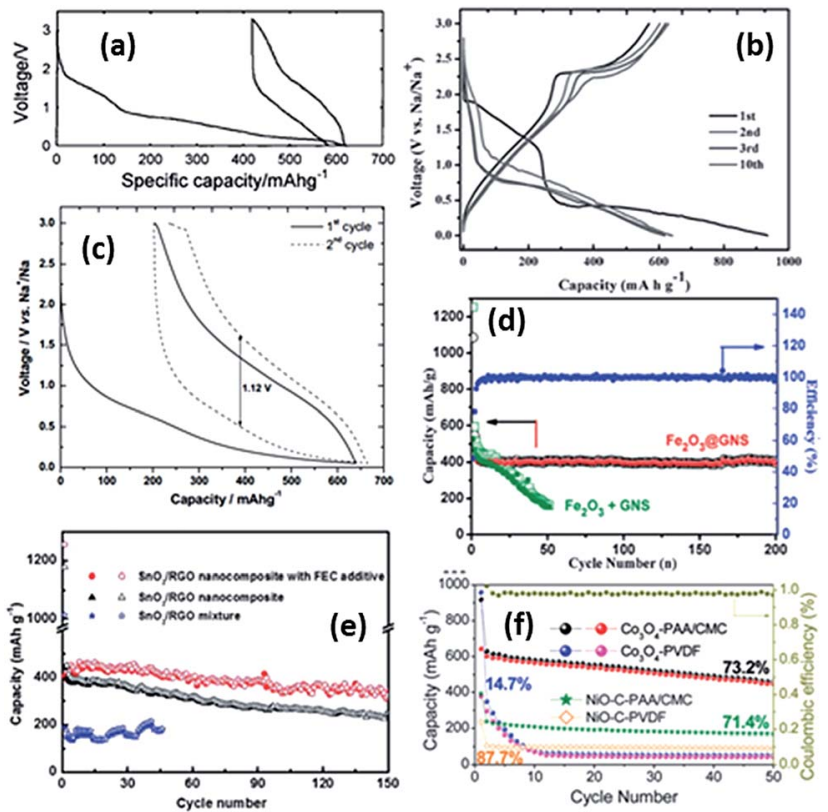

Fig. 24 Discharge/charge curves of (a) $\mathrm{NiCO}_{2} \mathrm{O}_{4}$ at a $0.1 \mathrm{C}$ rate; ${ }^{220}$ (b) a $\mathrm{CuO}$ nanorod array at a current density of $20 \mathrm{~mA} \mathrm{~g}^{-1.228}$ and (c) a nanostructured $\mathrm{Fe}_{2} \mathrm{O}_{3}$ at a current density of $40 \mathrm{~mA} \mathrm{~g}^{-1}$.223 (d) Cycling performance of $\mathrm{Fe}_{2} \mathrm{O}_{3}$ /GNS (mixture) and $\mathrm{Fe}_{2} \mathrm{O}_{3} \mathrm{aGNS}$ at a current of $100 \mathrm{~mA} \mathrm{~g}^{-1}$, and coulombic efficiency of the $\mathrm{Fe}_{2} \mathrm{O}_{3}$ @GNS sample. GNS: graphene nanosheets; ${ }^{224}$ (e) a $\mathrm{SnO}_{2}-\mathrm{RGO}$ (reduced graphene oxide) nanocomposite and a mixture in $1 \mathrm{M} \mathrm{NaClO}_{4}$ in $\mathrm{EC}-\mathrm{PC}$ with and without FEC additive at a current density of $100 \mathrm{~mA} \mathrm{~h} \mathrm{~g}^{-1,232}$ and ( $\mathrm{f}$ ) $\mathrm{CO}_{3} \mathrm{O}_{4}$ and $\mathrm{NiO}-\mathrm{C}$ using different kinds of binders at a current density of $50 \mathrm{~mA} \mathrm{~g}^{-1}$. Polyacrylic acid (PAA), carboxymethyl cellulose (CMC), polyvinylidene fluoride (PVDF). ${ }^{238}$ (a) Reprinted with permission from ref. 220. Copyright 2002 American Chemical Society. (b) Copyright 2014 Wiley-VCH Verlag GmbH \& Co. KGaA, Weinheim (c) reprinted with permission from ref. 223. Copyright 2014 Elsevier (d) reproduced from ref. 224 with permission from The Royal Society of Chemistry (e) reproduced from ref. 232 with permission from The Royal Society of Chemistry (f) reproduced from ref. 238 with permission from The Royal Society of Chemistry.

sodium and to show a significant capacity include $\mathrm{Co}_{3} \mathrm{O}_{4},{ }^{236,237}$ $\mathrm{NiO},{ }^{238} \mathrm{Mn}_{3} \mathrm{O}_{4},{ }^{222}$ and $\mathrm{FeWO}_{4}{ }^{236}$

Nonetheless, several obstacles for such conversion-type oxides in sodium storage still persist. For example, large potential hysteresis, low initial coulombic efficiency (most in the range of $30-70 \%$ ) and poor cyclability. Furthermore, the potential difference during discharge and charge are usually large, and could be even larger than $1 \mathrm{~V}$. Some examples are shown in Fig. 24a-c. The large hysteresis results in a very low round-trip efficiency, and is one of the main disadvantages of these materials. Fundamental knowledge about the origins of the hysteresis is quite limited, even in lithium storage applications. Several lithium storage studies have indicated that the hysteresis may have arisen from the different paths of the insertion/deinsertion reactions, the interfacial thermodynamics or even due to the mobility of the species during phase transformation. ${ }^{8}$ These might be helpful for understanding hysteresis in their sodium storage applications. Very few conversion oxides have exhibit an initial coulombic efficiency of greater 
than $80 \%$, with some materials even showing efficiencies of only $\sim 30 \%$. The low coulombic efficiency is related to the reversibility of the conversion reactions, as well as to the formation of the SEI layers. The reversibility of sodium insertion is usually worse than lithium insertion. This is usually attributed to the kinetic problems of the insertion/deinsertion reactions associated with the larger sodium ion, although this not quite fully understood. ${ }^{\mathbf{1 3 , 3 5}}$ The formation of SEI layers is also partially responsible for the low efficiency. One possible solution to this is to reduce the surface area of the materials. The conversion-type materials are not capable of long-term cycling without any modification. The poor cyclability could be, at least partially, due to the instability of the electrodes caused by the large volume change during sodiation/desodiation. By proper material/electrode design, such as carbon coating and using core-shell structures, the cyclability could be significantly improved. ${ }^{232-234}$ Some examples are shown in Fig. 24d-f. In addition, modification of the electrolytes, such as by the addition of FEC to form more stable SEI layers, has also been reported to be beneficial for the cyclability (Fig. 24e). ${ }^{232}$

\subsection{Sulfides}

Many metal sulfides can also electrochemically react with sodium based on a conversion reaction to form the metal and sodium sulfides. If the metal can electrochemically alloy with sodium, such as tin and antimony, the conversion reaction will follow by an alloying reaction. These conversion-type sulfides include $\mathrm{Ni}_{3} \mathrm{~S}_{2},{ }^{239} \mathrm{MoS}_{2},{ }^{208,240-242} \mathrm{SnS}_{2},{ }^{243-245} \mathrm{SnS}^{243,246} \mathrm{Co}_{9} \mathrm{~S}_{8},{ }^{247}$ $\mathrm{Fe}_{2} \mathrm{~S}$ (ref. 248) and $\mathrm{Sb}_{2} \mathrm{~S}_{3} \cdot{ }^{176}$ For some of these materials, it has been reported that the de-conversion reaction is unable to form the original metal sulfides. For example, Shadike et al. proposed that, after the first conversion reaction of $\mathrm{FeS}_{2}$ to form $\mathrm{Fe}$ and $\mathrm{Na}_{2} \mathrm{~S}$, the following charge/discharge reactions proceeded according to the mechanism: $\mathrm{Fe}+\mathrm{Na}_{2} \mathrm{~S} \leftrightarrow \mathrm{Na}_{x} \mathrm{FeS}_{2}+(4-x) \mathrm{Na}^{+}$ $+(4-x) \mathrm{e}^{-} \cdot{ }^{248}$ Similar to oxides based on the conversion reaction, these sulfides usually suffer from large hysteresis, low initial C.E. and poor cyclability. Lately, improvements in cycling performance have been made by using carbon composite materials and by modification of the electrolytes, such as with the addition of FEC. For example, Zhu et al. reported ultrasmall nanoplates of $\mathrm{MoS}_{2}$ embedded in carbon nanofibers with a rather stable cyclability (Fig. 25). ${ }^{240}$ Zhou et al. reported a SnS/ graphene composite with no significant fading after 250 cycles
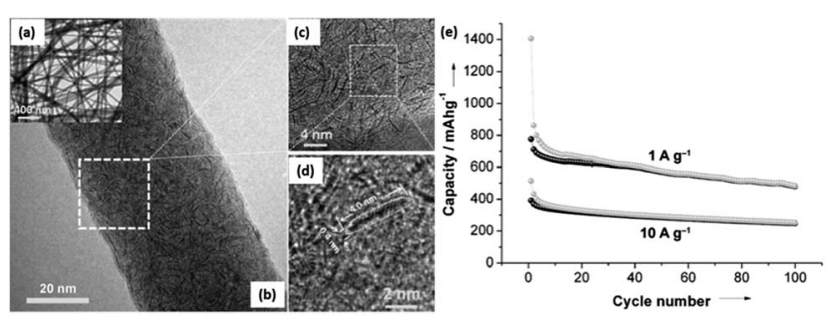

Fig. 25 (a) TEM, and (b)-(d) HRTEM images of a $M_{0} S_{2}$ embedded in the carbon nanofiber; (e) cycling performance of the $\mathrm{MoS}_{2}$ /carbon composite. ${ }^{240}$ Copyright 2014 Wiley-VCH Verlag GmbH \& Co. KGaA, Weinheim. by the addition of FEC in the electrolyte. ${ }^{243} \mathrm{Yu}$ et al. also reported a $\mathrm{Sb}_{2} \mathrm{~S}_{3} /$ reduced graphene oxide composite with excellent cycling performance with the presence of FEC in the electrolyte. ${ }^{176}$

\subsection{Phosphorus and phosphides}

Recently, phosphorus has been found to have the highest capacity among all the anodes for NIBs. ${ }^{249,250}$ Based on the reaction: $\mathrm{P}+3 \mathrm{Na} \leftrightarrow \mathrm{Na}_{3} \mathrm{P}$, this material has a theoretical capacity of $2596 \mathrm{~mA} \mathrm{~h} \mathrm{~g}{ }^{-1}$. Also, a reversible capacity of up to 1800-1900 $\mathrm{mA} \mathrm{h} \mathrm{g}^{-1}$ has been achieved. In addition, most of the capacity is delivered below $0.8 \mathrm{~V} v$ s. $\mathrm{Na}^{+} / \mathrm{Na}$ (Fig. 26a), and thus it holds promise for the construction of high voltage NIBs. The reported initial coulombic efficiency could be as high as $87 \%$, and could even reach $99 \%$ for the third cycle. Although this may still not high enough for practical application, this initial efficiency is among the highest of all the sodium anode materials reported to date. These features make phosphorus very promising as an anode for high energy density NIBs. The disadvantages of this material similarly includes the poor cycling performance, which could be mainly due to the large volume change $(308 \%)$ induced by uptake/extraction of the large amount of sodium. Modification of the interface between the electrode and electrolyte, such as by using an FEC additive, may also benefit the cycling performance. ${ }^{250}$

$\mathrm{Sn}_{4} \mathrm{P}_{3}$ has also been reported to reversibly provide a capacity of higher than $800 \mathrm{~mA} \mathrm{~h} \mathrm{~g}^{-1}$. Most of the capacity was observed to be delivered at a low potential window, $<1.0 \mathrm{~V} v s$. $\mathrm{Na}^{+} / \mathrm{Na}$. It is interesting that the studies carried out by different groups showed different processes for the sodiation/desodiation of this material. ${ }^{225,251,252} \mathrm{Kim}$ et al. reported the formation of amorphous $\mathrm{Na}_{x} \mathrm{P}$ and nanocrystalline $\mathrm{Na}_{15} \mathrm{Sn}_{4}$ after discharging to $0.01 \mathrm{~V} v s . \mathrm{Na}^{+/} \mathrm{Na}$. The subsequent charging process resulted in a gradual re-formation of $\mathrm{Sn}_{4} \mathrm{P}_{3}$, as monitored by XRD. ${ }^{251}$ However, while the formation of $\mathrm{Na}_{15} \mathrm{Sn}_{4}$ was confirmed after sodiation by Qian et al., they only found amorphous products during the subsequent desodiation. ${ }^{252}$ Further studies are needed to understand the mechanisms involved. This material also has a disadvantage of a large volume change during discharge/charge, and thus a poor cycling performance without modifications being carried out (Fig. 26b). Additionally another
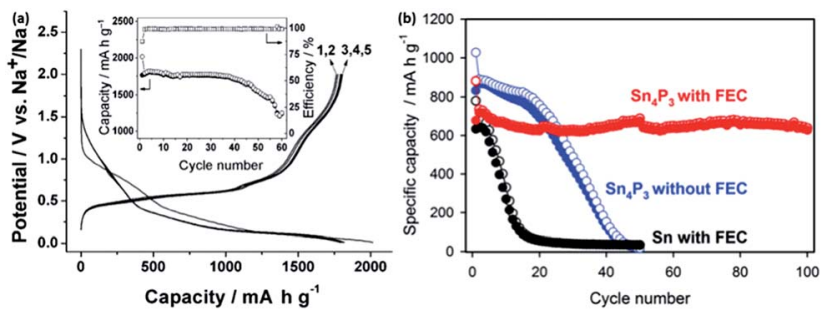

Fig. 26 (a) Charge/discharge curves of an amorphous phosphorus at a current density of $250 \mathrm{~mA} \mathrm{~g}^{-1}$; inset shows the cycling performance. ${ }^{250}$ (b) Comparison of the cycling performance of $\mathrm{Sn}_{4} \mathrm{P}_{3}$ and $\mathrm{Sn}$, with and without FEC. ${ }^{251}$ (a) Copyright 2013 Wiley-VCH Verlag GmbH \& Co. KGaA, Weinheim. (b) Copyright 2014 Wiley-VCH Verlag GmbH \& Co. KGaA, Weinheim. 
phosphide, $\mathrm{NiP}_{3}$, was also reported as an anode for NIBs, as it has a reversible capacity of larger than $1000 \mathrm{~mA} \mathrm{~h} \mathrm{~g}{ }^{-1} .{ }^{253}$

\subsection{Organic compounds}

Similarly, organic compounds have also been studied as prospective anode materials in NIBs. They bring higher structure flexibility and a cheaper cost, as well as an open structure for better structure kinetics. The use of disodium terephthalate $\left(\mathrm{Na}_{2} \mathrm{C}_{8} \mathrm{H}_{4} \mathrm{O}_{4}\right)$ was first demonstrated by Zhao et al. ${ }^{254}$ The anode was prepared via a ball milling method with commercially available $\mathrm{Na}_{2} \mathrm{C}_{8} \mathrm{H}_{4} \mathrm{O}_{4}$ and Ketjen black. The galvanostatic profile showed a flat-discharge plateau at $0.29 \mathrm{~V} v s$. $\mathrm{Na}^{+} / \mathrm{Na}$, with a reversible capacity of $250 \mathrm{~mA} \mathrm{~h} \mathrm{~g}^{-1}$. It was also reported that by providing an $\mathrm{Al}_{2} \mathrm{O}_{3}$ coating on the surface of $\mathrm{Na}_{2} \mathrm{C}_{8} \mathrm{H}_{4} \mathrm{O}_{4}$, the electrochemical storage and cycling performance could be improved. Park et al. also prepared $\mathrm{Na}_{2} \mathrm{C}_{8} \mathrm{H}_{4} \mathrm{O}_{4}$ using a facile wet chemistry method, as shown in Fig. 27a. When tested within a potential window from $0.0-2.0 \mathrm{~V} v s . \mathrm{Na}^{+} / \mathrm{Na}$, an initial capacity of approximately $500 \mathrm{~mA} \mathrm{~h} \mathrm{~g}{ }^{-1}$ was obtained, which subsequently dropped to $300 \mathrm{~mA} \mathrm{~h} \mathrm{~g}^{-1}$ (Fig. 27b). An ideal intercalation potential of $0.29 \mathrm{~V}$ was also observed from the $2^{\text {nd }}$ cycle onwards. This not only prevents the formation of dendrites, but could also provide for a high energy density when assembled in a full cell. The mechanism for the charge storage is via the stabilized conjugated structure between the carbonyl and phenyl groups. However, it worth noting that a high percentage of Super P (37.5\%) was used, due to the insulative nature of the organic compounds. ${ }^{255}$ Abouimrane probed into several sodium-based carboxylate molecules, as well as $3.6 \mathrm{~V}$ sodiumbased full cells that could operate at room temperature. Nonetheless, the $1^{\text {st }}$ cycle efficiency has to be improved before commercialization could be considered. ${ }^{256}$ Novel polymeric Schiff bases were also reported to be active for sodium storage. These compounds consist of two redox active Schiff base groups $(-\mathrm{N}=\mathrm{CH}-\mathrm{Ar}-\mathrm{HC}=\mathrm{N}-)$, and they were synthesized from a onestep polycondensation method between non-conjugated aliphatic/conjugated aromatic diamine blocks with a

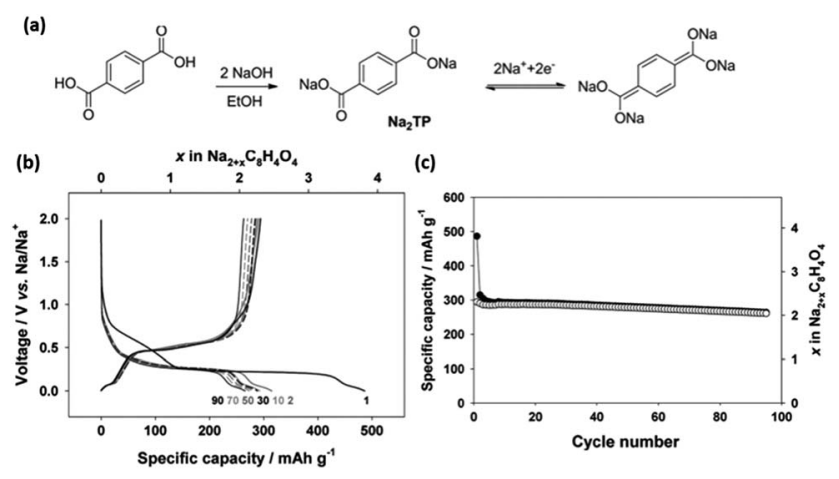

Fig. 27 (a) Schematic of the synthesis of sodium terephthalate as an organic anode material, as well as the reversible $\mathrm{Na}$ insertion/deinsertion mechanism. (b) Electrochemical charge-discharge voltage profile of sodium terephthalate at different cycles@30 $\mathrm{mA} \mathrm{g}^{-1}$ (c) cycling performance of sodium terephthalate(a $30 \mathrm{~mA} \mathrm{~g}^{-1}$ (ref. 255). Copyright 2012 Wiley-VCH Verlag GmbH \& Co. KGaA, Weinheim. terephthalaldehyde unit. NaFSI in methyltetrahydrofuran (MeTHF) was employed as the electrolyte and a maximum capacity of $350 \mathrm{~mA} \mathrm{~h} \mathrm{~g}{ }^{-1}$ could be achieved at a rate of $C / 10{ }^{257} 4,4^{\prime}-$ Biphenyldicarboxylate (BPDC) sodium coordinated compounds of different crystal structures were studied by Choi $e t$ al. A full discharge yields a capacity of about $200 \mathrm{~mA} \mathrm{~h} \mathrm{~g}^{-1}$, with a voltage plateau at $0.5 \mathrm{~V} v s$. $\mathrm{Na}^{+} / \mathrm{Na}$. However, despite the high cycling stability and rate performance, the amount of conductive additive added was still very high $(\sim 28.6 \%)$, which is undesirable in practical devices. ${ }^{140}$

\section{Summary and perspectives}

The development of energy storage devices has been ongoing for over 200 years. However, the performance of such devices constantly falls back on the increasing expectations and demands of the consumers. Reliability and safety are key factors that primarily determine the commercialization of batteries. As demand continues to rise, controversial debates have arisen in today's context on the limited availability of lithium reserves, which has encouraged researchers to investigate more appealing alternatives such as sodium. The key motivation for research on room-temperature sodium-based systems ultimately falls on the lower cost per unit energy that the device can provide. However, such technology is not new and review articles could be found even from the early 1980s. Nevertheless, despite the similar chemical properties of $\mathrm{Li}$ and $\mathrm{Na}$, the performance of sodium-based devices described in this review requires further improvement and is still far from commercialization requirements.

A wide variety of potential cathode materials, including layered oxides $\left(\mathrm{NaMO}_{2}\right.$, where $\mathrm{M}=\mathrm{Fe}, \mathrm{Ni}, \mathrm{Co}, \mathrm{Mn}$ and etc.); phosphates $\left(\mathrm{NaMPO}_{4}\right.$, where $\mathrm{M}=\mathrm{Fe}, \mathrm{Co}, \mathrm{Ni}, \mathrm{Mn}$ and etc.); pyrophosphates $\left(\mathrm{Na}_{2} \mathrm{MP}_{2} \mathrm{O}_{7}\right.$, where $\mathrm{M}=\mathrm{Fe}, \mathrm{Mn}$ and $\left.\mathrm{Co}\right)$; NASICON-based fluorophosphates $\left(\mathrm{Na}_{3} \mathrm{~V}_{2} \mathrm{PO}_{4} \mathrm{~F}\right)$; organic compounds and sulphates have been covered in this review. In general, sodium cathodes with a similar structure to their lithium analogues have shown lower operating potentials compared to their lithium counterparts, indicating the reduction of energy density. As was mentioned by Tarascon, the energy density in rechargeable batteries has been largely limited to date by the performance of the cathode material, in which doubling the cathode's specific capacity would lead to a $57 \%$ increment in energy density. ${ }^{258}$

Several ways to improve cathode performance have already been demonstrated, including having multiple active redox couples within a simple compound and the tailoring of the polyanionic group (in phosphates and sulfates). Partial substitution of metal oxides (e.g. P2-, O3- $\mathrm{Na}_{x} \mathrm{Fe}_{1 / 3} \mathrm{Mn}_{2 / 3} \mathrm{O}_{2}$, $\left.\mathrm{NaFe}_{1 / 3} \mathrm{Mn}_{1 / 2} \mathrm{Ti}_{1 / 6} \mathrm{O}_{2}, \mathrm{NaFe}_{1 / 2} \mathrm{Co}_{1 / 2}, \mathrm{NaNi}_{1 / 2} \mathrm{Mn}_{1 / 2} \mathrm{O}_{2}\right)$ has been observed to be a popular trend in resolving problems, compared to their primary form. For example, the issue of iron migration at high voltages in $\mathrm{P} 2-\mathrm{NaFeO}_{2}$ and the poor reversibility in $\mathrm{P} 2-$ $\mathrm{Na}_{x} \mathrm{Fe}_{1 / 3} \mathrm{Mn}_{2 / 3} \mathrm{O}_{2}$ during cycling was effectively suppressed in $\mathrm{NaFe}_{1 / 3} \mathrm{Mn}_{1 / 2} \mathrm{Ti}_{1 / 6} \mathrm{O}_{2}$ due to the synergistic effects from partial substitution of $\mathrm{Mn}$ and $\mathrm{Ti}$, respectively. Furthermore, despite $\mathrm{Na}$ and Li having similar properties, similar crystal analogues in 
respective systems have shown contrasting performances. It is well elaborated that the periodic arrangement of the atoms/ molecules are responsible for the nature of sodium-ion storage within the structure of the material. As shown in $\mathrm{NaCoO}_{2}$, the larger interslab distances provide a reduced diffusion energy barrier compared to its lithium counterpart, which could help overcome the sluggish kinetics of the larger-sized $\mathrm{Na}$ ions. One other example would be $\mathrm{NaCrO}_{2} v s$. $\mathrm{LiCrO}_{2}$, where the former is more electrochemically active compared to the latter. Other cathodic compounds, such as $\mathrm{MnO}_{2}, \mathrm{~V}_{2} \mathrm{O}_{5}$ and $\mathrm{FeF}_{3}$, have shown promising electrochemical performances; however, full cell practically is largely limited due to the additional presodiation step required. Their pre-sodiated compounds, i.e. $\mathrm{Na}_{0.44} \mathrm{MnO}_{2}, \mathrm{NaV}_{6} \mathrm{O}_{15}, \mathrm{NaV}_{3} \mathrm{O}_{8}, \mathrm{NaFeF}_{3}$, despite having a lower specific capacity, are more practical, when it comes to commercialization.

Additionally, the sodium storage mechanism and capability depends to a large extent on the crystal structure of the material. $A b$ initio calculations with a fundamental understanding of the crystal structure should provide interesting guidelines to understanding and designing more efficient electrodes and batteries. Comparisons between amorphous and crystalline materials might prove to be an interesting area, considering that amorphous $\mathrm{V}_{2} \mathrm{O}_{5}$ was able to outperform nanocrystlline $\mathrm{V}_{2} \mathrm{O}_{5}$. However, the charge storage mechanism of such amorphous materials is still vague and is leaning more towards a pseudocapacitive behaviour instead.

Comparatively, polyanionic materials appear to be a much better choice, as they benefit from the inductive effect from the $\mathrm{PO}_{4}{ }^{3-}$ group, which raises the intercalation redox potential and also the energy density of the system. Similar inductive effects were also observed in sulfate-based compounds, suggesting room for tailoring the redox potential in order to maximize the overall energy density. Novel compounds, including fluorophosphates, pryophosphates and co-pyrophosphate-polyanionic compounds, have also been explored; however, their use is limited by the low capacity they provide. Different synthesis techniques could also be explored in order to improve the electrochemical performance of the material via rational design. For instance, $\mathrm{Na}_{2} \mathrm{FePO}_{4} \mathrm{~F} / \mathrm{C}$ hollow particles prepared from spray pyrolysis were able to cycle for a longer period compared to $\mathrm{Na}_{2} \mathrm{FePO}_{4} \mathrm{~F} / \mathrm{C}$ prepared via a solid-state synthesis. New directions should be looked into for developing stable and high potential redox couple materials in order to narrow the gap between LIBs and NIBs. Nonetheless, fundamental questions regarding differences in the thermodynamic and electrochemical properties of $\mathrm{Na}$ analogues as opposed to Li-based structures have yet to be answered. Organic compounds (e.g. $\left.\mathrm{Na}_{4} \mathrm{DHTPA}, \mathrm{PTCDA}\right)$ and sulphates $\left(\mathrm{Na}_{2} \mathrm{Fe}_{2}\left(\mathrm{SO}_{4}\right)_{3}\right)$ have proven to be greener alternatives, due to the use of cheaper and more abundant biomass elements. ${ }^{259}$ In the organic compounds category, despite the high specific capacity they are able to provide, the operating potential of such materials remain too low ( $\sim 1.7$ to $1.9 \mathrm{~V} v s . \mathrm{Na}^{+} / \mathrm{Na}$ ). By tuning the different electron withdrawing aromatic groups in the polyimides, the overall energy level of the compounds can be varied. Further improvements to develop better materials will heavily rely on an intersection of knowledge between the fields of organic chemistry and electrochemistry.

As for anode materials, carbonaceous materials appear to be the most cost-effective candidates, although they possess relatively low capacity. Their cyclability has been significantly improved over the past years; however, challenges still remain with these materials, especially in terms of the low initial coulombic efficiency. Additionally, the low voltage plateau $(\sim 0.1 \mathrm{~V})$ is a safety concern for sodium plating, especially when subjected to tests under high current rates. Other oxides undergoing conversion reactions, e.g. $\mathrm{CuO}$, and materials undergoing alloying reactions, e.g. $\mathrm{Sn}, \mathrm{Sb}, \mathrm{Pb}$ and $\mathrm{Ge}$, have shown very high specific capacity, but are unsuitable for long-term cycling operations, due to their large volume change during sodiation and desodiation processes. The recent development in sulfides, organic compounds, and phosphorus-based materials also provides the possibility for use in high-capacity anodes. Nonetheless, all of these materials suffer from a relatively low initial coulombic efficiency and/or poor cyclability. We believe that a tailored design to suit the large volume expansion is necessary to meet the shortcomings of these materials. In addition, for oxides and sulfides based on conversion reactions, a large potential hysteresis is one of their main drawbacks. A fundamental understanding on the low reversibility and the formation of SEI layers, which together result in the low coulombic efficiency, and on the large hysteresis is significantly lacking, and is essential for future commercialization. Very few of the anode materials that have been investigated so far have shown initial C.E. that are $>80 \%$. For practical application, probably $>90 \%$ is needed according to commercial LIB anode standards. Interestingly, $\mathrm{P} 2-\mathrm{Na}_{0.66}\left[\mathrm{Li}_{0.22} \mathrm{Ti}_{0.78}\right] \mathrm{O}_{2}$ showed an excellent performance in terms of rate capability and cycling life, owing to the quasi-single phase transformation and minimal volume change during cycling. Such a zero-strain material is also seen in spinel $\mathrm{Li}_{4} \mathrm{Ti}_{5} \mathrm{O}_{12}$ that is used as an anode in LIBs and could be exploited for the further development of electrodes in NIBs. These parameters are crucial for the development and commercialization of cheap, large-scale efficient energy storage devices.

Mixed transition metal oxides (MTMO) (designated as $\mathrm{A}_{x^{-}}$ $\mathrm{B}_{3-x} \mathrm{O}_{4}$, where $\mathrm{A}, \mathrm{B}=\mathrm{Co}, \mathrm{Ni}, \mathrm{Fe}$, etc.) have received a tremendous amount of success as anodes in LIB technology, but up until now, only $\mathrm{NiCo}_{2} \mathrm{O}_{4}$ has been reported. We believe that an in-depth understanding, in terms of the conversion process of these oxides in sodium-based systems, is necessary.

Although the chemistry of electrolytes was not covered in detail in this review, optimization of the salts and solvents for several examples were briefly discussed. While the use of $\mathrm{NaClO}_{4}$ salt is widespread, other salts, such as NaFSI, $\mathrm{NaBF}_{4}$, $\mathrm{NaPF}_{6}$, have been explored as well. The electrochemical performance of NaFSI appears to be promising, but further work has to be done to understand the mechanism for improvement. To improve their cyclability, advanced material/electrode design and modification of the interface between the electrode and electrolyte are required. Different passivation chemistries at the interface compared to LIBs, could also be another factor resulting in the low coulombic efficiency of the electrode 
materials. The addition of FEC additives has found immense success in stabilizing the passivation layer, and has resulted in improved cyclability and electrochemical performances. However, despite the success, the high cost of such additives is counter-objective for when developing cheap alternative sodium-based electrochemical energy storage. Therefore, one must look for other alternatives/additives to improve the cycling and electrochemical performance in the overall system. Nonetheless, this is easier said than done.

All in all, the progress of sodium-based electrochemical devices is still in its infancy. The end application of such technology has not been clearly defined yet. However, we can be sure that this technology will be employed in applications where weight is of no concern. One such example could be for largescale grid energy storage, where the source of energy comes from intermittent sources such as wind, tidal and solar. Much work has to be done to improve the performance matrix of such systems, mainly in energy and power density, cyclability, thermal stability, coulombic efficiency, cost, etc. Most of these issues could be addressed with better design of materials, e.g. carbon coating, nanosizing, doping and etc., while using only earth abundant resources as precursors for materials. We are confident that the development of low cost, large-scale and long-lasting sodium-based electrochemical devices would be an interesting route and that they will be able to compete with lithium-based systems in the long run, especially in the fields where both high performance and low-cost storage systems are required.

\section{Acknowledgements}

This work is supported by Tier 1 grants of Singapore Ministry of Education (RGT8/13, RG131/14, \& RG13/13) and the Singapore National Research Foundation under its Campus for Research Excellence And Technological Enterprise (CREATE) programme.

\section{Notes and references}

1 J.-M. Tarascon and M. Armand, Nature, 2001, 414, 359-367. 2 A. S. Arico, P. Bruce, B. Scrosati, J.-M. Tarascon and W. van Schalkwijk, Nat. Mater., 2005, 4, 366-377.

3 C. Liu, F. Li, L.-P. Ma and H.-M. Cheng, Adv. Mater., 2010, 22, E28-E62.

4 W. H. Meyer, Adv. Mater., 1998, 10, 439-448.

5 Y. Sun, Q. Wu and G. Shi, Energy Environ. Sci., 2011, 4, 11131132.

6 H. Li, Z. Wang, L. Chen and X. Huang, Adv. Mater., 2009, 21, 4593-4607.

7 V. Etacheri, R. Marom, R. Elazari, G. Salitra and D. Aurbach, Energy Environ. Sci., 2011, 4, 3243-3262.

8 J. Cabana, L. Monconduit, D. Larcher and M. Rosa Palacin, Adv. Mater., 2010, 22, E170-E192.

9 J. W. Fergus, J. Power Sources, 2010, 195, 939-954.

10 S. Flandrois and B. Simon, Carbon, 1999, 37, 165-180.

11 L. Ji, Z. Lin, M. Alcoutlabi and X. Zhang, Energy Environ. Sci., 2011, 4, 2682-2699.
12 L. P. Wang, L. Yu, R. Satish, J. Zhu, Q. Yan, M. Srinivasan and Z. Xu, RSC Adv., 2014, 4, 37389-37394.

13 S.-W. Kim, D.-H. Seo, X. Ma, G. Ceder and K. Kang, Adv. Energy Mater., 2012, 2, 710-721.

14 M. D. Slater, D. Kim, E. Lee and C. S. Johnson, Adv. Funct. Mater., 2013, 23, 947-958.

15 V. Palomares, P. Serras, I. Villaluenga, K. B. Hueso, J. Carretero-Gonzalez and T. Rojo, Energy Environ. Sci., 2012, 5, 5884-5901.

16 T. L. Site, http://www.lithiumsite.com/market.html, August 2014.

17 S. Y. Hong, Y. Kim, Y. Park, A. Choi, N.-S. Choi and K. T. Lee, Energy Environ. Sci., 2013, 6, 2067-2081.

18 K. B. Hueso, M. Armand and T. Rojo, Energy Environ. Sci., 2013, 6, 734-749.

19 B. L. Ellis and L. F. Nazar, Curr. Opin. Solid State Mater. Sci., 2012, 16, 168-177.

20 C.-X. Zu and H. Li, Energy Environ. Sci., 2011, 4, 2614-2624.

21 T. Nagaura and K. Tozawa, Prog. Batteries Sol. Cells, 1990, 9, 209-213.

22 Y. Nishi, Chem. Rec., 2001, 1, 406-413.

23 S. P. Ong, V. L. Chevrier, G. Hautier, A. Jain, C. Moore, S. Kim, X. Ma and G. Ceder, Energy Environ. Sci., 2011, 4, 3680-3688.

24 H. Huang, S. C. Yin, T. Kerr, N. Taylor and L. F. Nazar, Adv. Mater., 2002, 14, 1525-1528.

25 M. M. Ren, Z. Zhou, X. P. Gao, W. X. Peng and J. P. Wei, J. Phys. Chem. C, 2008, 112, 5689-5693.

26 W. Song, X. Ji, Z. Wu, Y. Zhu, Y. Yao, K. Huangfu, Q. Chen and C. E. Banks, J. Mater. Chem. A, 2014, 2, 2571-2577.

27 W. Song, X. Ji, Y. Yao, H. Zhu, Q. Chen, Q. Sun and C. E. Banks, Phys. Chem. Chem. Phys., 2014, 16, 3055-3061.

28 B. L. Ellis, T. N. Ramesh, W. N. Rowan-Weetaluktuk, D. H. Ryan and L. F. Nazar, J. Mater. Chem., 2012, 22, 4759-4766.

29 H. Kim, I. Park, D.-H. Seo, S. Lee, S.-W. Kim, W. J. Kwon, Y.-U. Park, C. S. Kim, S. Jeon and K. Kang, J. Am. Chem. Soc., 2012, 134, 10369-10372.

30 N. R. Khasanova, O. A. Drozhzhin, D. A. Storozhilova, C. Delmas and E. V. Antipov, Chem. Mater., 2012, 24, 4271-4273.

31 S. Y. Hong, Y. Kim, Y. Park, A. Choi, N. S. Choi and K. T. Lee, Energy Environ. Sci., 2013, 6, 2067-2081.

32 K. Kubota, N. Yabuuchi, H. Yoshida, M. Dahbi and S. Komaba, MRS Bull., 2014, 39, 416-422.

33 M. H. Han, E. Gonzalo, G. Singh and T. Rojo, Energy Environ. Sci., 2015, 8, 81-102.

34 M. Dahbi, N. Yabuuchi, K. Kubota, K. Tokiwa and S. Komaba, Phys. Chem. Chem. Phys., 2014, 16, 1500715028.

35 V. Palomares, M. Casas-Cabanas, E. Castillo-Martinez, M. H. Han and T. Rojo, Energy Environ. Sci., 2013, 6, 2312-2337.

36 A. Ponrouch, D. Monti, A. Boschin, B. Steen, P. Johansson and M. R. Palacin, J. Mater. Chem. A, 2015, 3, 22-42.

37 N. Yabuuchi, K. Kubota, M. Dahbi and S. Komaba, Chem. Rev., 2014, 114, 11636-11682. 
38 Y. Kim, K.-H. Ha, S. M. Oh and K. T. Lee, Chem.-Eur. J., 2014, 20, 11980-11992.

39 H. Pan, Y.-S. Hu and L. Chen, Energy Environ. Sci., 2013, 6, 2338-2360.

40 M. S. Islam and C. A. J. Fisher, Chem. Soc. Rev., 2014, 43, 185-204.

41 C. F. Delmas and P. Hagenmuller, Physica $B+C, 1980,99$, 81-85.

42 J.-J. Braconnier, C. Delmas, C. Fouassier and P. Hagenmuller, Mater. Res. Bull., 1980, 15, 1797-1804.

43 C. Fouassier, G. Matejka, J.-M. Reau and P. Hagenmuller, J. Solid State Chem., 1973, 6, 532-537.

44 G. J. Shu and F. C. Chou, Phys. Rev. B: Condens. Matter Mater. Phys., 2008, 78, 052101.

45 Q. Huang, M. L. Foo, R. A. Pascal, J. W. Lynn, B. H. Toby, T. He, H. W. Zandbergen and R. J. Cava, Phys. Rev. B: Condens. Matter Mater. Phys., 2004, 70, 184110.

46 J. B. Goodenough and Y. Kim, Chem. Mater., 2009, 22, 587603.

47 B. L. Ellis, K. T. Lee and L. F. Nazar, Chem. Mater., 2010, 22, 691-714.

48 C. Delmas, J.-J. Braconnier, C. Fouassier and P. Hagenmuller, Solid State Ionics, 1981, 3-4, 165-169.

49 J. Molenda, C. Delmas and P. Hagenmuller, Solid State Ionics, 1983, 9-10, 431-435.

50 T. Shibata, W. Kobayashi and Y. Moritomo, Appl. Phys. Express, 2013, 6, 097101.

51 H. Xia, L. Lu and G. Ceder, J. Power Sources, 2006, 159, 1422-1427.

52 J.-H. Cheng, C.-J. Pan, J.-F. Lee, J.-M. Chen, M. Guignard, C. Delmas, D. Carlier and B.-J. Hwang, Chem. Mater., 2013, 26, 1219-1225.

53 D. Carlier, J. H. Cheng, R. Berthelot, M. Guignard, M. Yoncheva, R. Stoyanova, B. J. Hwang and C. Delmas, Dalton Trans., 2011, 40, 9306-9312.

$54 \mathrm{H}$. Yoshida, N. Yabuuchi and S. Komaba, Electrochem. Commun., 2013, 34, 60-63.

55 N. Yabuuchi, M. Kajiyama, J. Iwatate, H. Nishikawa, S. Hitomi, R. Okuyama, R. Usui, Y. Yamada and S. Komaba, Nat. Mater., 2012, 11, 512-517.

56 N. Yabuuchi, H. Yoshida and S. Komaba, Electrochemistry, 2012, 80, 716-719.

57 S. Kim, X. Ma, S. P. Ong and G. Ceder, Phys. Chem. Chem. Phys., 2012, 14, 15571-15578.

58 H. Yoshida, N. Yabuuchi, K. Kubota, I. Ikeuchi, A. Garsuch, M. Schulz-Dobrick and S. Komaba, Chem. Commun., 2014, 50, 3677-3680.

59 M. H. Han, E. Gonzalo, M. Casas-Cabanas and T. Rojo, J. Power Sources, 2014, 258, 266-271.

60 P. Vassilaras, X. Ma, X. Li and G. Ceder, J. Electrochem. Soc., 2013, 160, A207-A211.

61 I. Hasa, D. Buchholz, S. Passerini, B. Scrosati and J. Hassoun, Adv. Energy Mater., 2014, 4, 1400083.

62 D. Kim, E. Lee, M. Slater, W. Lu, S. Rood and C. S. Johnson, Electrochem. Commun., 2012, 18, 66-69.

63 X. Li, D. Wu, Y.-N. Zhou, L. Liu, X.-Q. Yang and G. Ceder, Electrochem. Commun., 2014, 49, 51-54.
64 H. Y.-S. Mu Lin-Qin and C. Li-Quan, Chin. Phys. B, 2015, 24, 38202-038202.

65 S.-Y. Xu, X.-Y. Wu, Y.-M. Li, Y.-S. Hu and L.-Q. Chen, Chin. Phys. B, 2014, 23, 118202.

66 Y. Ono, Y. Yui, M. Hayashi, K. Asakura, H. Kitabayashi and K. I. Takahashi, ECS Trans., 2014, 58, 33-39.

67 S. Komaba, C. Takei, T. Nakayama, A. Ogata and N. Yabuuchi, Electrochem.Commun., 2010, 12, 355-358.

68 C.-Y. Chen, K. Matsumoto, T. Nohira, R. Hagiwara, A. Fukunaga, S. Sakai, K. Nitta and S. Inazawa, J. Power Sources, 2013, 237, 52-57.

69 S. Komaba, T. Nakayama, A. Ogata, T. Shimizu, C. Takei, S. Takada, A. Hokura and I. Nakai, ECS Trans., 2009, 16, 43-55.

70 J.-J. Ding, Y.-N. Zhou, Q. Sun and Z.-W. Fu, Electrochem. Commun., 2012, 22, 85-88.

71 D. A. Tompsett and M. S. Islam, Chem. Mater., 2013, 25, 2515-2526.

72 D. Su, H.-J. Ahn and G. Wang, J. Mater. Chem. A, 2013, 1, 4845-4850.

73 J. M. Tarascon, D. G. Guyomard, B. Wilkens, W. R. Mc Kinnon and P. Barboux, Solid State Ionics, 1992, 57, 113120.

74 F. Sauvage, L. Laffont, J. M. Tarascon and E. Baudrin, Inorg. Chem., 2007, 46, 3289-3294.

75 H. Kim, D. J. Kim, D.-H. Seo, M. S. Yeom, K. Kang, D. K. Kim and Y. Jung, Chem. Mater., 2012, 24, 1205-1211.

76 Y. Cao, L. Xiao, W. Wang, D. Choi, Z. Nie, J. Yu, L. V. Saraf, Z. Yang and J. Liu, Adv. Mater., 2011, 23, 3155-3160.

77 L. Su, J. Winnick and P. Kohl, J. Power Sources, 2001, 101, 226-230.

78 P. E. Tang, J. S. Sakamoto, E. Baudrin and B. Dunn, J. NonCryst. Solids, 2004, 350, 67-72.

79 J.-C. Badot and N. Baffier, J. Mater. Chem., 1992, 2, 11671174.

80 S. Tepavcevic, H. Xiong, V. R. Stamenkovic, X. Zuo, M. Balasubramanian, V. B. Prakapenka, C. S. Johnson and T. Rajh, ACS Nano, 2011, 6, 530-538.

81 D. Su and G. Wang, ACS Nano, 2013, 7, 11218-11226.

82 D. W. Su, S. X. Dou and G. X. Wang, J. Mater. Chem. A, 2014, 2, 11185-11194.

83 V. Raju, J. Rains, C. Gates, W. Luo, X. Wang, W. F. Stickle, G. D. Stucky and X. Ji, Nano Lett., 2014, 14, 4119-4124.

84 E. Uchaker, Y. Z. Zheng, S. Li, S. L. Candelaria, S. Hu and G. Z. Cao, J. Mater. Chem. A, 2014, 2, 18208-18214.

85 A. Maazaz, C. Delmas and P. Hagenmuller, J. Inclusion Phenom., 1983, 1, 45-51.

86 C. Didier, M. Guignard, C. Denage, O. Szajwaj, S. Ito, I. Saadoune, J. Darriet and C. Delmas, Electrochem. SolidState Lett., 2011, 14, A75-A78.

87 D. Hamani, M. Ati, J.-M. Tarascon and P. Rozier, Electrochem. Commun., 2011, 13, 938-941.

88 M. Guignard, C. Didier, J. Darriet, P. Bordet, E. Elkaïm and C. Delmas, Nat. Mater., 2013, 12, 74-80.

89 H. Wang, W. Wang, Y. Ren, K. Huang and S. Liu, J. Power Sources, 2012, 199, 263-269. 
90 H. He, G. Jin, H. Wang, X. Huang, Z. Chen, D. Sun and Y. Tang, J. Mater. Chem. A, 2014, 2, 3563-3570.

91 H. Wang, S. Liu, Y. Ren, W. Wang and A. Tang, Energy Environ. Sci., 2012, 5, 6173-6179.

92 H. Liu, H. Zhou, L. Chen, Z. Tang and W. Yang, J. Power Sources, 2011, 196, 814-819.

93 H. He, X. Zeng, H. Wang, N. Chen, D. Sun, Y. Tang, X. Huang and Y. Pan, J. Electrochem. Soc., 2015, 162, A39A43.

94 A. K. Padhi, K. S. Nanjundaswamy, C. Masquelier and J. B. Goodenough, J. Electrochem. Soc., 1997, 144, 25812586.

95 A. K. Padhi, K. S. Nanjundaswamy and J. B. Goodenough, J. Electrochem. Soc., 1997, 144, 1188-1194.

96 A. K. Padhi, K. S. Nanjundaswamy, C. Masquelier, S. Okada and J. B. Goodenough, J. Electrochem. Soc., 1997, 144, 16091613.

97 K. Zaghib, J. Trottier, P. Hovington, F. Brochu, A. Guerfi, A. Mauger and C. M. Julien, J. Power Sources, 2011, 196, 9612-9617.

98 P. Moreau, D. Guyomard, J. Gaubicher and F. Boucher, Chem. Mater., 2010, 22, 4126-4128.

99 M. Casas-Cabanas, V. V. Roddatis, D. Saurel, P. Kubiak, J. Carretero-Gonzalez, V. Palomares, P. Serras and T. Rojo, J. Mater. Chem., 2012, 22, 17421-17423.

100 S.-M. Oh, S.-T. Myung, J. Hassoun, B. Scrosati and Y.-K. Sun, Electrochem. Commun., 2012, 22, 149-152.

101 B. L. Ellis, W. R. M. Makahnouk, Y. Makimura, K. Toghill and L. F. Nazar, Nat. Mater., 2007, 6, 749-753.

102 N. Recham, J.-N. Chotard, L. Dupont, K. Djellab, M. Armand and J.-M. Tarascon, J. Electrochem. Soc., 2009, 156, A993-A999.

103 A. Langrock, Y. Xu, Y. Liu, S. Ehrman, A. Manivannan and C. Wang, J. Power Sources, 2013, 223, 62-67.

104 J. Barker, M. Y. Saidi and J. L. Swoyer, Electrochem. SolidState Lett., 2003, 6, A1-A4.

105 Y.-U. Park, D.-H. Seo, H.-S. Kwon, B. Kim, J. Kim, H. Kim, I. Kim, H.-I. Yoo and K. Kang, J. Am. Chem. Soc., 2013, 135, 13870-13878.

106 Y.-U. Park, D.-H. Seo, B. Kim, K.-P. Hong, H. Kim, S. Lee, R. A. Shakoor, K. Miyasaka, J.-M. Tarascon and K. Kang, Sci. Rep., 2012, 2, 704.

107 G. Li, D. Jiang, H. Wang, X. Lan, H. Zhong and Y. Jiang, J. Power Sources, 2014, 265, 325-334.

108 C. Delmas, A. Nadiri and J. L. Soubeyroux, Solid State Ionics, 1988, 28-30, 419-423.

109 Z. Jian, L. Zhao, H. Pan, Y.-S. Hu, H. Li, W. Chen and L. Chen, Electrochem. Commun., 2012, 14, 86-89.

110 Z. Jian, W. Han, X. Lu, H. Yang, Y.-S. Hu, J. Zhou, Z. Zhou, J. Li, W. Chen, D. Chen and L. Chen, Adv. Energy Mater., 2013, 3, 156-160.

111 Z. Jian, C. Yuan, W. Han, X. Lu, L. Gu, X. Xi, Y.-S. Hu, H. Li, W. Chen, D. Chen, Y. Ikuhara and L. Chen, Adv. Funct. Mater., 2014, 24, 4265-4272.

112 H. Kim, I. Park, S. Lee, H. Kim, K.-Y. Park, Y.-U. Park, H. Kim, J. Kim, H.-D. Lim, W.-S. Yoon and K. Kang, Chem. Mater., 2013, 25, 3614-3622.
113 P. Barpanda, G. Rousse, T. Ye, C. D. Ling, Z. Mohamed, Y. Klein and A. Yamada, Inorg. Chem., 2013, 52, 3334-3341.

114 J. Du, L. Jiao, Q. Wu, Y. Liu, Y. Zhao, L. Guo, Y. Wang and H. Yuan, Electrochim. Acta, 2013, 103, 219-225.

115 P. Barpanda, T. Ye, S.-C. Chung, Y. Yamada, S.-i. Nishimura and A. Yamada, J. Mater. Chem., 2012, 22, 13455-13459.

116 T. Ye, P. Barpanda, S.-i. Nishimura, N. Furuta, S.-C. Chung and A. Yamada, Chem. Mater., 2013, 25, 3623-3629.

117 P. Barpanda, T. Ye, S.-i. Nishimura, S.-C. Chung, Y. Yamada, M. Okubo, H. Zhou and A. Yamada, Electrochem. Commun., 2012, 24, 116-119.

118 P. Barpanda, T. Ye, M. Avdeev, S.-C. Chung and A. Yamada, J. Mater. Chem. A, 2013, 1, 4194-4197.

119 P. Barpanda, J. Lu, T. Ye, M. Kajiyama, S.-C. Chung, N. Yabuuchi, S. Komaba and A. Yamada, RSC Adv., 2013, 3, 3857-3860.

120 I. Hasa, J. Hassoun, Y.-K. Sun and B. Scrosati, ChemPhysChem, 2014, 15, 2152-2155.

121 K. Sakaushi, E. Hosono, G. Nickerl, T. Gemming, H. Zhou, S. Kaskel and J. Eckert, Nat. Commun., 2013, 4, 1485.

122 S. Wang, L. Wang, Z. Zhu, Z. Hu, Q. Zhao and J. Chen, Angew. Chem., 2014, 126, 6002-6006.

123 X. Wu, W. Deng, J. Qian, Y. Cao, X. Ai and H. Yang, J. Mater. Chem. A, 2013, 1, 10130-10134.

124 C. D. Wessells, R. A. Huggins and Y. Cui, Nat. Commun., 2011, 2, 550.

125 H. Lee, Y.-I. Kim, J.-K. Park and J. W. Choi, Chem. Commun., 2012, 48, 8416-8418.

126 H.-W. Lee, R. Y. Wang, M. Pasta, S. Woo Lee, N. Liu and Y. Cui, Nat. Commun., 2014, 5, 5280.

127 L. Wang, Y. Lu, J. Liu, M. Xu, J. Cheng, D. Zhang and J. B. Goodenough, Angew. Chem., Int. Ed., 2013, 52, 19641967.

128 Y. You, X.-L. Wu, Y.-X. Yin and Y.-G. Guo, Energy Environ. Sci., 2014, 7, 1643-1647.

129 Y. Lu, L. Wang, J. Cheng and J. B. Goodenough, Chem. Commun., 2012, 48, 6544-6546.

130 P. Barpanda, G. Oyama, S.-i. Nishimura, S.-C. Chung and A. Yamada, Nat. Commun., 2014, 5, 4358.

131 A. S. Nagelberg and W. L. Worrell, J. Solid State Chem., 1979, 29, 345-354.

132 G. H. Newman and L. P. Klemann, J. Electrochem. Soc., 1980, 127, 2097-2099.

133 M. S. Whittingham, Prog. Solid State Chem., 1978, 12, 41-99. 134 K. M. Abraham, Solid State Ionics, 1982, 7, 199-212.

135 Y. Baba, S. Okada and J.-i. Yamaki, Solid State Ionics, 2002, 148, 311-316.

136 D. D. MacNeil and J. R. Dahn, J. Electrochem. Soc., 2002, 149, A912-A919.

137 F. Badway, F. Cosandey, N. Pereira and G. G. Amatucci, J. Electrochem. Soc., 2003, 150, A1318-A1327.

138 I. D. Gocheva, M. Nishijima, T. Doi, S. Okada, J.-i. Yamaki and T. Nishida, J. Power Sources, 2009, 187, 247-252.

139 Y. Yamada, T. Doi, I. Tanaka, S. Okada and J.-i. Yamaki, J. Power Sources, 2011, 196, 4837-4841.

140 A. Choi, Y. K. Kim, T. K. Kim, M.-S. Kwon, K. T. Lee and H. R. Moon, J. Mater. Chem. A, 2014, 2, 14986-14993. 
141 M. Nishijima, I. D. Gocheva, S. Okada, T. Doi, J.-i. Yamaki and T. Nishida, J. Power Sources, 2009, 190, 558-562.

142 D.-l. Ma, H.-g. Wang, Y. Li, D. Xu, S. Yuan, X.-l. Huang, X.-b. Zhang and Y. Zhang, Nano Energy, 2014, 10, 295-304.

143 Y. Shao, J. Xiao, W. Wang, M. Engelhard, X. Chen, Z. Nie, M. Gu, L. V. Saraf, G. Exarhos, J.-G. Zhang and J. Liu, Nano Lett., 2013, 13, 3909-3914.

144 P. G. Bruce, S. A. Freunberger, L. J. Hardwick and J.-M. Tarascon, Nat. Mater., 2012, 11, 19-29.

145 Y. Liu, F. Fan, J. Wang, Y. Liu, H. Chen, K. L. Jungjohann, Y. Xu, Y. Zhu, D. Bigio, T. Zhu and C. Wang, Nano Lett., 2014, 14, 3445-3452.

146 D. P. Divincenzo and E. J. Mele, Phys. Rev. B: Condens. Matter Mater. Phys., 1985, 32, 2538-2553.

147 Y. Maeda and S. Harada, Synth. Met., 1989, 31, 389-393.

148 D. A. Stevens and J. R. Dahn, J. Electrochem. Soc., 2000, 147, 4428-4431.

149 D. A. Stevens and J. R. Dahn, J. Electrochem. Soc., 2001, 148, A803-A811.

150 P. Thomas and D. Billaud, Electrochim. Acta, 2002, 47, 33033307.

151 D. A. Stevens and J. R. Dahn, J. Electrochem. Soc., 2000, 147, 1271-1273.

152 M. M. Doeff, Y. P. Ma, S. J. Visco and L. C. Dejonghe, J. Electrochem. Soc., 1993, 140, L169-L170.

153 R. Alcantara, J. M. Jimenez-Mateos, P. Lavela and J. L. Tirado, Electrochem. Commun., 2001, 3, 639-642.

154 R. Alcántara, P. Lavela, G. F. Ortiz and J. L. Tirado, Electrochem. Solid-State Lett., 2005, 8, A222-A225.

155 J. R. Dahn, T. Zheng, Y. H. Liu and J. S. Xue, Science, 1995, 270, 590-593.

156 K. Gotoh, T. Ishikawa, S. Shimadzu, N. Yabuuchi, S. Komaba, K. Takeda, A. Goto, K. Deguchi, S. Ohki, K. Hashi, T. Shimizu and H. Ishida, J. Power Sources, 2013, 225, 137-140.

157 K. Tang, R. J. White, X. Mu, M.-M. Titirici, P. A. van Aken and J. Maier, ChemSusChem, 2012, 5, 400-403.

158 K. Xu, Chem. Rev., 2004, 104, 4303-4417.

159 X. Xia, M. N. Obrovac and J. R. Dahn, Electrochem. SolidState Lett., 2011, 14, A130-A133.

160 X. Xia and J. R. Dahn, J. Electrochem. Soc., 2012, 159, A515A519.

161 J. Zhao, L. W. Zhao, K. Chihara, S. Okada, J. Yamaki, S. Matsumoto, S. Kuze and K. Nakane, J. Power Sources, 2013, 244, 752-757.

162 A. Ponrouch, E. Marchante, M. Courty, J. M. Tarascon and M. R. Palacin, Energy Environ. Sci., 2012, 5, 8572-8583.

163 S. Komaba, T. Ishikawa, N. Yabuuchi, W. Murata, A. Ito and Y. Ohsawa, ACS Appl. Mater. Interfaces, 2011, 3, 4165-4168.

164 S. Wenzel, T. Hara, J. Janek and P. Adelhelm, Energy Environ. Sci., 2011, 4, 3342-3345.

165 K. Tang, L. Fu, R. J. White, L. Yu, M.-M. Titirici, M. Antonietti and J. Maier, Adv. Energy Mater., 2012, 2, 873-877.

166 Y. Cao, L. Xiao, M. L. Sushko, W. Wang, B. Schwenzer, J. Xiao, Z. Nie, L. V. Saraf, Z. Yang and J. Liu, Nano Lett., 2012, 12, 3783-3787.
167 J. Ding, H. Wang, Z. Li, A. Kohandehghan, K. Cui, Z. Xu, B. Zahiri, X. Tan, E. M. Lotfabad, B. C. Olsen and D. Mitlin, ACS Nano, 2013, 7, 11004-11015.

168 Y. Yan, Y.-X. Yin, Y.-G. Guo and L.-J. Wan, Adv. Energy Mater., 2014, 4, 1301584.

169 E. M. Lotfabad, J. Ding, K. Cui, A. Kohandehghan, W. P. Kalisvaart, M. Hazelton and D. Mitlin, ACS Nano, 2014, 8, 7115-7129.

170 X. Zhou and Y.-G. Guo, ChemElectroChem, 2014, 1, 83-86.

171 Y. Li, S. Xu, X. Wu, J. Yu, Y. Wang, Y.-S. Hu, H. Li, L. Chen and X. Huang, J. Mater. Chem. A, 2015, 3, 71-77.

172 H.-g. Wang, Z. Wu, F.-l. Meng, D.-l. Ma, X.-l. Huang, L.-m. Wang and X.-b. Zhang, ChemSusChem, 2013, 6, 56-60.

173 L. Fu, K. Tang, K. Song, P. A. van Aken, Y. Yu and J. Maier, Nanoscale, 2014, 6, 1384-1389.

174 H. Song, N. Li, H. Cui and C. Wang, Nano Energy, 2014, 4, 81-87.

175 Z. Wang, L. Qie, L. Yuan, W. Zhang, X. Hu and Y. Huang, Carbon, 2013, 55, 328-334.

176 Y.-X. Wang, S.-L. Chou, H.-K. Liu and S.-X. Dou, Carbon, 2013, 57, 202-208.

177 Y. Matsuo and K. Ueda, J. Power Sources, 2014, 263, 158162.

178 D. Datta, J. Li and V. B. Shenoy, ACS Appl. Mater. Interfaces, 2014, 6, 1788-1795.

179 V. L. Chevrier and G. Ceder, J. Electrochem. Soc., 2011, 158, A1011-A1014.

180 S. Komaba, Y. Matsuura, T. Ishikawa, N. Yabuuchi, W. Murata and S. Kuze, Electrochem. Commun., 2012, 21, 65-68.

181 Y. Liu, Y. Xu, Y. Zhu, J. N. Culver, C. A. Lundgren, K. Xu and C. Wang, ACS Nano, 2013, 7, 3627-3634.

182 H. Zhu, Z. Jia, Y. Chen, N. Weadock, J. Wan, O. Vaaland, X. Han, T. Li and L. Hu, Nano Lett., 2013, 13, 3093-3100.

183 Y. Xu, Y. Zhu, Y. Liu and C. Wang, Adv. Energy Mater., 2013, 3, 128-133.

184 J. W. Wang, X. H. Liu, S. X. Mao and J. Y. Huang, Nano Lett., 2012, 12, 5897-5902.

185 I. A. Courtney and J. R. Dahn, J. Electrochem. Soc., 1997, 144, 2045-2052.

186 D. Bresser, F. Mueller, D. Buchholz, E. Paillard and S. Passerini, Electrochim. Acta, 2014, 128, 163-171.

187 S.-M. Oh, S.-T. Myung, M.-W. Jang, B. Scrosati, J. Hassoun and Y.-K. Sun, Phys. Chem. Chem. Phys., 2013, 15, 38273833.

188 J.-C. Kim and D.-W. Kim, Electrochem. Commun., 2014, 46, 124-127.

189 J. R. Gonzalez, F. Nacimiento, R. Alcantara, G. F. Ortiz and J. L. Tirado, CrystEngComm, 2013, 15, 9196-9202.

190 J. S. Thorne, R. A. Dunlap and M. N. Obrovac, Electrochim. Acta, 2013, 112, 133-137.

191 T. Yamamoto, T. Nohira, R. Hagiwara, A. Fukunaga, S. Sakai, K. Nitta and S. Inazawa, Electrochim. Acta, 2014, 135, 60-67.

192 Y.-M. Lin, P. R. Abel, A. Gupta, J. B. Goodenough, A. Heller and C. B. Mullins, ACS Appl. Mater. Interfaces, 2013, 5, 82738277. 
193 A. Darwiche, C. Marino, M. T. Sougrati, B. Fraisse, L. Stievano and L. Monconduit, J. Am. Chem. Soc., 2012, 134, 20805-20811.

194 M. He, K. Kravchyk, M. Walter and M. V. Kovalenko, Nano Lett., 2014, 14, 1255-1262.

195 J. Qian, Y. Chen, L. Wu, Y. Cao, X. Ai and H. Yang, Chem. Commun., 2012, 48, 7070-7072.

196 L. Baggetto, E. Allcorn, R. R. Unocic, A. Manthiram and G. M. Veith, J. Mater. Chem. A, 2013, 1, 11163-11169.

197 L. Baggetto, M. Marszewski, J. Gorka, M. Jaroniec and G. M. Veith, J. Power Sources, 2013, 243, 699-705.

198 I. T. Kim, E. Allcorn and A. Manthiram, Energy Technol., 2013, 1, 319-326.

199 D.-H. Nam, K.-S. Hong, S.-J. Lim and H.-S. Kwon, J. Power Sources, 2014, 247, 423-427.

200 C. Nithya and S. Gopukumar, J. Mater. Chem. A, 2014, 2, 10516-10525.

201 L. Baggetto, H.-Y. Hah, J.-C. Jumas, C. E. Johnson, J. A. Johnson, J. K. Keum, C. A. Bridges and G. M. Veith, J. Power Sources, 2014, 267, 329-336.

202 P. R. Abel, Y.-M. Lin, T. de Souza, C.-Y. Chou, A. Gupta, J. B. Goodenough, G. S. Hwang, A. Heller and C. B. Mullins, J. Phys. Chem. C, 2013, 117, 18885-18890.

203 L. Baggetto, J. K. Keum, J. F. Browning and G. M. Veith, Electrochem. Commun., 2013, 34, 41-44.

204 B. Farbod, K. Cui, W. P. Kalisvaart, M. Kupsta, B. Zahiri, A. Kohandehghan, E. M. Lotfabad, Z. Li, E. J. Luber and D. Mitlin, ACS Nano, 2014, 8, 4415-4429.

205 A. Darwiche, M. T. Sougrati, B. Fraisse, L. Stievano and L. Monconduit, Electrochem. Commun., 2013, 32, 18-21.

206 S. A. Webb, L. Baggetto, C. A. Bridges and G. M. Veith, J. Power Sources, 2014, 248, 1105-1117.

207 Y. Zhu, X. Han, Y. Xu, Y. Liu, S. Zheng, K. Xu, L. Hu and C. Wang, ACS Nano, 2013, 7, 6378-6386.

208 K. Dai, H. Zhao, Z. Wang, X. Song, V. Battaglia and G. Liu, J. Power Sources, 2014, 263, 276-279.

209 L. Wu, D. Bresser, D. Buchholz, G. Giffin, C. R. Castro, A. Ochel and S. Passerini, Adv. Energy Mater., 2015, 5, 1401142.

210 Y. Xu, E. Memarzadeh Lotfabad, H. Wang, B. Farbod, Z. Xu, A. Kohandehghan and D. Mitlin, Chem. Commun., 2013, 49, 8973-8975.

211 J. P. Huang, D. D. Yuan, H. Z. Zhang, Y. L. Cao, G. R. Li, H. X. Yang and X. P. Gao, RSC Adv., 2013, 3, 12593-12597.

212 H. Xiong, M. D. Slater, M. Balasubramanian, C. S. Johnson and T. Rajh, J. Phys. Chem. Lett., 2011, 2, 2560-2565.

213 J. C. Perez-Flores, C. Baehtz, A. Kuhn and F. GarciaAlvarado, J. Mater. Chem. A, 2014, 2, 1825-1833.

214 Y. Sun, L. Zhao, H. Pan, X. Lu, L. Gu, Y.-S. Hu, H. Li, M. Armand, Y. Ikuhara, L. Chen and X. Huang, Nat. Commun., 2013, 4, 1870.

215 L. Zhao, H.-L. Pan, Y.-S. Hu, H. Li and L.-Q. Chen, Chin. Phys. B, 2012, 21, 028201.

216 X. Yu, H. Pan, W. Wan, C. Ma, J. Bai, Q. Meng, S. N. Ehrlich, Y.-S. Hu and X.-Q. Yang, Nano Lett., 2013, 13, 4721-4727.

217 J. Liu, K. Tang, K. Song, P. A. van Aken, Y. Yu and J. Maier, Phys. Chem. Chem. Phys., 2013, 15, 20813-20818.
218 P. Senguttuvan, G. Rousse, V. Seznec, J.-M. Tarascon and M. R. Palacín, Chem. Mater., 2011, 23, 4109-4111.

219 Y. Wang, X. Yu, S. Xu, J. Bai, R. Xiao, Y.-S. Hu, H. Li, X.-Q. Yang, L. Chen and X. Huang, Nat. Commun., 2013, 4, 2365.

220 R. Alcantara, M. Jaraba, P. Lavela and J. L. Tirado, Chem. Mater., 2002, 14, 2847-2848.

221 M. C. Lopez, P. Lavela, G. F. Ortiz and J. L. Tirado, Electrochem. Commun., 2013, 27, 152-155.

222 Y. Jiang, M. Hu, D. Zhang, T. Yuan, W. Sun, B. Xu and M. Yan, Nano Energy, 2014, 5, 60-66.

223 M. Valvo, F. Lindgren, U. Lafont, F. Bjorefors and K. Edstrom, J. Power Sources, 2014, 245, 967-978.

224 Z. Jian, B. Zhao, P. Liu, F. Li, M. Zheng, M. Chen, Y. Shi and H. Zhou, Chem. Commun., 2014, 50, 1215-1217.

225 S.-M. Oh, S.-T. Myung, C. S. Yoon, J. Lu, J. Hassoun, B. Scrosati, K. Amine and Y.-K. Sun, Nano Lett., 2014, 14, 1620-1626.

226 S. Hariharan, K. Saravanan, V. Ramar and P. Balaya, Phys. Chem. Chem. Phys., 2013, 15, 2945-2953.

227 S. Hariharan, K. Saravanan and P. Balaya, Electrochem. Commun., 2013, 31, 5-9.

228 S. Yuan, X.-l. Huang, D.-l. Ma, H.-g. Wang, F.-z. Meng and X.-b. Zhang, Adv. Mater., 2014, 26, 2273-2279.

229 Q. Sun, Q.-Q. Ren, H. Li and Z.-W. Fu, Electrochem. Commun., 2011, 13, 1462-1464.

230 D. Su, X. Xie and G. Wang, Chem.-Eur. J., 2014, 20, 31923197.

231 M. Shimizu, H. Usui and H. Sakaguchi, J. Power Sources, 2014, 248, 378-382.

232 Y.-X. Wang, Y.-G. Lim, M.-S. Park, S.-L. Chou, J. H. Kim, H.-K. Liu, S.-X. Dou and Y.-J. Kim, J. Mater. Chem. A, 2014, 2, 529-534.

233 Y. Wang, D. Su, C. Wang and G. Wang, Electrochem. Commun., 2013, 29, 8-11.

234 D. Su, H.-J. Ahn and G. Wang, Chem. Commun., 2013, 49, 3131-3133.

235 M. Gu, A. Kushima, Y. Shao, J.-G. Zhang, J. Liu, N. D. Browning, J. Li and C. Wang, Nano Lett., 2013, 13, 5203-5211.

236 W. Wang, L. Hu, J. Ge, Z. Hu, H. Sun, H. Sun, H. Zhang, H. Zhu and S. Jiao, Chem. Mater., 2014, 26, 3721-3730.

237 K. C. Klavetter, S. Garcia, N. Dahal, J. L. Snider, J. Pedro de Souza, T. H. Cell, M. A. Cassara, A. Heller, S. M. Humphrey and C. B. Mullins, J. Mater. Chem. A, 2014, 2, 14209-14221.

238 J. Ming, H. Ming, W.-J. Kwak, C. Shin, J. Zheng and Y.-K. Sun, Chem. Commun., 2014, 50, 13307-13310.

239 H. S. Ryu, J. S. Kim, J. Park, J. Y. Park, G. B. Cho, X. Liu, I. S. Ahn, K. W. Kim, J. H. Ahn, J. P. Ahn, S. W. Martin, G. Wang and H. J. Ahn, J. Power Sources, 2013, 244, 764-770.

240 C. B. Zhu, X. K. Mu, P. A. van Aken, Y. Yu and J. Maier, Angew. Chem., Int. Ed., 2014, 53, 2152-2156.

241 L. David, R. Bhandavat and G. Singh, ACS Nano, 2014, 8, 1759-1770.

242 G. S. Bang, K. W. Nam, J. Y. Kim, J. Shin, J. W. Choi and S.-Y. Choi, ACS Appl. Mater. Interfaces, 2014, 6, 7084-7089. 
243 T. Zhou, W. K. Pang, C. Zhang, J. Yang, Z. Chen, H. K. Liu and Z. Guo, ACS Nano, 2014, 8, 8323-8333.

244 X. Xie, D. Su, S. Chen, J. Zhang, S. Dou and G. Wang, Chem.Asian J., 2014, 9, 1611-1617.

245 B. Qu, C. Ma, G. Ji, C. Xu, J. Xu, Y. S. Meng, T. Wang and J. Y. Lee, Adv. Mater., 2014, 26, 3854-3859.

246 L. Wu, X. Hu, J. Qian, F. Pei, F. Wu, R. Mao, X. Ai, H. Yang and Y. Cao, J. Mater. Chem. A, 2013, 1, 7181-7184.

247 Q. Su, G. Du, J. Zhang, Y. Zhong, B. Xu, Y. Yang, S. Neupane and W. Li, ACS Nano, 2014, 8, 3620-3627.

248 Z. Shadike, Y. N. Zhou, F. Ding, L. Sang, K. W. Nam, X. Q. Yang and Z. W. Fu, J. Power Sources, 2014, 260, 72-76.

249 Y. Kim, Y. Park, A. Choi, N.-S. Choi, J. Kim, J. Lee, J. H. Ryu, S. M. Oh and K. T. Lee, Adv. Mater., 2013, 25, 3045-3049.

250 J. Qian, X. Wu, Y. Cao, X. Ai and H. Yang, Angew. Chem., Int. Ed., 2013, 52, 4633-4636.

251 Y. Kim, Y. Kim, A. Choi, S. Woo, D. Mok, N.-S. Choi, Y. S. Jung, J. H. Ryu, S. M. Oh and K. T. Lee, Adv. Mater., 2014, 26, 4139-4144.
252 J. Qian, Y. Xiong, Y. Cao, X. Ai and H. Yang, Nano Lett., 2014, 14, 1865-1869.

253 J. Fullenwarth, A. Darwiche, A. Soares, B. Donnadieu and L. Monconduit, J. Mater. Chem. A, 2014, 2, 2050-2059.

254 L. Zhao, J. Zhao, Y.-S. Hu, H. Li, Z. Zhou, M. Armand and L. Chen, Adv. Energy Mater., 2012, 2, 962-965.

255 Y. Park, D.-S. Shin, S. H. Woo, N. S. Choi, K. H. Shin, S. M. Oh, K. T. Lee and S. Y. Hong, Adv. Mater., 2012, 24, 3562-3567.

256 A. Abouimrane, W. Weng, H. Eltayeb, Y. Cui, J. Niklas, O. Poluektov and K. Amine, Energy Environ. Sci., 2012, 5, 9632-9638.

257 E. Castillo-Martínez, J. Carretero-González and M. Armand, Angew. Chem., 2014, 126, 5445-5449.

258 J.-M. Tarascon, Philos. Trans. R. Soc., A, 2010, 368, 32273241.

259 D. Larcher and J. M. Tarascon, Nat. Chem., 2015, 7, 19-29. 